\title{
Estimation of skin factor by using pressure transient testing results of a Single Rate Well Test
}

Delal Gunaydin

West Virginia University

Follow this and additional works at: https://researchrepository.wvu.edu/etd

\section{Recommended Citation}

Gunaydin, Delal, "Estimation of skin factor by using pressure transient testing results of a Single Rate Well Test" (2007). Graduate Theses, Dissertations, and Problem Reports. 1855.

https://researchrepository.wvu.edu/etd/1855

This Thesis is protected by copyright and/or related rights. It has been brought to you by the The Research Repository @ WVU with permission from the rights-holder(s). You are free to use this Thesis in any way that is permitted by the copyright and related rights legislation that applies to your use. For other uses you must obtain permission from the rights-holder(s) directly, unless additional rights are indicated by a Creative Commons license in the record and/ or on the work itself. This Thesis has been accepted for inclusion in WVU Graduate Theses, Dissertations, and Problem Reports collection by an authorized administrator of The Research Repository @ WVU. For more information, please contact researchrepository@mail.wvu.edu. 


\title{
Estimation of Skin Factor by Using Pressure Transient Testing Results of a Single Rate Well Test
}

\author{
Delal Gunaydin
}

\author{
Thesis submitted to the \\ College of Engineering and Mineral Resources \\ at West Virginia University \\ in partial fulfillment of the requirements \\ for the degree of \\ Master of Science \\ in \\ Petroleum and Natural Gas Engineering
}
Shahab D. Mohaghegh, PhD., Chair
Khashayar Aminian, Ph.D.
Razi Gaskari, Ph.D.
Kenneth G. Brown, M.S.

Department of Petroleum and Natural Gas Engineering

\author{
Morgantown, West Virginia \\ 2007
}

Keywords: Gas Storage, Well Testing, Single Point/Rate Test, Skin Factor, Numerical History Matching, Reservoir Simulation.

Copyright 2007 Delal Gunaydin 


\section{ABSTRACT \\ Estimation of Skin Factor by Using Pressure Transient Testing Results of a Single Rate Well Test}

\section{Delal Gunaydin}

About one-fifth of the natural gas used by Americans each winter comes from natural gas storage sites. Gas storage is the primary means for the gas industry to manage fluctuations in supply and demand. Natural gas can be stored in a variety of ways. Most commonly, it is held in underground formations, in depleted oil or gas reservoirs, or in natural aquifers.

Many gas storage wells show a decline in deliverability as a function of time due to several damage mechanisms. The remedial operations such as stimulation and workovers are used to restore the loss in deliverability and to enhance the productivity of a well.

Candidate well selection for the stimulation or workover process is generally based on well history. Skin factor is an important parameter to predict the well performance. Skin is usually calculated from a Multi Rate Well Test (MRT). However performing a MRT on a regular basis is an unattractive activity when considering the economic issues. First of all, performing a well test may cause temporary production or injection interruptions. Secondly, the cost associated with well test is considered as an operating expense, a fact that does not help the overall economics of operating a Gas Storage Field. Single Rate Well Tests (SRT) are also performed to estimate the deliverability, but they do not contain sufficient data in order to estimate true skin factor by conventional well testing calculations.

The objective of this study is to introduce a new methodology to enhance the current practices of estimating true skin factor from a SRT. This method includes history matching of the actual MRT and then estimation of skin value from SRT using the history matched model. Using this methodology it is shown that change in the skin can be estimated with reasonably accuracy. 
To my family, 


\section{ACKNOWLEDGMENTS}

First of all, I would like to express my gratitude to my supervisor Dr. Shahab D. Mohaghegh whose knowledge, leadership, professionalism, attention to detail and hard work have set an example I hope to match some day. He provided me direction, technical support and became more of a mentor than a professor throughout my graduate study. I want to thank to him for giving me the opportunity to work in his research team and studying in West Virginia University.

Secondly, I would like to thank Dr. Razi Gaskari for his consistent effort and true desire to keep me on track. He was always there when I need assistance. He is not only a master of his craft, Visual Basic, but also an excellent professional and great friend.

I must also acknowledge Dr. Kashy Aminian for his willingness to assist me in my early stages of planning helped to encourage my interest in this project. I really appreciate his help, his suggestions and the materials he provided in this study.

A very special thanks goes out to Ken Brown for his suggestions and for agreeing to be on my thesis committee despite his extremely busy schedule. He was always understanding for my extremely long and boring emails.

Many thanks to Department Chair Samuel Ameri and my professors in the PNGE Department for their support. The administrative associate of PNGE, Beverly Matheny, never gets the recognition that she deserves. Without her hard work, PNGE would cease the function.

Thanks to my colleagues and friends Jalal Jalali, Kazim Malik, Miguel Tovar, Daniel Gonzales and Domingo Mata for their help to get me through two years of graduate school. Special thanks to Emre Artun, who was always there for me from the beginning with his suggestions and guidance. Cesar Silva was tolerant enough to answer my questions about statistical concepts.

Most importantly, I would like to thank my family for the support they provided me through my entire life. Without their love, encouragement and guidance, I would not have finished this thesis.

Finally, I thank for the one who has made this entire effort and work seem worthwhile after all, Berk. 


\section{TABLE OF CONTENTS}

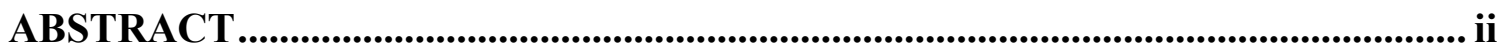

ACKNOWLEDGMENTS .................................................................................... iv

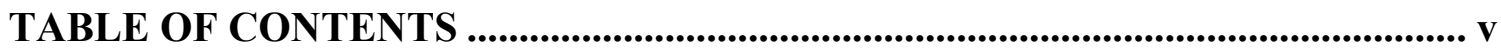

LIST OF FIGURES ........................................................................................... vi

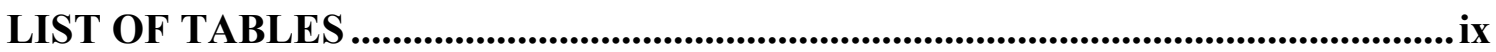

LIST OF SYMBOLS \& ABBREVIATIONS ......................................................

1 INTRODUCTION

2 LITERATURE REVISION ......................................................................... 3

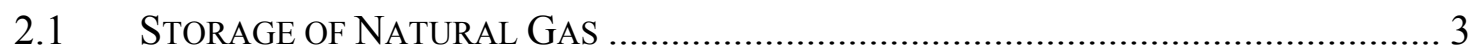

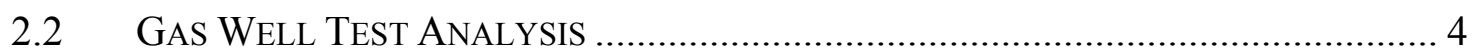

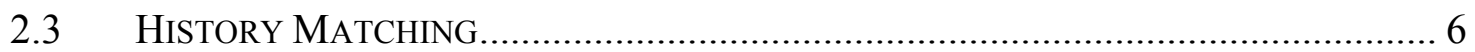

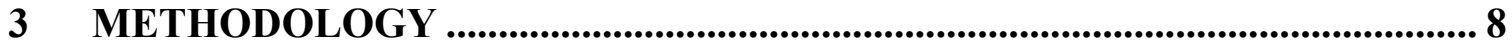

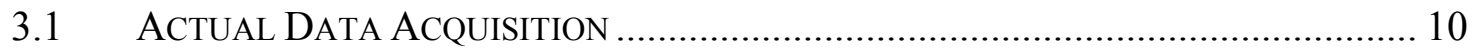

3.2 ANALYTICAL WELL TEST ANALYSIS ............................................................. 13

3.3 NUMERICAL MODELING................................................................................ 17

3.4 History MATCH OF Multi RATE TEST (MRT) .......................................... 18

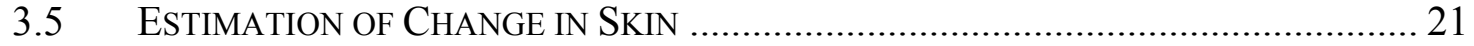

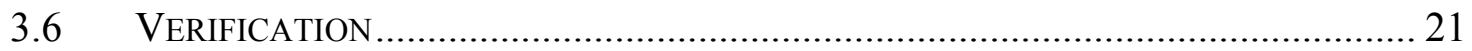

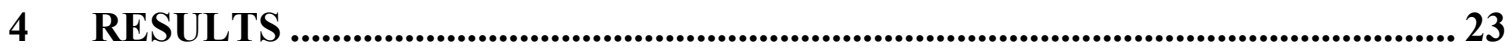

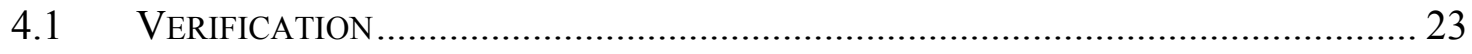

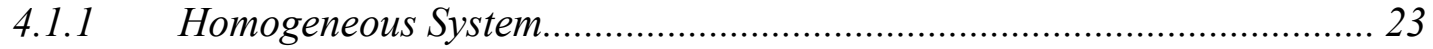

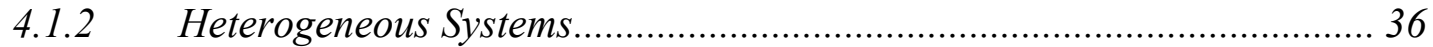

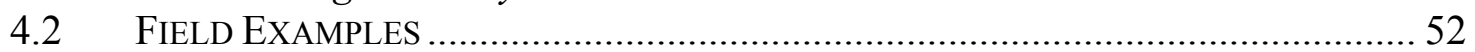

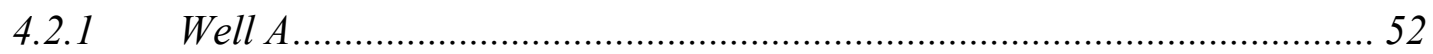

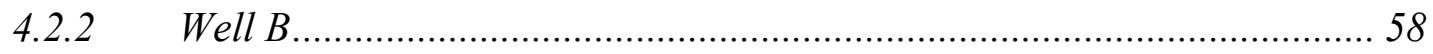

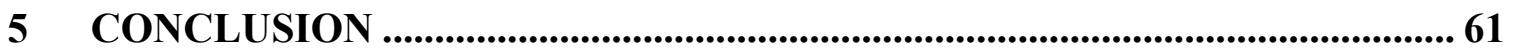

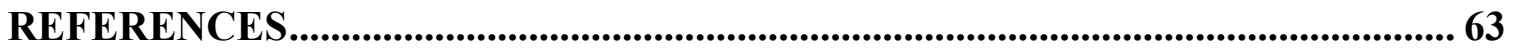




\section{LIST OF FIGURES}

Figure 2-1: Underground Natural Gas Storage Facilities in the United States.................. 3

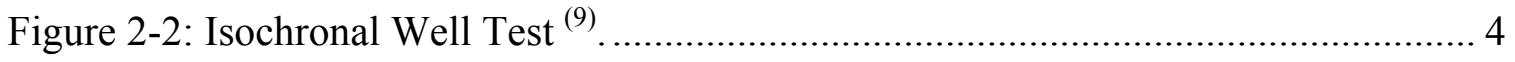

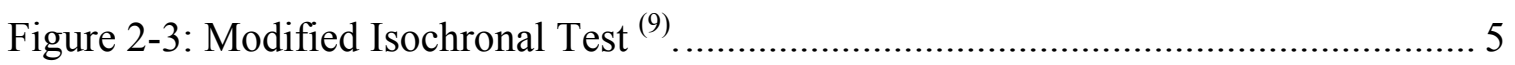

Figure 3-1: Flow Diagram of the Problem Statement................................................ 9

Figure 3-2: The Well Test Data Plot of the Gas Storage Technology Consortium

Software. This plot shows all the well tests performed on the selected well.

Figure 3-3: Well Test Plot showing the tests more clearly by zooming in.

Figure 3-4: Actual Data of the First Drawdown Period of the MPT Performed on Well3872. The figure shows change in the flow rate data with respect to time data.

Figure 3-5: Estimation of $S$ and $D$ factors based on the formula $s^{1}=S+D q$.

Figure 3-6: Schematic of 4th step of methodology. History match of the MRT data of simulation model with actual MRT data.

Figure 3-7: History match of simulator generated multi rate test data with actual MRT data. 20

Figure 3-8: Finalized history match of multi rate tests ............................................. 20

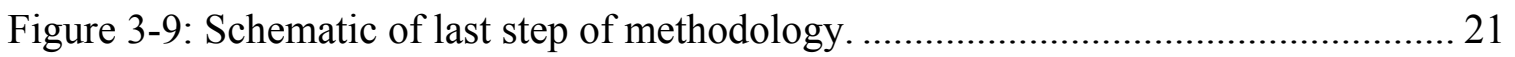

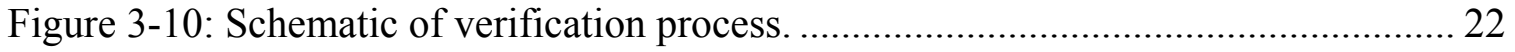

Figure 4-1: Semi-log plot of the first drawdown period of the multi rate test performed on the homogeneous Cartesian model. 24

Figure 4-2: Semi-log plot of the second drawdown period of the multi rate test performed on the homogeneous Cartesian model.

Figure 4-3: Semi-log plot of the third and the last drawdown period of the multi rate test performed on the homogeneous Cartesian model. The calculated parameters are shown on the table. 28

Figure 4-4: Estimation of true skin factor and Darcy factor by regression of the apparent skin factors calculated from well test analysis. 
Figure 4-5: History match of the MRT data of radial model with homogeneous Cartesian model data by using the calculated parameters in the radial model........... 30

Figure 4-6: History match of SRT could not be obtained by modifying change in delta skin values of both models equally...................................................... 31

Figure 4-7: History match of MRT data of radial model with different modified parameters in homogeneous case for verification.

Figure 4-8: History match of SRT data of the radial model by changing S from 3.38 to 4.68 . 33

Figure 4-9: History match of MRT data of radial model with different modified parameters in homogeneous case for verification (Case 2)..... 34

Figure 4-10: History match of the SRT data of the radial model by changing S from 2.2 to 3.5 . 35

Figure 4-11: Permeability distribution on the Cartesian model of Case 1, heterogeneous case.

Figure 4-12: Estimation of true skin factor and D-factor by regression of the data calculated by conventional analysis method, heterogeneity, Case 1 38

Figure 4-13: MRT match of the radial model with Cartesian model data of Heterogeneous system, case 1 .

Figure 4-14: History match of MRT data of radial model with modified parameters in heterogeneous case 1 for verification. 40

Figure 4-15: History match of SRT data of the radial model by changing S from 1.08 to 1.74 .

Figure 4-16: Permeability distribution on the Cartesian model of Case 2 of heterogeneous system. 42

Figure 4-17: MRT match of the radial model with initially calculated values, Case 2 of heteregeneous system.

Figure 4-18: SRT match could not get obtained with the initial k, S and D parameters of radial model, Case 2 of heterogeneous model.

Figure 4-19: The MRT match of radial model with the Cartesian model of Case 2 with first set of adjusted parameters. 
Figure 4-20: History match of SRT data of the radial model by changing the skin of

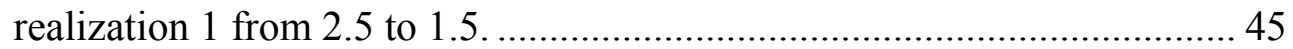

Figure 4-21: MRT match of radial model with the Cartesian model of Case 2 with second set of adjusted parameters. 46

Figure 4-22: History match of SRT data of the radial model by changing the skin of realization 2 from 1.56 to 0.56 . 46

Figure 4-23: Type of the heterogeneity of Case 3. 47

Figure 4-24: Estimation of true skin factor and Darcy factor by regression of the apparent skin factor values calculated from well test analysis. 48

Figure 4-25: Match of the multi rate test data with heterogeneous Cartesian model's data, Case 3. 49

Figure 4-26: Permeability distribution of the heterogeneous Cartesian model of Case 3. The minimum permeability is $3 \mathrm{md}$ and the maximum is $150 \mathrm{md}$. 50

Figure 4-27: Match of the SRT data of the radial model with heterogeneous Cartesian model's SRT data, Case 3................................................................... 51

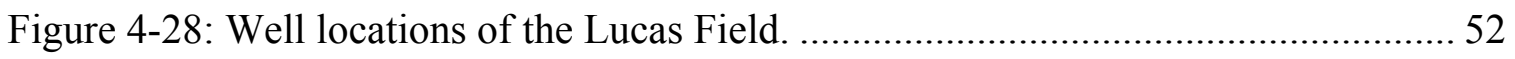

Figure 4-29: Cartesian model with its refined grids to be matched with Well A............ 53

Figure 4-30: History match of the MRT of the numerical model with the test data of Well A, Case 1. 54

Figure 4-31: History match of the SRT data of the simulation model with the data of Well A, Case 1. 55

Figure 4-32: History match of the MRT of numerical model with the test data of Well A, Case 2. 56

Figure 4-33: History match of the SRT data of the simulation model with the data of Well A, Case 2. 57

Figure 4-34: History match of multi rate test data with the actual data of Well B. 59

Figure 4-35: History match of single rate test data with the actual data of Well B 60 


\section{LIST OF TABLES}

Table 3-1: The Reservoir Characteristics of a Gas Storage Field Located in Ohio. 10

Table 4-1: Reservoir characteristics of homogeneous Cartesian model filled with dry gas.

Table 4-2: Conventional well test analysis results from three drawdown periods of the MRT performed on the homogeneous Cartesian Model....

Table 4-3: Summary of parameters adjusted in the history match of multi rate test data, homogeneous case..................................................................... 35

Table 4-4: Summary of change in skin factor for homogeneous case verification. 35

Table 4-5: Conventional well test analysis results from the three drawdown periods of the MRT performed on the heterogeneous Cartesian model of case 1............ 37

Table 4-6: Summary of the parameters to be adjusted during the history match, Case 1 of

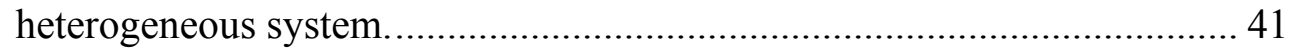

Table 4-7: Summary of change in skin factor for Case-1 of heteregeneous system......... 41

Table 4-8: Summary of the parameters to be adjusted during the history matc, Case 2 of

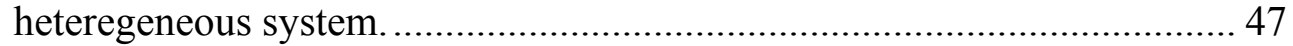

Table 4-9: Summary of change in skin factor for Case 2 of heteregeneous system........ 47

Table 4-10: Results of the conventional analysis performed on the Cartesian model of Case 3. 48

Table 4-11: Summary of parameters adjusted in the history match of multi rate test data, heterogeneous Case 3.

Table 4-12: Summary of change in skin factor for the Case 3 of the heterogeneous system, verification.

Table 4-13: Reservoir parameters of Well A. 53 


\section{LIST OF SYMBOLS \& ABBREVIATIONS}

$\bar{c}:$ Average Compressibility

cp: Centipoises

D: Darcy Factor

$\mathrm{ft}$ : feet

q: Flow Rate

h: Thickness

k: Permeability

$\mathrm{K}$ : Kelvin

LGR: Local Grid Refinement

md: milidarcy

Mscf/D: Thousand Standard Cubic Feet per Day

MRT: Multi Rate Test

$r_{w}:$ Well Bore Radius

$s^{\prime}$ : Apparent Skin Factor

S: Non-Darcy Skin Factor, (True Skin Factor) or (Mechanical Skin Factor)

SRT: Single Rate Test

$\mathrm{T}$ : Temperature

$\bar{z}:$ Average Gas Deviation Factor

$\phi$ : Porosity

$\bar{\mu}$ : Average Viscosity 


\section{INTRODUCTION}

About one-fifth of the natural gas used by Americans each winter comes from natural gas storage sites. Gas storage industry has more than 400 reservoirs and 15,000 wells to inject, store and withdraw natural gas and is thus a primary means for the gas industry to manage fluctuations in supply and demand ${ }^{(1)}$. Natural gas can be stored in a variety of ways. Most commonly, it is held in underground formations, in depleted oil or gas reservoirs, or in natural aquifers.

Gas storage fields usually include tens and sometimes hundreds of wells. These wells turn into the producer wells during the peak seasonal demand and to injector wells during the low demand periods. Many gas storage wells show a decline in deliverability with time due to this cycling process and some other factors. The decline in deliverability with time has two major contributors. The first contributor is geology and reservoir characteristics and the second contributor is damage around the wellbore, also known as "skin".

Damage in the storage well can have multiple reasons, such as bacterial growth, inorganic precipitates, including iron compounds, salts, calcium carbonate, and barium sulfate, hydrocarbons, organic residues and production chemicals, and particulate plugging ${ }^{(2)}$.

To maintain an optimum level of deliverability on a storage field, remedial operations such as stimulation and workovers are needed. Since stimulating all the wells on a storage field is an un-attractive activity in terms of cost, candidate well selection for these remedial operations becomes the most critical aspect.

Candidate selection is generally based on the well performance history. Skin factor is an important parameter to predict this performance. Change in Skin ( $\Delta$ Skin) generally is a good indicator whether a well needs remedial operations or not. Skin factor is usually calculated from a well test by conventional well test analysis. To maintain an accurate mimic of the well performance for the candidate selection, gas storage wells need to be tested regularly. However, performing a well test regularly is not an economic way. First of all, performing a well test may cause temporary production or injection interruptions and secondly, the cost associated with well test is considered an OpEx (Operating 
Expense), a fact that does not help the overall economics of operating a Gas Storage field.

Each year Gas Storage operators spend thousands of their OpEx dollars to test their storage wells. In industry, Multi Rate Tests (MPT) and Single Rate Tests (SPT) are being performed to have a qualitative assessment for candidate well selection by comparing the AOF (absolute open flow potential) of the wells or they are being performed to have an approximate estimation of the skin factor. Since, a MRT causes temporary production interruptions and a SRT do not contain sufficient data to estimate the "true skin factor", getting the best possible and reliable reservoir and well bore characterization from the performed test becomes very important.

The objective of this study is to introduce a new methodology to enhance the current practices of estimating true skin factor from a SRT. This method includes history matching of the actual MRT and then estimation of skin value from SRT using the history matched model. Using this methodology change in true skin factor with time has been studied.

In this study, optimization of well test analysis has been aimed. This optimization can have two dual benefits for the storage operators. It can reduce OpEx by reducing the number of multi rate tests that must be performed, thus fewer production/ injection interruptions, while by improving the analysis process a more realistic assessment of the damage over time ( identified by skin) becomes possible.

Using a commercial numerical simulator and well test data representative of a gas storage field called "Lucas Field" in Ohio, we verified the methodology mentioned above as well as the conventional technique currently used in the industry that is based on fundamentals of reservoir engineering for the multi rate tests and involves serious assumptions for extending the results to single rate well tests. Results show that the new method shows more reliable results in terms of the damage around the wellbore with time. 


\section{LITERATURE REVISION}

\subsection{Storage of Natural Gas}

Natural gas is one of the principle sources of energy and like most other commodities it can be stored for an indefinite period of time. Since natural gas has been a seasonal fuel, i.e. its demand is usually higher during the winter; stored natural gas plays a critical role in ensuring that any excess supply delivered during the summer month is available to meet the increased demand of the winter months.

Natural gas is usually stored underground, in large storage reservoir or it can be stored as liquefied natural gas (LNG). There are three main types of underground natural gas storage facilities:

1. Depleted Gas Reservoirs

2. Aquifers

3. Salt Caverns

Figure 2-1 shows the location of the three types of natural gas storage facilities in US. (3)

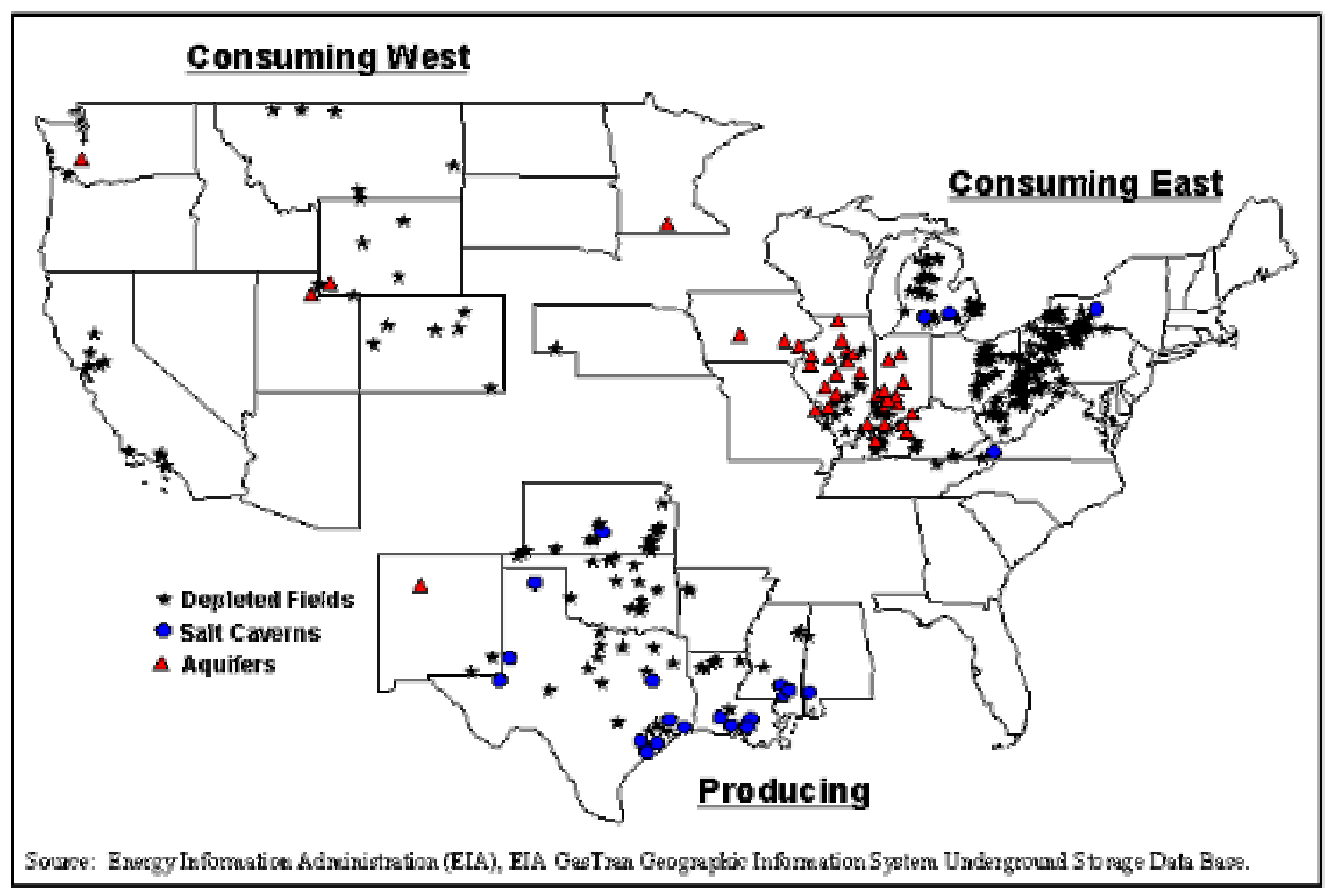

Figure 2-1: Underground Natural Gas Storage Facilities in the United States. 


\subsection{Gas Well Test Analysis}

In order to understand the behavior of the gas well with a reasonable accuracy and forecast the productivity, the gas wells should be tested regularly.

Essentially, tests performed on gas wells can be divided in two categories. The first category involves tests designed primarily to measure the deliverability of gas wells and the second category involves tests designed primarily to yield knowledge of the reservoir $^{(4)}$. For the first category, the conventional backpressure test, isochronal test, modified isochronal test can be given as examples. The second category contains buildup tests and drawdown tests which are performed primarily to have information about the reservoir by estimating some parameters like permeability and skin near to well bore with reasonable accuracy. They can also be used to investigate the deliverability of a well.

The first widely known well test analysis method was presented by Rawlin and Schelhardt ${ }^{(5)}$ in 1936 with the deliverability equation shown below.

$q=C\left(P_{R}^{2}-P_{w f}^{2}\right)^{n}$

This equation is not as accurate as the pseudo-steady state equation, which is $P_{R}^{2}-P_{w f}^{2}=a q+b q^{2}$

The coefficients $\mathrm{a}$, and $\mathrm{b}$ are usually estimated with isochronal or modified isochronal tests ${ }^{(6)}$. Cullender ${ }^{(7)}$ proposed the isochronal test method, consisting of equal duration of flow periods of a well and at the end of the each flow period shutting the well in for stabilization (Figure 2-2).

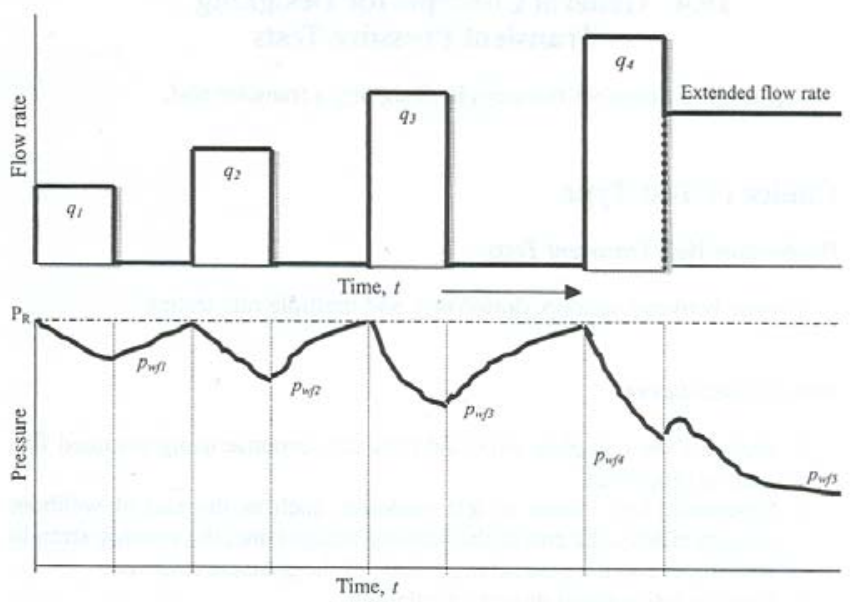

Figure 2-2: Isochronal Well Test ${ }^{(9)}$. 
In the low permeability reservoirs, waiting for stabilization can be very long. Katz et al ${ }^{(8)}$ presented a new type of well test, modified isochronal test. This test is widely used in industry. In a modified isochronal test, the duration of the flow periods (drawdown periods) is same with the shut-in (buildup) periods so there is no wait for stabilization. The pressure vs. time data of a modified isochronal test is in Figure 2-3.

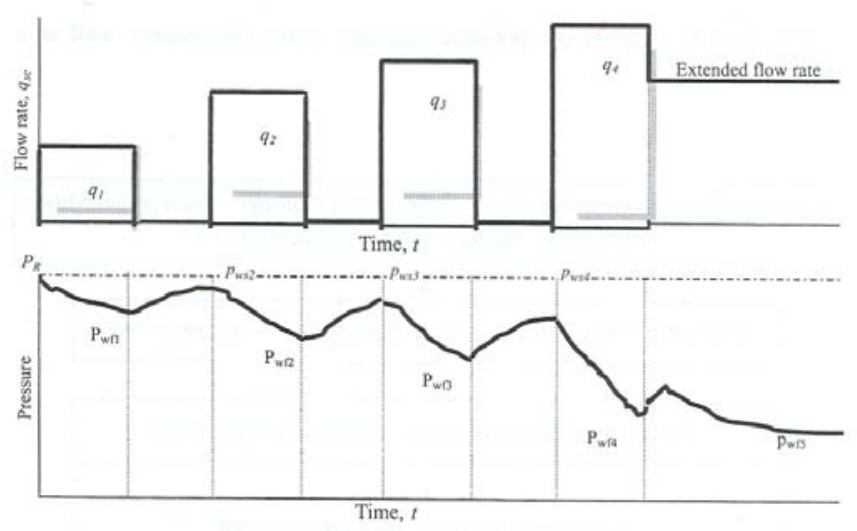

Figure 2-3: Modified Isochronal Test ${ }^{(9)}$.

Swift and Kiel ${ }^{(10)}$ introduced a significant analysis of gas well testing including the non-Darcy flow. They obtained the Darcy factor (D) from drawdown tests. From at least two drawdown period, apparent skin factors $\left(s_{1}^{l}, s_{2}^{l}\right)$ were calculated with the below equation, $s^{\prime}=1.151\left[\left(\frac{P_{i}^{2}-\left(P_{w f}^{2}\right)_{t=1 h r}}{m}\right)-\log \left(\frac{k}{(\phi)(\bar{\mu})(\bar{c})\left(r_{w}^{2}\right)}\right)+3.23\right]$

And if the flow rates changes slowly in the drawdown period, the equation becomes, $s^{\prime}=1.151\left[\left(\frac{P_{i}^{2}-P_{w f}^{2}}{q}\right)_{t=1 h r}\left(\frac{1}{m}\right)-\log \left(\frac{k}{(\phi)(\bar{\mu})(\bar{c})\left(r_{w}^{2}\right)}\right)+3.23\right]$

From the two drawdown periods two apparent skin factors were calculated and there are two different flow rates for each period. By using the formula:

$s^{\prime}=S+(D)(q)$

A plot of $s^{\prime}$ vs. $q$ should result in a straight line and the slope of the line gives D factor and the intercept gives the true skin factor $(\mathrm{S})$. 
In industry, estimation of the $\mathrm{k}, \mathrm{S}$ and $\mathrm{D}$ is based on this method. They use the three drawdown periods of a multi rate test, which is a modified isochronal test performed on the well with three drawdown and three buildup periods, to estimate three apparent skin factors, $s_{1}^{\prime}, s_{2}{ }^{\prime}, s_{3}^{\prime}$, and based on the formula $s^{\prime}=S+(D)(q)$, they get a plot of q vs. $s^{\prime}$ with a line of extrapolation between the three points. The slope of the line is Darcy factor, $\mathrm{D}$, and the intercept is true skin factor, S. A multi rate test is basically a modified isochronal test with three drawdown periods followed by three buildup periods at the end of each drawdown period. In industry, single rate test is preferable because it requires shorter time steps to perform and it is more economical. A single rate test contains only one drawdown period and sometimes a buildup period following the drawdown period.

Since evaluation of true skin factor necessitate at least two drawdown periods, a single rate test is not enough for this estimation. In this paper, a new methodology is introduced to estimate the true skin factor from using data of a single rate well test.

\subsection{History Matching}

In order to have best estimates for the input data for the reservoir model of the field under study, initial data generally need to be adjusted for the simulation model to predict reservoir performance adequately ${ }^{(11)}$.

The main objective of history matching is to improve and to validate the reservoir simulation model. Some studies have been done to use transient pressure well test data to improve reservoir description since well tests provide important dynamic information about reservoirs. Kamal ${ }^{(12)}$ presented a method about obtaining quantitative heterogeneous reservoir descriptions by interpreting and applying the results of multiple well tests in combination with single well tests. Landa, et al ${ }^{(13)}$ showed that well test data and reservoir performance history can be used effectively to infer reservoir description by using a numerical model of the reservoir. Kamal, et al ${ }^{(14)}$ developed a procedure of a step by step approach of incorporating well test data into full-field simulation model using transient analysis standard. This method, numerical well testing (NWT), enables the use of the information deduced from transient well tests on regular basis in reservoir description and performance predictions using numerical simulation. In this study, the 
information obtained from analytical analysis of well tests was used as initial information for the final model. 


\section{METHODOLOGY}

Deliverability of gas storage wells decline with time. The decline in deliverability with time has two major contributors. The first contributor is geology and reservoir characteristics and the second contributor is damage around the wellbore, also known as "skin".

To maintain an optimum level of deliverability on a storage field, remedial operations such as stimulation and workovers are needed. Since stimulating all the wells on a storage field is an un-attractive activity from an economic point of view, candidate well selection for these remedial operations becomes the most critical aspect. Change in skin in time usually is a good indicator whether a well needs remedial operations or not.

Well tests are being performed in gas storage industry in order to estimate the deliverability. These deliverability tests mainly are Multi Rate Tests (MRT), Single Rate Tests (SRT) or Open- flow Tests. Multi rate test's data can also be used to calculate nonDarcy skin factor (S), called also as True Skin factor, and the Darcy factor (D) with conventional well test analysis by using at least two drawdown or build-up periods of the well test. It is not preferable performing a MRT to calculate skin factor or AOF based on the economic point of view because it causes temporary production interruptions and the performing time is longer. Single rate tests; on the other hand, are more economical when considering performing cost but they do not contain sufficient data to estimate the "true skin factor" by conventional well test analysis. At this point getting the best and reliable well bore data from a single rate test becomes very important.

Figure 3-1 shows the problem definition. If a MRT is performed on time $t_{1}$, skin factor $_{1}$ can be calculated by doing conventional well test analysis. However; at the time $t_{2}$ skin factor will be changed on the same well to a value as skin factor ${ }_{2}$. How can this 


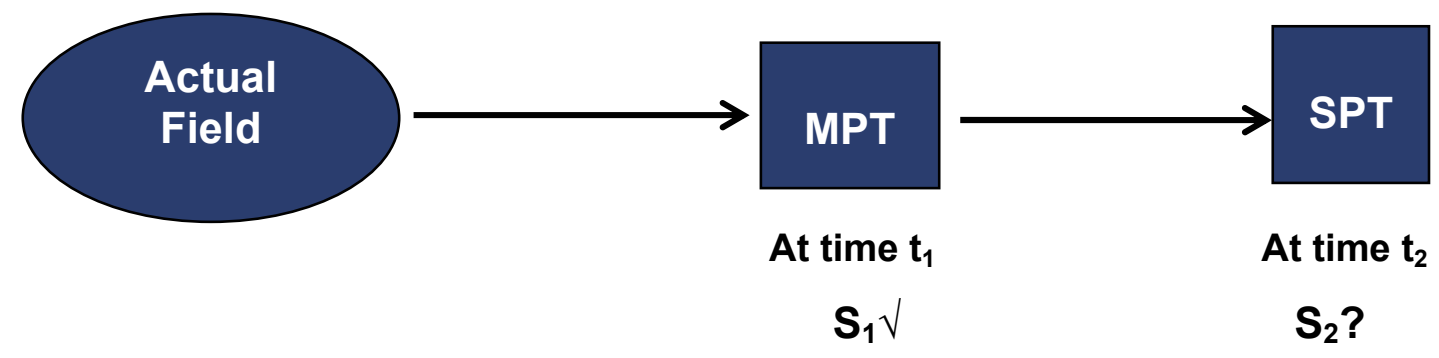

Figure 3-1: Flow Diagram of the Problem Statement.

new skin factor, skin factor 2 , be estimated from a single rate test at the time $t_{2}$ since at that time only a SRT is performed on the well because of the economic concerns?

Having a reliable technique that can reasonably predict the change in the skin with time for each well in a storage field can be great help to storage operators. In this research project a new methodology of estimating the true skin factor (S) from a single rate test has been studied. This method includes history match of the actual MRT with simulator generated MRT and then estimation of skin value from SRT using the history matched model.

In this study "Eclipse", a world-wide recognized commercial reservoir simulator package licensed by Schlumberger, is used.

This chapter explains the methods used in carrying out the study. The steps involved in achieving the objective of this study are as follows:

1. Identifying a well with at least one detailed pressure vs. time data of a multi rate test followed by a single rate test with its pressure vs. time data. (Actual data acquisition)

2. Analyzing the multi rate test data by using one of the conventional analytical analysis methods to calculate permeability (k) and skin factor (S). (Analytical well test analysis)

3. Building a high resolution numerical simulation model to history match the actual data. (Numerical modeling)

4. Estimating the parameters to be adjusted during the history match and modifying them until getting a match of the pressure data of the actual multi rate test with the simulated model's pressure response. (History match of the multi rate test) 
5. Performing a single rate well test on the history matched model. Modifying only skin factor parameter while keeping the other parameters constant to history match the single rate well test. (Estimation of change in skin)

At the end of this procedure, change of the true skin factor with time (in reality, there is a time gap between the multi rate test and single rate test) is estimated as well as the reservoir permeability. It is a fact that the history matched model is one probable version of reality in which there can be several possibilities. Thus, the history matched model is non-unique but the key in this method is consistency and attributing the change in the well production behavior to skin. In order to test the accuracy of this method two cases are studied with different skin estimations on the same well. A verification study was also performed with two numerical simulation models.

\subsection{Actual Data Acquisition}

The data used in this study is detailed pressure vs. time data of each flow and buildup period of a multi rate test followed by an at least one single rate well test. The data has been obtained from database of a gas storage field located in Ohio. The fluid PVT properties are known with some other reservoir parameters like porosity and well bore radius. The gas storage formation is Clinton sand stone and its properties are shown in Table 3-1. The permeability distribution near the well bore an, distances to the boundaries and skin are the unknown parameters.

Table 3-1: The Reservoir Characteristics of a Gas Storage Field Located in Ohio.

\begin{tabular}{|l|c|}
\hline \multicolumn{2}{|l|}{ Gas Storage Reservoir Characteristics } \\
\hline Average formation depth & $1200 \mathrm{ft}$ \\
\hline Porosity & $14 \%$ \\
\hline Average thickness of formation & $10 \mathrm{ft}$ \\
\hline Specific gravity of gas & 0.585 \\
\hline Well bore radius & $0.26 \mathrm{ft}$ \\
\hline
\end{tabular}

This storage field has more than 250 wells. Pressure vs. time data of a multi rate test followed by a single rate test performed on the same well was searched in the database for all the 275 wells. In order to obtain most reliable data for this study, Gas Technology 
Consortium Software was used. The following is the procedure of selecting the appropriate data to be used as the actual data in the history matching:

1) In the Software a well with a MRT followed by a SRT has been found. The data in the software is segregated into six main tabs which are Wellbore data, Completion data, Perforation data, Stimulation data, Well Test data and Reservoir Characteristics data. Well Test data has been used in this study. All the well tests performed on the selected well can be seen in the Well Test tab of the software. Figure 3-2 is the plot showing all the well tests performed on the selected well. Each point on the plot represents the well test type corresponding to the time that the test has been performed on the well. The plot shows 'Date' in $\mathrm{x}$-axis and $\mathrm{y}$ axis has not any variable. The colored markers show the type of the well test. Red points are for open flow tests, blue points are for single point tests and pink points show the multi point tests. Stimulation date can bee seen by straight vertical lines on the plot.

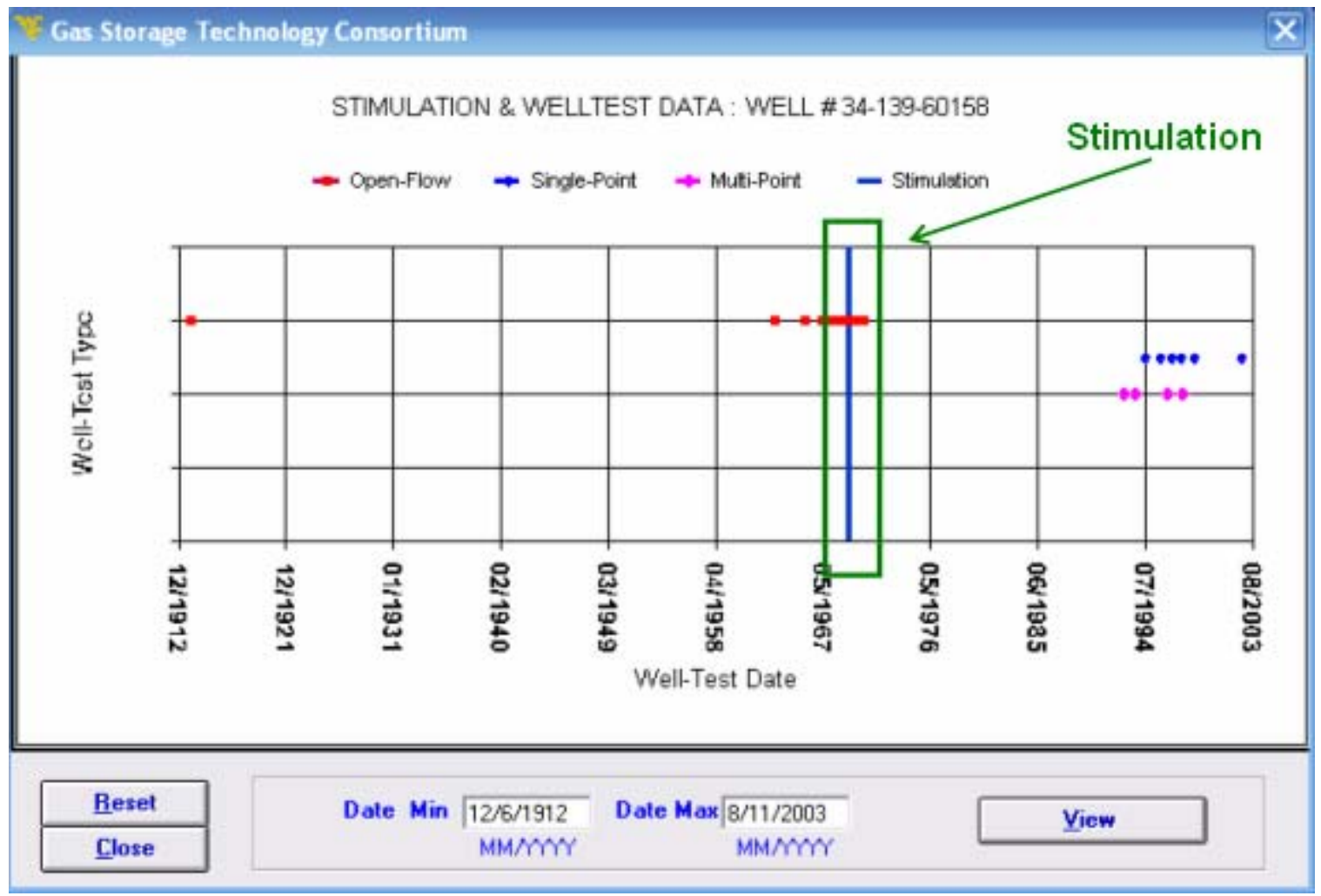

Figure 3-2: The Well Test Data Plot of the Gas Storage Technology Consortium Software. This plot shows all the well tests performed on the selected well. 
2) In accordance with the properties listed above, a MPT followed by at least one SPT has been searched in the software by zooming in between the dates to make it more clearly for this search (Figure 3-3). After finding the appropriate well on the software, the same well has been searched with its API number in the database. It has been checked that the well found in the software has the detailed pressure vs. time of its tests ( not only three points of the MPT) since all the wells in the software do not contain detailed well test data in the database.

3) The wells with the detailed pressure versus time data of a Multi Point Test followed by a detailed data of a Single Point Test have been identified. Since those found tests have detailed pressure vs. time data they are called in this study as multi/ single "rate" tests instead of multi/single point tests.

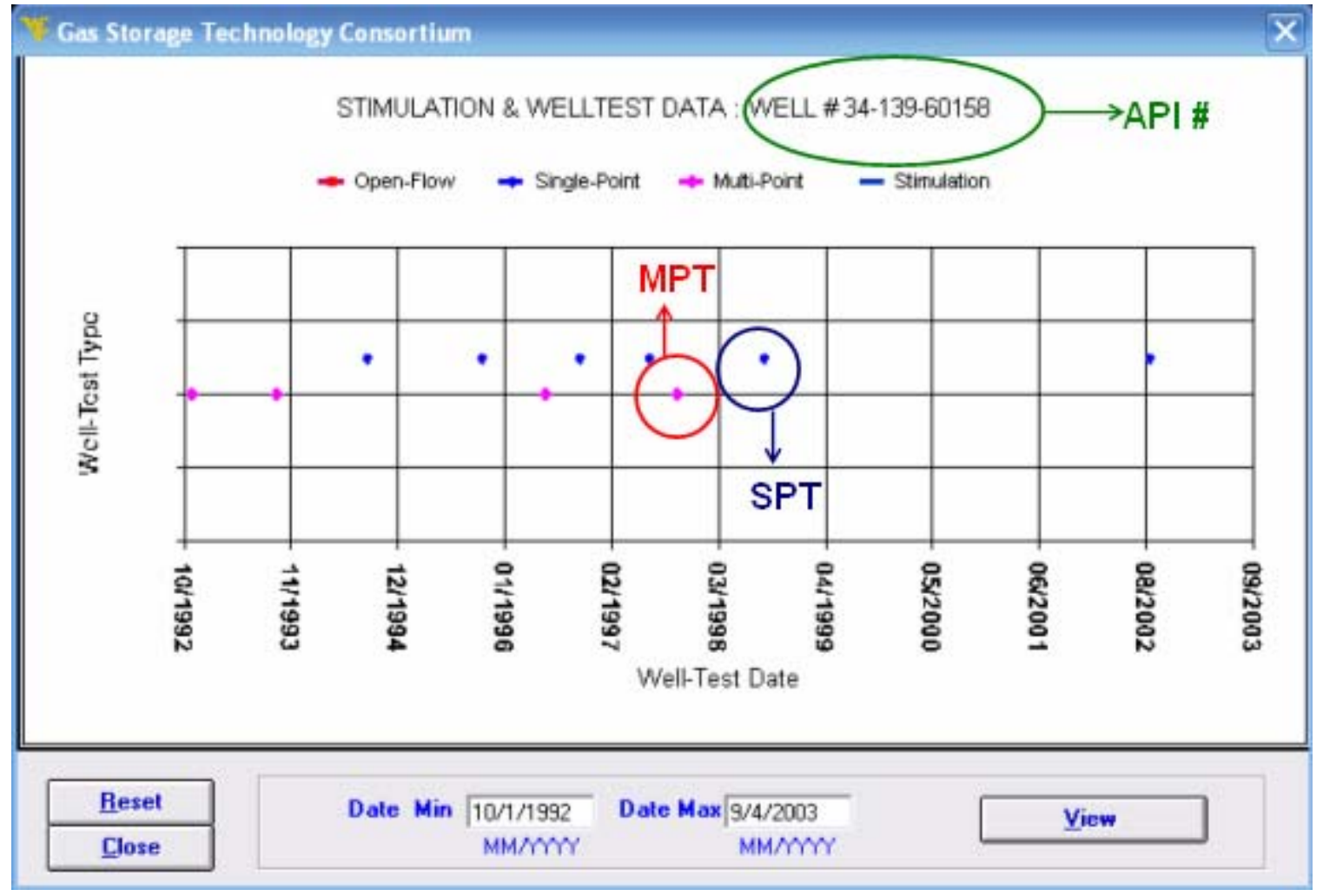

Figure 3-3: Well Test Plot showing the tests more clearly by zooming in. 


\subsection{Analytical Well Test Analysis}

The data of three drawdown periods of the actual multi rate test is analyzed by using the conventional well test analysis methods. Since the permeability of the reservoir does not change with time the values of permeability, calculated from each drawdown period, should be the same. Calculated parameters, which are permeability (k), non-Darcy skin factor, also called as true skin factor (S) and Darcy factor (D), are used as initial values for history matching. The other input model parameters such as fluid PVT properties or flow rates for the each drawdown period of the multi rate test are sane as those used in the well test analysis of the actual data. So, they are the known parameters of the actual field. Radius of investigation is also another parameter calculated by conventional analysis to determine the area under the influence of the multi rate test.

True skin factor and Darcy factor are two of the input parameters of the numerical simulation model. History match starts with the first drawdown period of the multi point test. Before starting history match of the simulator data with the actual data those parameters, true skin factor (S) and Darcy factor (D), are calculated as the initial values of the model. Conventional well test analysis techniques were followed in order to calculate these parameters. In this chapter the procedure of these calculations is given.

Three drawdown periods of the multi rate test is used for the analysis. From each flow period, which are Drawdown-1, Drawdown-2 and, Drawdown-3, permeability values and apparent skin factors, $s_{1}^{\prime}, s_{2}^{\prime}, s_{3}^{\prime}$ are calculated to estimate the True Skin factor with the formula shown below:

$$
s^{\prime}=S+(D)(q)
$$

In which;

$s^{\prime}$ is the apparent skin factor,

$\mathrm{D}$ is the Darcy factor

$\mathrm{q}$ is the gas flow rate

$\mathrm{S}$ is the non-Darcy Skin factor (true Skin Factor)

For the analysis $\mathrm{P}^{2}$ Approach is followed since the average reservoir pressure is less than 2000 psia. This procedure is based on the assumption that if the reservoir pressure is less than 2000 psia, $(\mu z)$ product in the flow equation can be approximated to the average 
of this product as $(\overline{\mu z})$. The followings are steps taken in order to calculate the apparent skin factor for one drawdown period.

1) A diagnostic plot is prepared in order to estimate the beginning of the middle time region of the semi-log plot. Diagnostic plot is $\Delta P^{2}$ vs. Time on logarithmic coordinates.

$\left(\Delta P^{2}\right)_{i}$ is $P_{\text {initial }}^{2}-\left(P_{w f}^{2}\right)_{i}$, in which $\left(P_{w f}^{2}\right)_{i}$ is flowing well-bore pressure at the corresponding time step, $t_{i}$.

A straight line is plotted on the diagnostic plot through the earliest data points. The type of the slope of the straight line is examined because that type gives the information whether there is a fracture on the well-bore or not. The beginning of the middle time region (MTR) of the semi-log plot is found by the formula shown below as;

$t_{M T R}=(50)\left(t^{*}\right)$ in which $\left(t^{*}\right)$ is the first deviating point from the straight line of the diagnostic plot if the slope of the line is $\tan 45^{\circ}$.

If the slope of the straight line is either $\tan 30^{\circ}=1 / 2$ or $\tan 14^{\circ} \approx 1 / 4$, the beginning of the middle time region will be estimated with the formula;

$$
t_{\text {MTR }}=(10)\left(t^{*}\right)
$$

2) After calculating the time at which the middle time region (MTR) starts, " $P_{w f}^{2}$ vs. Time" data (also called as semi-log plot) is plotted on a semi-log graph. A straight line is plotted on the most probable data of the MTR. By using the slope, $m$, of that straight line permeability $(\mathrm{k})$ and apparent skin factor $\left(s^{\prime}\right)$ is calculated with the formulas shown below,

$$
\begin{aligned}
& k=\frac{(1637)(q)(T)(\overline{\mu z})}{m h} \\
& s^{\prime}=1.151\left[\left(\frac{P_{i}^{2}-\left(P_{w f}^{2}\right)_{t=1 h r}}{m}\right)-\log \left(\frac{k}{(\phi)(\bar{\mu})(\bar{c})\left(r_{w}\right)^{2}}\right)+3.23\right]
\end{aligned}
$$


3) In step 2, the semi-log plot is plotted with the assumption that flow rate is constant although in actual data it is not. In the actual data, flow rate changes at each time step of the drawdown periods.

4)

5)

6) Figure 3-4 shows actual time-pressure-flow rate data of the first drawdown period of the multi rate test performed on Well-B of Lucas field. As it is seen in the figure, the flow rate decreases corresponding to the each time step alter

\begin{tabular}{|c|c|c|}
\hline \multicolumn{2}{|c|}{ CONTROL DATA } & $\mathrm{Pi}_{\mathrm{i}}$ \\
\hline Time, hours & Pressure, psia & Gas Rate, Mcf/D \\
\hline 0.1528 & 1166.7 & \\
\hline 0.1556 & 1160.7 & 3869.8 \\
\hline 0.1584 & 1152.7 & $3843.5<$ \\
\hline 0.1611 & 1148.7 & 3829.3 \\
\hline 0.1639 & 1144.7 & 3815.7 \\
\hline 0.1667 & 1142.7 & 3808.3 \\
\hline 0.1695 & 1140.7 & 3801.5 \\
\hline 0.1723 & 1140.7 & 3801.5 \\
\hline 0.1751 & 1138.7 & 3794.7 \\
\hline 0.1778 & 1134.7 & 3781.2 \\
\hline 0.1806 & 1134.7 & 3781.2 \\
\hline 0.1833 & 1132.7 & 3774.5 \\
\hline 0.1861 & 1132.7 & 3774.5 \\
\hline 0.1889 & 1130.7 & 3767.7 \\
\hline 0.1917 & 1128.7 & 3761 \\
\hline 0.1944 & 1128.7 & 3761 \\
\hline 0.1972 & 1128.7 & 3761 \\
\hline 0.2000 & 1126.7 & 3754.2 \\
\hline 0.2028 & 1126.7 & 3754.2 \\
\hline 0.2056 & 1124.7 & 3747.5 \\
\hline 0.2084 & 1124.7 & 3747.5 \\
\hline 0.2111 & 1124.7 & 3747.5 \\
\hline 0.2139 & 1122.7 & 3740.7 \\
\hline 0.2167 & 1122.7 & 3740.7 \\
\hline 0.2195 & 1122.7 & 3740.7 \\
\hline 0.2223 & 1122.7 & 3741.5 \\
\hline 0.2251 & 1120.7 & 3734.7 \\
\hline 0.2278 & 1120.7 & 3734 \\
\hline 0.2306 & 1120.7 & 3734 \\
\hline 0.2333 & 1120.7 & 3734 \\
\hline 0.2361 & 1120.7 & 3734 \\
\hline 0.2389 & 1120.7 & 3734 \\
\hline 0.2417 & 1118.7 & 3727.2 \\
\hline 0.2444 & 1118.7 & 3727.2 \\
\hline 0.2472 & 1118.7 & $3728^{\prime}$ \\
\hline 0.2500 & 9.7 & \\
\hline
\end{tabular}

Figure 3-4: Actual Data of the First Drawdown Period of the MPT Performed on Well-3872. The figure shows change in the flow rate data with respect to time data.

After realizing that the preparation of semi-log plot should encounter the change in the actual flow rate data, the plot is changed as " $\left(P_{i}^{2}-P_{w f}^{2}\right) / q$ vs. Time" on the plot. The $\mathrm{x}$-axis of the plot is the time data on the logarithmic coordinate. The formulas for the calculation of permeability and apparent skin factor is modified as,

$$
k=\frac{(1637)(T)(\overline{\mu z})}{m h}
$$




$$
s^{\prime}=1.151\left[\left(\frac{P_{i}^{2}-P_{w f}^{2}}{q}\right)_{t=1 h r}\left(\frac{1}{m}\right)-\log \left(\frac{k}{(\phi)(\bar{\mu})(\bar{c})\left(r_{w}\right)^{2}}\right)+3.23\right]
$$

Where,

$\mathrm{T}$ is the temperature in ${ }^{\circ} \mathrm{K}$,

$\bar{\mu}$ is the average viscosity in cp (centipoise)

$\bar{z}$ is the average gas deviation factor,

$\mathrm{h}$ is the thickness of the reservoir in $\mathrm{ft}$,

$\left(\frac{P_{i}^{2}-P_{w f}^{2}}{q}\right)_{t=1 h r}$ is the point on the y-axis of the Horner plot when the time on the x-axis is equal to 1 hour. This value should be obtained by fallowing the corresponding value of Time $=1$ hour on the straight line.

$\mathrm{k}$ is the permeability in md (milidarcy),

$\phi$ is the porosity in fraction,

$\bar{c}$ is the average total compressibility,

$r_{w}$ is the well bore radius in $\mathrm{ft}$.

The average parameters are estimated on the average pressure of that drawdown period. Average pressure is calculated by taking the harmonic average of the initial pressure and the last flowing pressure of that flow-period.

$\bar{P}=\sqrt{\frac{P_{i}+P_{w f}}{2}} P_{\mathrm{i}}$ is the pressure at the time step flow-period starts. $\mathrm{P}_{\mathrm{wf}}$ is the last
pressure data before the flowing period (drawdown period) ends.

Since there are 3 drawdown periods in a multi rate test of the actual data, three apparent skin factors, $s^{\prime}$, are calculated. From the formula, $s^{\prime}=S+(D)(q)$, q values are put on the $\mathrm{x}$-axis and $s^{\prime}$ values are placed on the y-axis of a Cartesian plot as shown in Figure 3-5. From the best straight line which is obtained from the three data points by extrapolation it's slope is given the Darcy-factor, D and it's interception with y-axis is given the non-Darcy Skin Factor, S. 


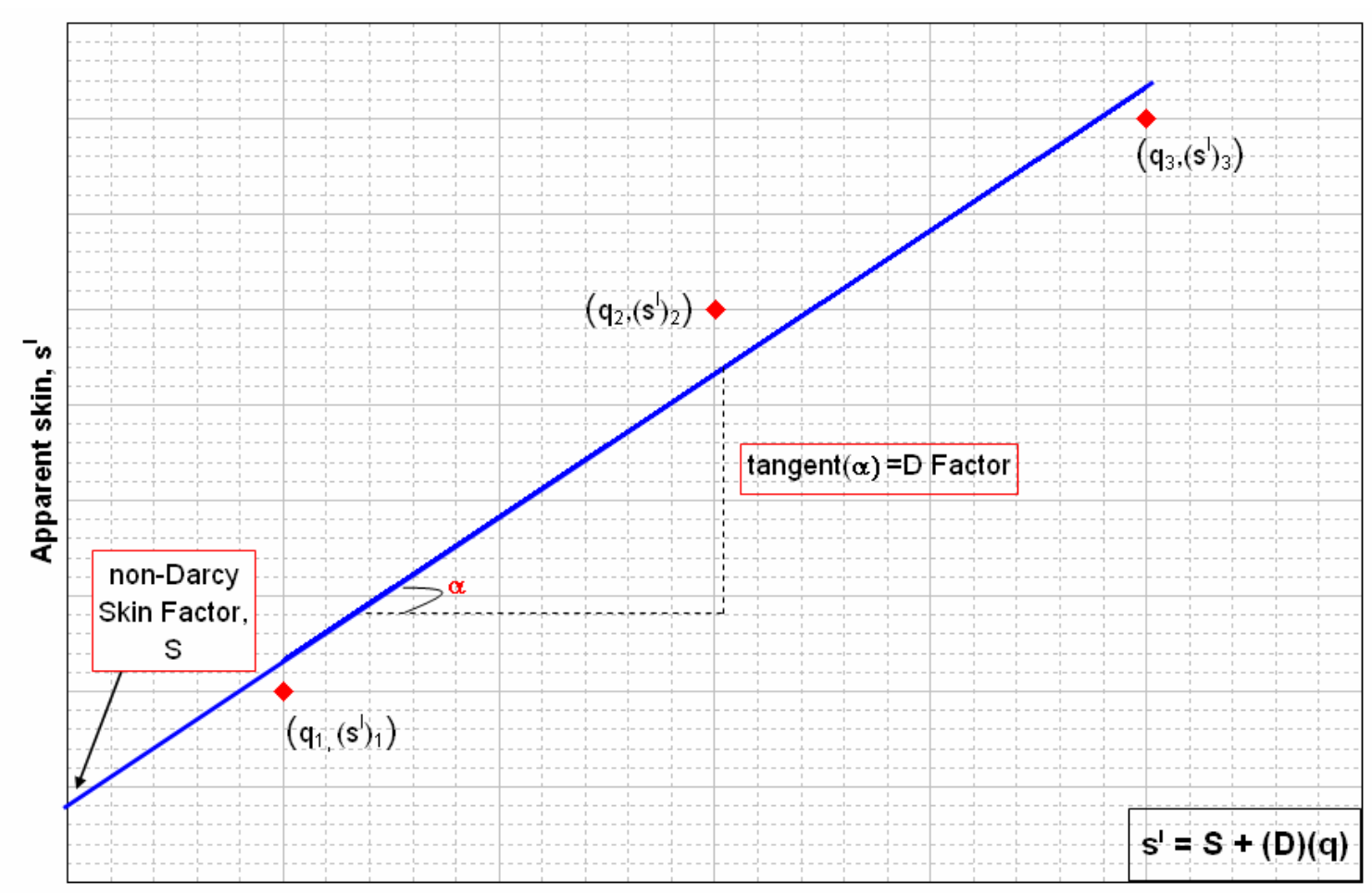

Flow Rate, q

Figure 3-5: Estimation of $S$ and $D$ factors based on the formula $s^{1}=S+D q$

The calculated parameters $\mathrm{k}, \mathrm{S}$ and $\mathrm{D}$ are used as initial values of the numerical simulation model and they are decided as the parameters to be adjusted during the history match since they are also the least accurately known parameters of the actual well data.

\subsection{Numerical Modeling}

In this study, a high resolution, single layer, numerical reservoir simulation model with one well is built in Eclipse simulator to be a controlled environment. The input parameters of the model are based on the values of actual data since in the project, obtaining a mimic of the real reservoir is aimed. However, there are some unknown parameters do exist in the actual reservoir data. By using the multi rate test data of the actual field, some of the unknown parameters are calculated like permeability, skin factor and Darcy factor by conventional analysis. Still, it can not be said that calculated parameters are the exact values of the field. In order to have a better understanding of the process occurring in the reservoir and to improve the actual reservoir description, history matching is performed. Calculated parameters from the actual data are used as initial 
input values to the numerical model. These parameters, $\mathrm{k}, \mathrm{S}$ and $\mathrm{D}$, are decided as the parameters to be adjusted during the history match process since they are the least accurately known values of the field and they have significant impact on the pressure response. Other input values of the model are assumed to be the known parameters of actual field with reasonably accuracy.

The grid size of the numerical model is also changed from coarse grid size to the fine grid size. Actually, local grid refinement has been (LGR) applied to the simulation model in order to get the best and the most reliable match of pressure history with the actual data. The model is 3-D, single layer and Cartesian. The length of $\mathrm{x}$ axis is equal to $\mathrm{y}$ axis which is $2000 \mathrm{ft}$. The growth factor for the refinement in $\mathrm{x}, \mathrm{y}$ and $\mathrm{z}$ directions is selected as 2 in the model. Length of the first 4 grids around the well bore ( 2 grids in $\mathrm{x}$ direction and 2 grids in y direction) are $3 \mathrm{ft}$. The length of the grid sizes increases by a multiplier of 2 from the well bore to the boundaries. As a result the length of the grid blocks change from $3 \mathrm{ft}$ to $6 \mathrm{ft}, 12 \mathrm{ft}, 24 \mathrm{ft}$ and goes so on. The grid sizes are kept coarse on the blocks near to the boundary since the history match is only with bottom-hole pressure data.

The time step of the model is adjusted also according to the actual well test's time steps.

\subsection{History Match of Multi Rate Test (MRT)}

Getting the best match of simulator generated well test data with the actual data is summarized under this section. Firstly, the parameters to be adjusted during the history match are selected. These parameters are unknown parameters of the actual field and since our aim is to get the pressure match at the end of the each drawdown/buildup period of the multi rate test, these properties should also be major contributors to the well response in the transient flow. The parameters decided to be adjusted during the history match are permeability (k), non-Darcy skin factor (S) and Darcy factor (D). Calculated values of these properties by analytical analysis are set as initial values in the matching process. The matching starts with the first drawdown period of the multi rate test. Those parameters are modified until a good and reasonable match is obtained with the actual data (Figure 3-6). 


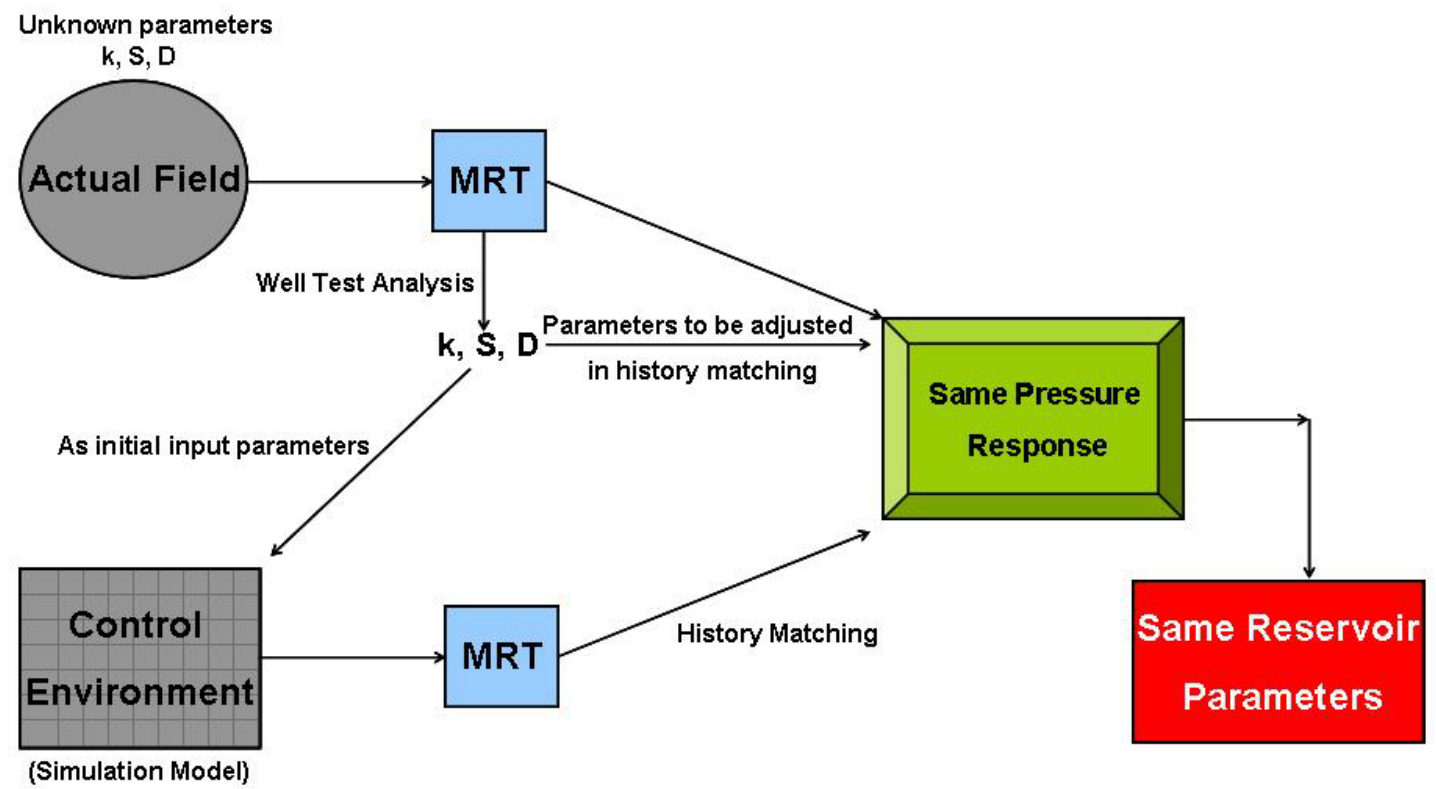

Figure 3-6: Schematic of 4th step of methodology. History match of the MRT data of simulation model with actual MRT data.

It is a step-wise matching process which is matching one test period at a time to finally converge to a single set of reservoir parameters for the entire multi rate test. Figure 3-7 shows this procedure. It means that if there is a need to change the value of these parameters, it should be done at the beginning of the test. For example, if there is a problem in the third drawdown period although the match is obtained in the previous test periods, everything should start from the scratch. The parameters should be changed with new values at the beginning of the first drawdown period and they should be kept constant until an acceptable match is obtained with the last buildup period of the multi rate test. 


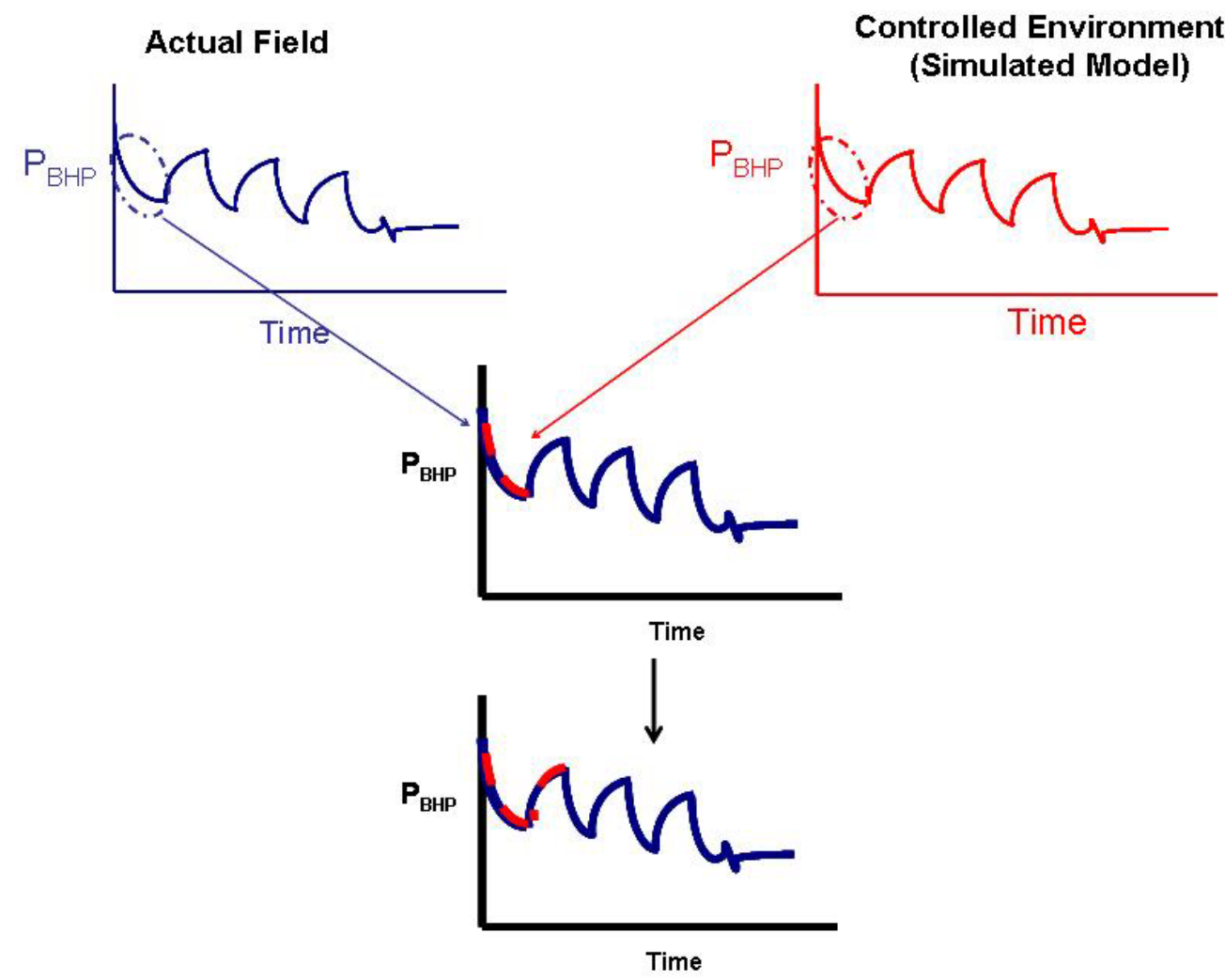

Figure 3-7: History match of simulator generated multi rate test data with actual MRT data.

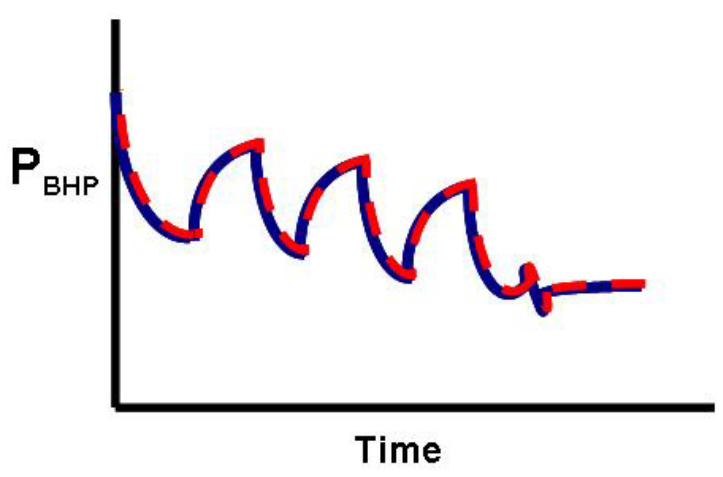

When the match is obtained with the last buildup period of the MRT, the parameters are finalized and called "Realization \#1" which is consisted of $\mathrm{k}_{1}, \mathrm{~S}_{1}$ and $\mathrm{D}_{1}$. At this point, we have modeled the actual reservoir and we have a representation of it (Figure 3-8)

Figure 3-8: Finalized history match of multi rate tests Pressure vs. time data 


\subsection{Estimation of Change in Skin}

The next set of pressure data, to get a match with, is the single rate well test data. In the previous step the numerical simulation model was modified to represent the actual reservoir with adjusted $\mathrm{k}, \mathrm{S}$ and D parameters. In this step firstly a single rate test (SRT) is performed on the history matched numerical model and the match process starts with the pressure vs. time data of this SRT with the actual SRT data. However, in this step, the true skin factor (S) is the only parameter to be adjusted during the process while keeping the other two parameters, $\mathrm{k}$ and $\mathrm{D}$, constant. At the time the match is obtained we have a set of finalized parameters called "Realization \#2" which is consisted of true skin factor $\mathrm{S}_{2}$, and previously modified parameters, $\mathrm{k}_{1}$ and $\mathrm{D}_{1}$. Thus, we obtain a new skin factor from the SPT and it shows that there is a change in the skin, delta skin, which is equal to:

$$
\Delta S=S_{2}-S_{1}
$$

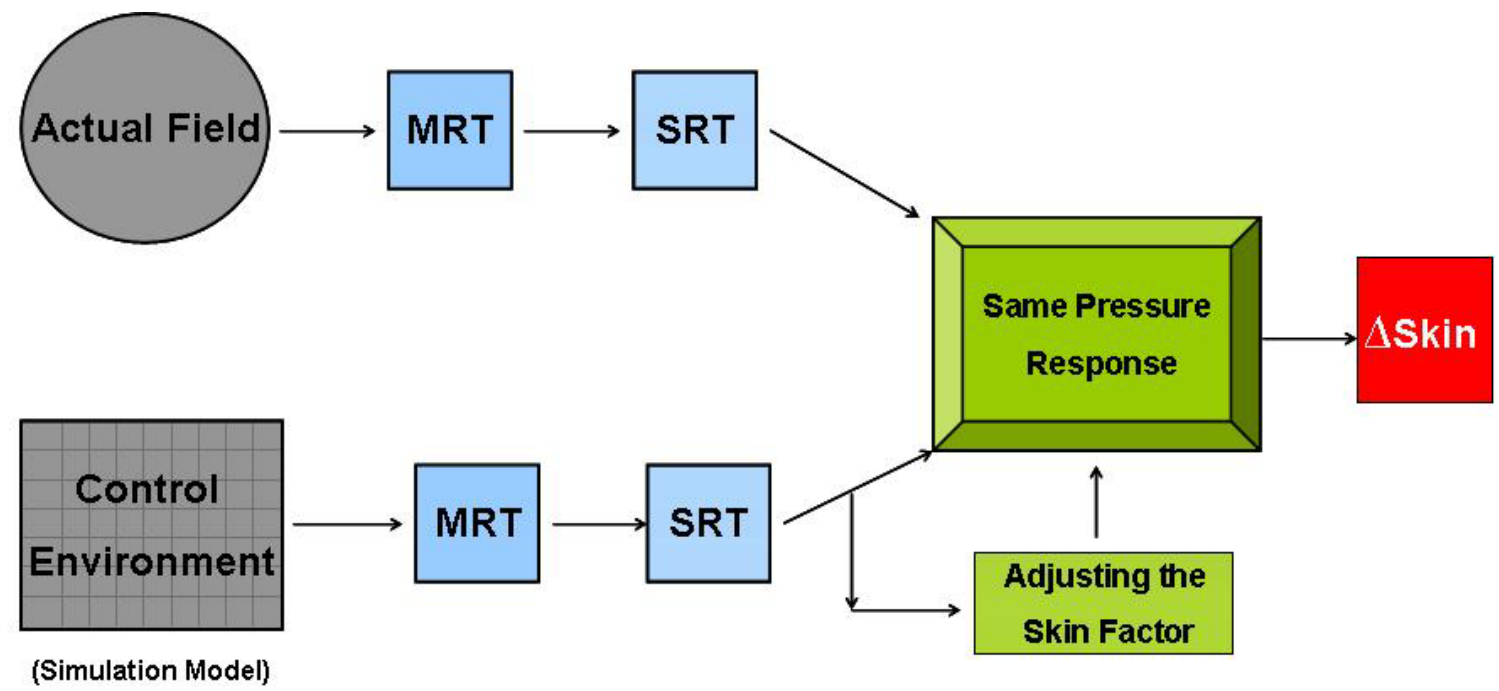

Figure 3-9: Schematic of last step of methodology.

\subsection{Verification}

To verify the methodology and the results of the field examples, a simplified radial simulation model was generated to history match with a high resolution Cartesian numerical model. In this verification process an actual physical reservoir is substituted with the Cartesian model. Figure 3-10 shows this procedure. Two different models are built in the simulator with different reservoir characteristics. The input parameters of the 
Cartesian model are not changed during the whole matching process except one parameter, true skin factor. This parameter is changed from $\mathrm{S}_{1}$ to $\mathrm{S}_{1}{ }^{*}$ before the single rate test (SRT) starts since this process is verification of real life and in real life skin factor changes in time. A multi rate well test followed by a single rate well test is performed on both models. From the multi rate test (MRT) data of Cartesian model conventional analysis is done. Permeability, true skin factor and Darcy factor are calculated and are compared with the input values of them. The calculated parameters are put into the radial model to be the initial values of the history match. At the time the match is obtained with MRT data, the skin factor of the radial model is $S_{2}$ and Darcy factor is $\mathrm{D}_{2}$. Before performing a SRT in the Cartesian model $\mathrm{S}_{1}$ is changed to $\mathrm{S}_{1}{ }^{*}$. A SRT is also performed in the radial model with the same flow rate of Cartesian model's test. $\mathrm{S}_{2}$ of the radial model is modified until a good match is obtained with the Cartesian model's SRT data while keeping the other parameters, $\mathrm{k}_{1}$ and $\mathrm{D}_{1}$ constant. At the time we have the match of SRT data, skin factor of the radial model is changed from $\mathrm{S}_{2}$ to $\mathrm{S}_{2}{ }^{*}$ and skin factor of Cartesian model is changed to from $S_{1}$ to $S_{1}{ }^{*}$.

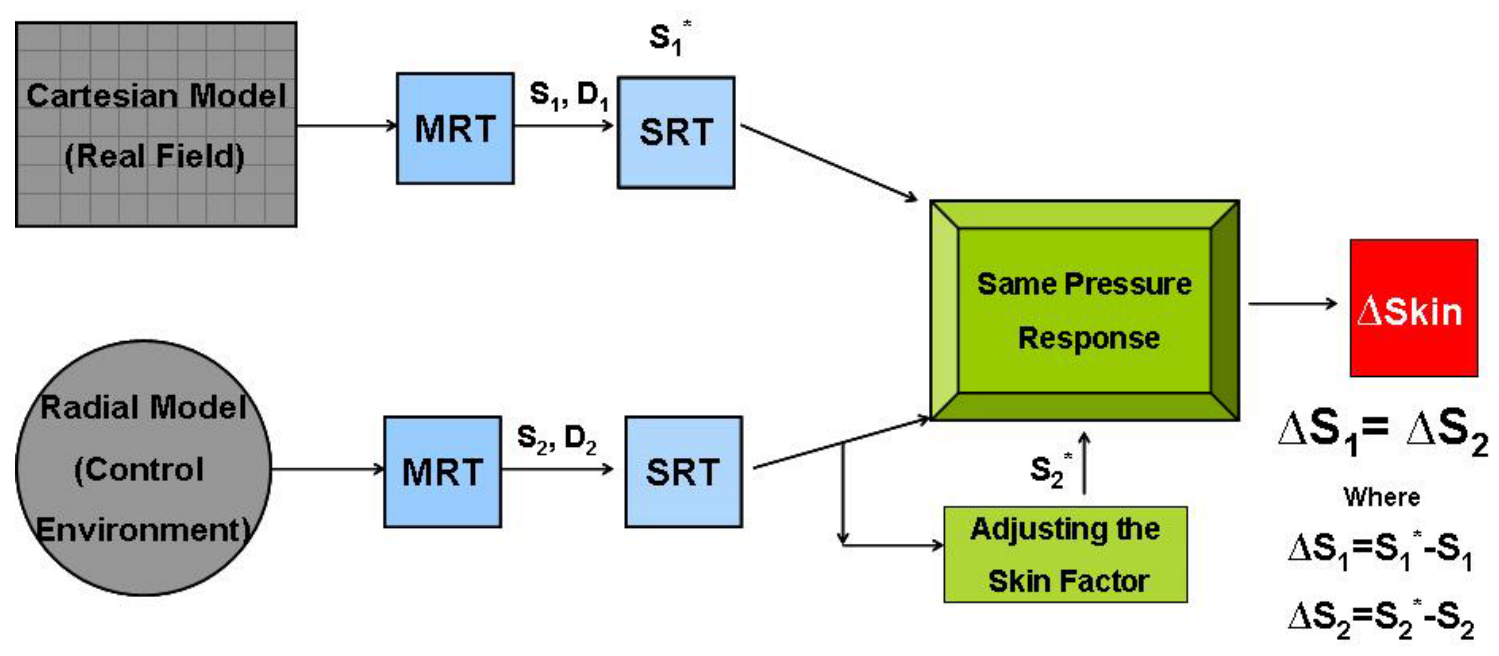

Figure 3-10: Schematic of verification process.

If we abbreviate the change in skin with $\Delta S$, Skin factor of the Cartesian model is changed as,

$\Delta S_{1}=S_{1}^{*}-S_{1}$

And the radial model's skin factor changes as,

$\Delta S_{2}=S_{2}^{*}-S_{2}$

In this part of the study it has been verified that $\Delta S_{1}=\Delta S_{2}$. 


\section{RESULTS}

Results presented in this section consist of Cartesian plots showing history match of pressure against time data obtained from simulation model and actual reservoir. The results of verification are also presented in this section. For easier understanding of the outcomes, a summary table of the parameters is presented in each subchapter.

\subsection{Verification}

To verify the methodology and the results of the field examples, a simplified radial simulation model was generated to history match with a high resolution Cartesian numerical model. In this verification process an actual physical reservoir is substituted with the Cartesian model. Four different cases were studied. In each case, the permeability distribution of the Cartesian model was changed. In the first case, the permeability is distributed homogeneously on the Cartesian model. The other three cases have heterogeneous permeability distributions.

\subsubsection{Homogeneous System}

Both models are homogeneous with different reservoir/well characteristics. The parameters adjusted during the history match are permeability $(\mathrm{k})$, non-Darcy skin factor, called as true skin factor (S), and Darcy factor (D).

In order to substitute an actual physical reservoir, a high resolution Cartesian model was built in the Eclipse simulator with a single well located at the center of the reservoir model. Reservoir input parameters such as permeability and porosity were distributed homogeneously on this reservoir model. Second column of Table 4-3: Summary of parameters adjusted in the history match of multi rate test data, homogeneous case. Table 4-3 shows the input parameters k, S and D of the Cartesian model. Table 4-1 shows input parameters of the Cartesian simulation model.

Table 4-1: Reservoir characteristics of homogeneous Cartesian model filled with dry gas.

\begin{tabular}{|l|c|l|c|}
\hline Grid blocks & $17 \times 17 \times 1$ & Gas Gravity, $(\mathrm{Y})$ & 0.7 \\
\hline Porosity, $(\Phi)$ & $14 \%$ & $\mathrm{~T}_{\text {reservoir }}$, & $75^{\circ} \mathrm{F}$ \\
\hline Permeability, $(\mathrm{k})$ & $80 \mathrm{md}$ & $\mathrm{P}_{\text {initial }}$ & $1190 \mathrm{psia}$ \\
\hline Thickness, $(\mathrm{h})$ & $10 \mathrm{ft}$ & Well radius, $\left(\mathrm{r}_{\mathrm{w}}\right)$ & $0.3 \mathrm{ft}$ \\
\hline Area, $(\mathrm{A})$ & $91.8 \mathrm{acre}$ & True skin factor, $(\mathrm{S})$ & 1.2 \\
\hline Depth, $(\mathrm{D})$ & $1200 \mathrm{ft}$ & Darcy factor, $(\mathrm{D})$ & $9.00 \mathrm{E}-05$ \\
\hline
\end{tabular}


A multi rate test was performed on the model. From the pressure vs. time data of the three drawdown periods of this test; $\mathrm{k}, \mathrm{S}$ and $\mathrm{D}$ were calculated by using the conventional well test analysis methods.

For each flow period, $\left(P_{i}^{2}-P_{w f}^{2}\right) / q$ vs. Time data was plotted on a semi log graph. Figure 4-1 shows the semi-log plot of first drawdown period (DD-1). A diagnostic plot was also prepared in order to estimate the beginning of the middle time region of the semi-log plot. However, a straight line could not get obtained on the diagnostic plot data since the data is from a simulated reservoir model and in numerical models well bore storage is not modeled unless the first grid near the well bore is changed. As a consequence, the straight line was plotted with most probable data of semi-log graph.

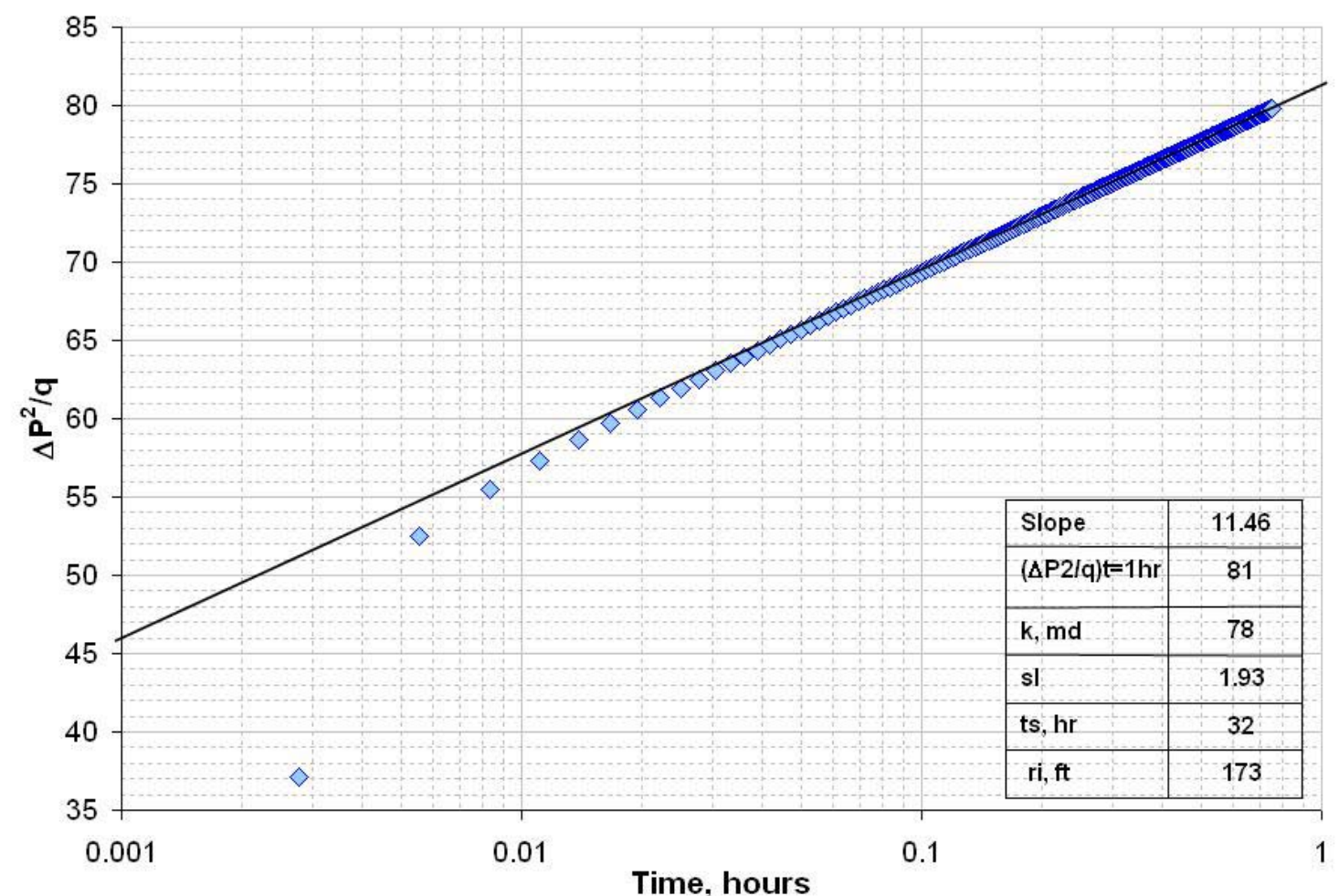

Figure 4-1: Semi-log plot of the first drawdown period of the multi rate test performed on the homogeneous Cartesian model.

The slope of the straight line was calculated as,

$\frac{(69.36-57.90)}{(\log (0.1)-\log (0.01))}=11.46$ 
By using this slope and other input reservoir and fluid properties, permeability, apparent skin factor, radius of investigation $\left(\mathrm{r}_{\mathrm{i}}\right)$ and time to stabilization $\left(\mathrm{t}_{\mathrm{s}}\right)$ were calculated with the formulas shown below,

$k=\frac{(1637)(T)(\overline{\mu z})}{m h}$

In order to calculate average PVT parameters average pressure for this flow period was calculated as,

$\bar{P}=\sqrt{\frac{P_{i}^{2}+P_{i}^{2}}{2}}=\sqrt{\frac{1190^{2}+935^{2}}{2}}$

$\bar{P}=1070$ psia

After estimating the $\bar{\mu}, \bar{z}, \bar{c}$ the analysis was finalized as,

$k=\frac{(1637)\left(535^{\circ} R\right)(0.012836 c p)(0.797168)}{(11.46)(10 f t)}$

$k \cong 78 m d$

Apparent skin factor was calculated around 1.93

$s^{\prime}=1.151\left[\left(\frac{P_{i}^{2}-P_{w f}^{2}}{q}\right)_{t=1 h r}\left(\frac{1}{m}\right)-\log \left(\frac{k}{(\phi)(\bar{\mu})(\bar{c})\left(r_{w}\right)^{2}}\right)+3.23\right]$

$s^{\prime}=1.151\left[(81)_{t=1 h r}\left(\frac{1}{11.46}\right)-\log \left(\frac{78 m d}{(0.14)(0.012836 c p)\left(0.001149 p s i a^{-1}\right)(0.3 f t)^{2}}\right)+3.23\right]$

$s^{\prime} \cong 1.93$

Radius of investigation and time to stabilization were also calculated with the formulas shown below,

$r_{i}=\left(\frac{k t}{948 \phi \overline{\mu c}}\right)^{1 / 2}$

$r_{i}=\left(\frac{(78 m d)(0.75 h r)}{(948)(0.14)(0.012836 c p)\left(0.001149 p s i a^{-1}\right)}\right)^{1 / 2}$

$r_{i}=173 f t$ 
By replacing the external radius of the reservoir into radius of investigation in the formula shown above, the length of time required to achieve stabilized flow was calculated.

$t_{s}=\frac{(948) \phi \overline{\mu c} r_{i}^{2}}{k}$

The area of the Cartesian model was set as 91.8 acre. Hence the length of the $\mathrm{x}$ axis of the model is equal to the length of the y axis; this parameter was converted to a radius in order to be able to replace it on the above formula.

Area of the reservoir $=(91.8$ acre $) \times\left(43560 \mathrm{ft}^{2} /\right.$ lacre $)=(\pi)\left(r_{e}^{2}\right)$

$r_{e} \cong 1128 f t$

By substituting $r_{e}$ into the formula stabilized time was calculated as,

$t_{s}=\frac{(948)(0.14)(0.012836 c p)\left(0.001149{p s i a^{-1}}^{-1}\right)\left(1128^{2} f t^{2}\right)}{78 m d}$

$t_{s} \cong 32 h r$

The same calculations were performed for the second drawdown (DD-2) and the last drawdown (DD-3) periods. Figure 4-2 shows the semi-log plot of the Delta $\mathrm{P}^{2} / \mathrm{q}$ vs. time data of second drawdown period. 


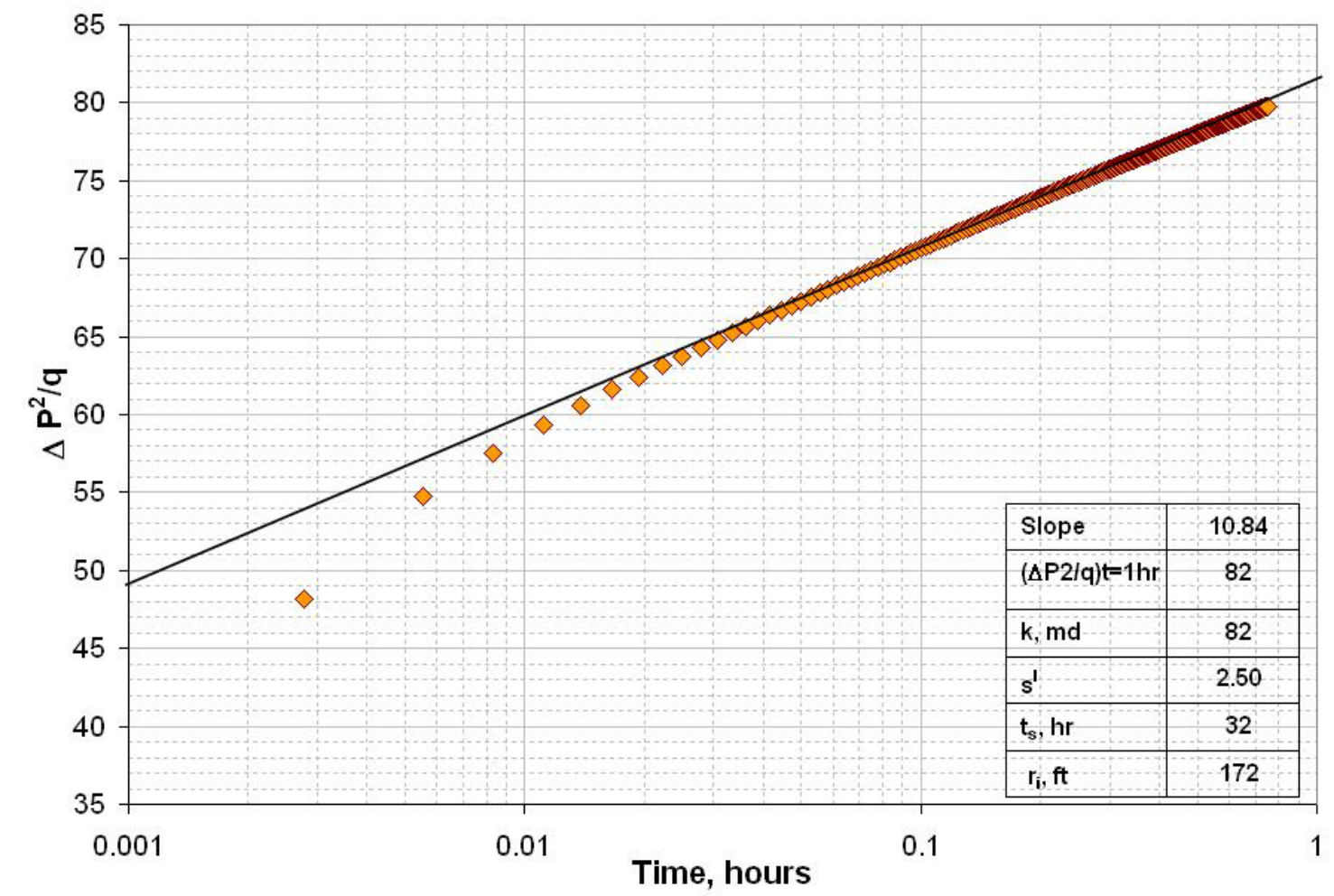

Figure 4-2: Semi-log plot of the second drawdown period of the multi rate test performed on the homogeneous Cartesian model.

Figure 4-3 shows the semi-log plot of the third (and the last) drawdown period data of the multi rate test. The calculated parameters by using this data are shown in a table located on the right bottom corner of the same figure. From three drawdown periods, three different permeability values and three different apparent skin factors were calculated (Table 4-2). Non-Darcy skin factor (S) and Darcy factor (D) were estimated by performing linear regression between the three data points which is apparent skin factor and its corresponding flow rate value (Figure 4-4). On a Cartesian graph, after placing the flow rates on $\mathrm{x}$ - axis and apparent skin factor data on $\mathrm{y}$-axis the slope of the linear line gave the $\mathrm{D}$ and the interception with the $\mathrm{y}$ axis gave the $\mathrm{S}$ based on the formula, $s^{\prime}=S+D q$

Table 4-2: Conventional well test analysis results from three drawdown periods of the MRT performed on the homogeneous Cartesian Model.

\begin{tabular}{|c|c|c|c|}
\hline & Permeability (k) & Apparent Skin $\left(\mathrm{s}^{\prime}\right)$ & Flow Rate $(\mathrm{q})$ \\
\hline Drawdown-1 (DD-1) & $78 \mathrm{md}$ & 1.93 & $6800 \mathrm{Mscf} / \mathrm{D}$ \\
\hline Drawdown-2 (DD-2) & $82 \mathrm{md}$ & 2.50 & $12000 \mathrm{Mscf} / \mathrm{D}$ \\
\hline Drawdown-3 (DD-3) & $80 \mathrm{md}$ & 2.15 & $8750 \mathrm{Mscf} / \mathrm{D}$ \\
\hline
\end{tabular}




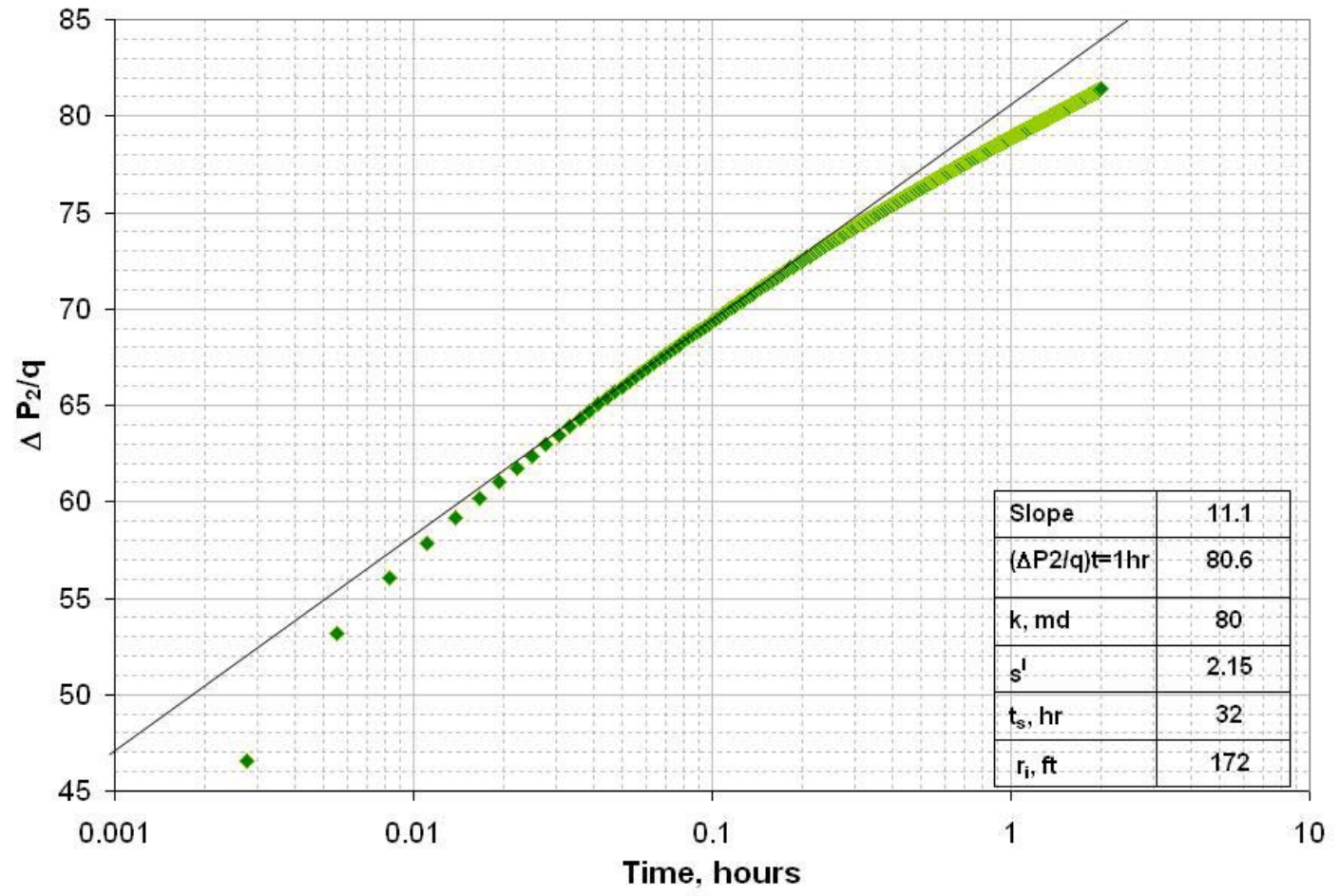

Figure 4-3: Semi-log plot of the third and the last drawdown period of the multi rate test performed on the homogeneous Cartesian model. The calculated parameters are shown on the table. 


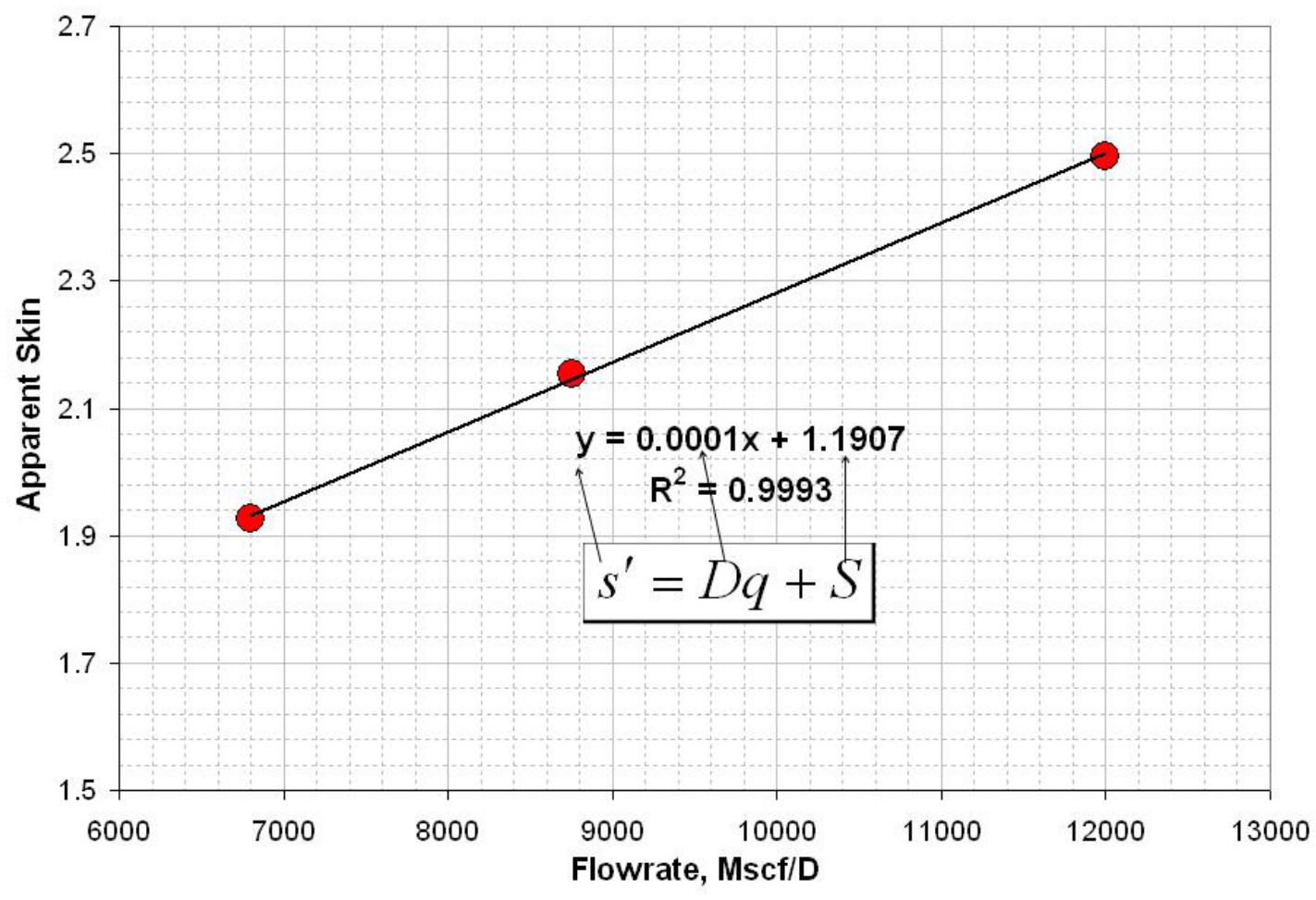

Figure 4-4: Estimation of true skin factor and Darcy factor by regression of the apparent skin factors calculated from well test analysis.

As a result true skin factor and Darcy factor were estimated as,

$S \cong 1.19$

$D=1 E-04$

These numbers are very close to their input values. This fact shows that the conventional analysis gave very precise results as long as the reservoir is homogeneously modeled. Since in reality dealing with a homogeneous reservoir is impossible, the analysis has been tested with three different heterogeneous models in this study as well. Their results are shown in the following sections of this chapter.

A homogeneous radial model was built with the same input reservoir parameters of Cartesian model and with the parameters, $\mathrm{k}, \mathrm{S}$ and $\mathrm{D}$, calculated by performing conventional analysis. The same multi rate test was also performed. This radial model was prepared to history match with the Cartesian model's multi rate test data. Permeability, skin factor and D-factor are the parameters to be adjusted in the history match. The matching procedure started with the calculated values of these parameters. Multi rate test match was obtained successfully (Figure 4-5). 


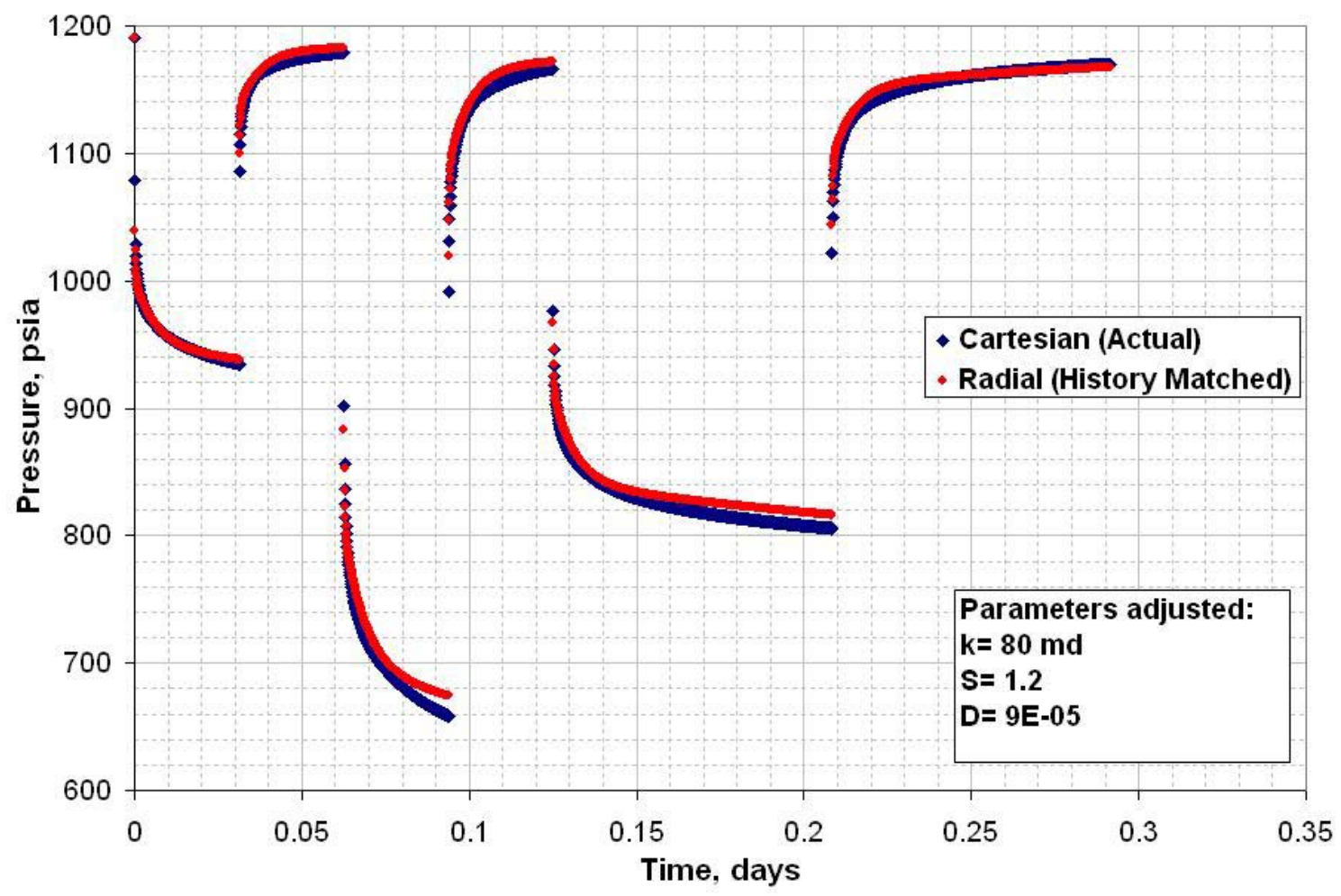

Figure 4-5: History match of the MRT data of radial model with homogeneous Cartesian model data by using the calculated parameters in the radial model.

After getting the match with the multi rate test data (MRT), a single rate test (SRT) was performed on the Cartesian model with a changing skin factor equal to 2.5 . The change in the skin factor from the MRT to SRT in the Cartesian model became,

$$
\begin{aligned}
& \Delta S=S_{2}-S_{1} \\
& \Delta S=2.5-1.2 \\
& \Delta S=1.3
\end{aligned}
$$

On the radial model a single rate well test was performed to get a match with the Cartesian model's single rate test data. 


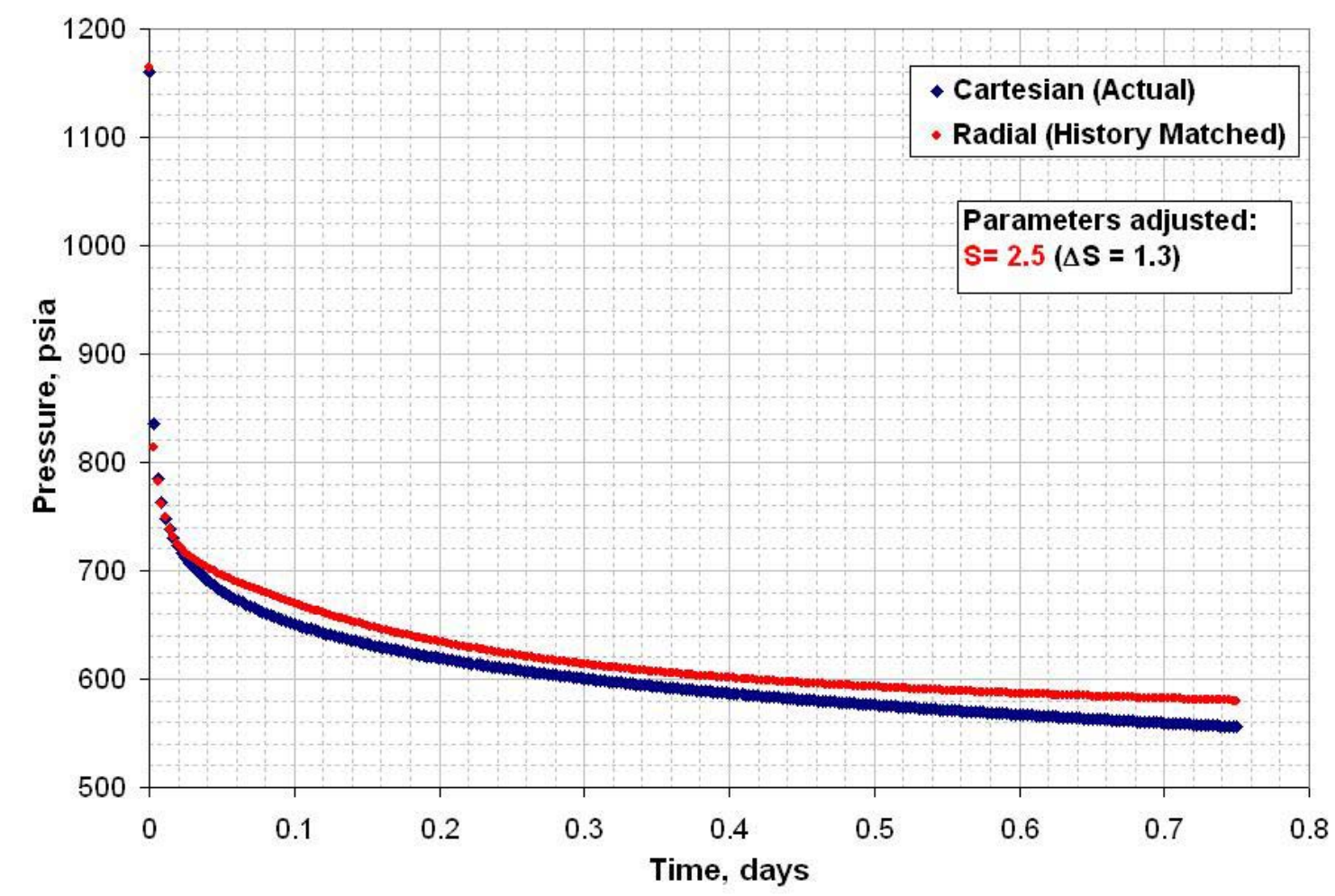

Figure 4-6: History match of SRT could not be obtained by modifying change in delta skin values of both models equally.

Although the MRT match of the models are acceptable, the parameters k, S and D of the radial model were decided to be adjusted during the MRT match since a match of the single rate test data could not get obtained (Figure 4-6).

By adjusting the permeability as $100 \mathrm{md}$, skin factor as 3.38 and Darcy factor $9 E-05$, shown on the $5^{\text {th }}$ column of Table 4-3, in the radial model, a match was obtained. The results are illustrated in Figure 4-7 showing pressure (psia) vs. time (days) data of both multi rate tests in a Cartesian plot. Blue line represents the Cartesian model's data (the model is assumed to be a substitute of an actual reservoir for verification) and the red line is the match of radial model's data.

After getting the match with the MRT data, a SRT was performed on the Cartesian model with a changing skin factor equal to 2.5. The change in the skin factor is still 1.3 when compared to the previous case. 


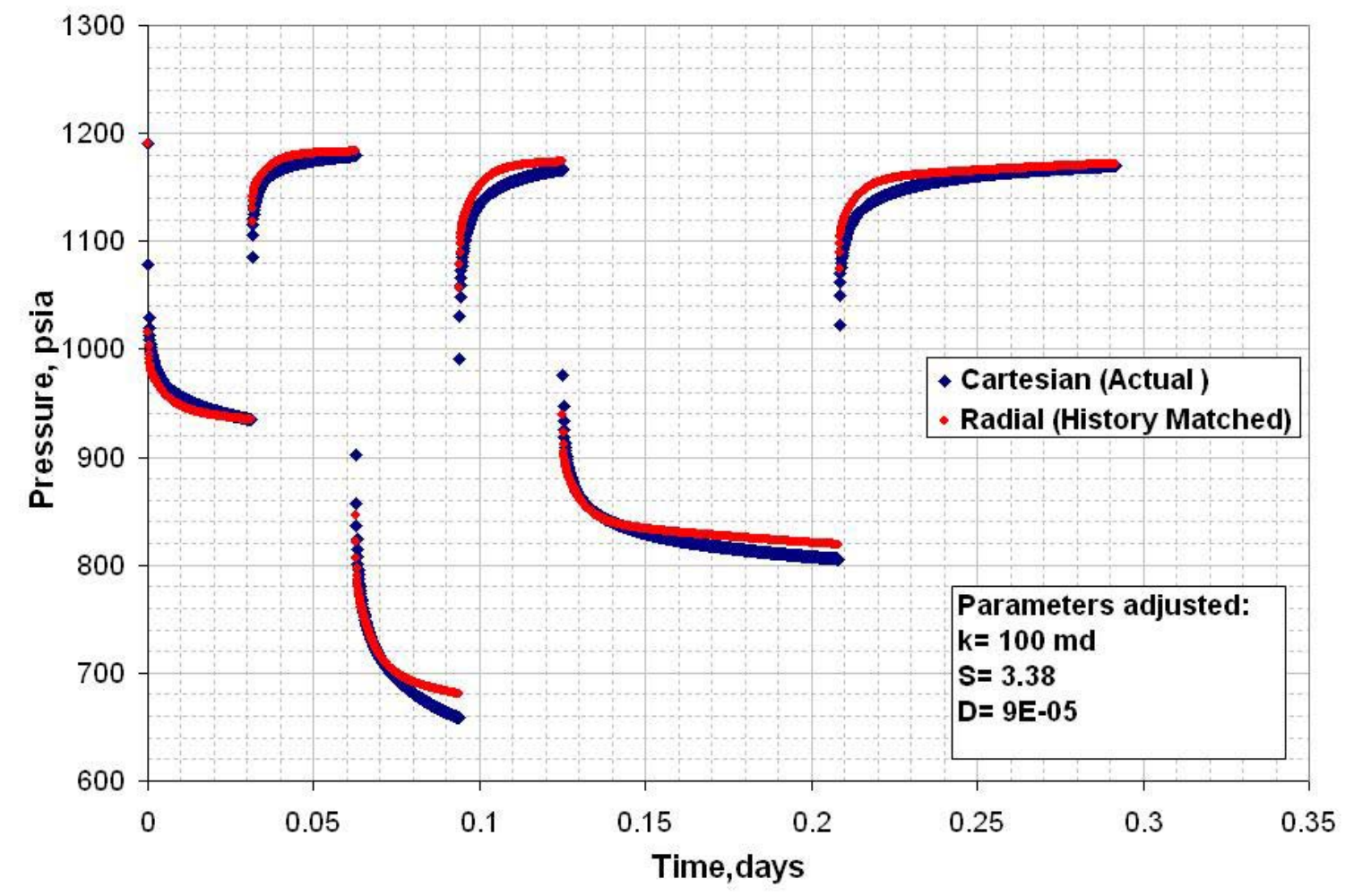

Figure 4-7: History match of MRT data of radial model with different modified parameters in homogeneous case for verification.

On the radial model a SRT was performed to get a match with the Cartesian model's SRT data. The match was obtained when the skin factor of the radial model was modified to $S=4.68$ while keeping the other parameters constant ( $k=100 \mathrm{md}$ and $\mathrm{D}=9 \mathrm{E}-05)$. Figure 4-8 shows the result of the pressure match of both model's SRT data on a Cartesian plot. As a result, the match was obtained when $\Delta S=1.3$ in the radial model.
$\Delta S=S_{2}-S_{1}$
$\Delta S=4.68-3.38$
$\Delta S=1.3$ 


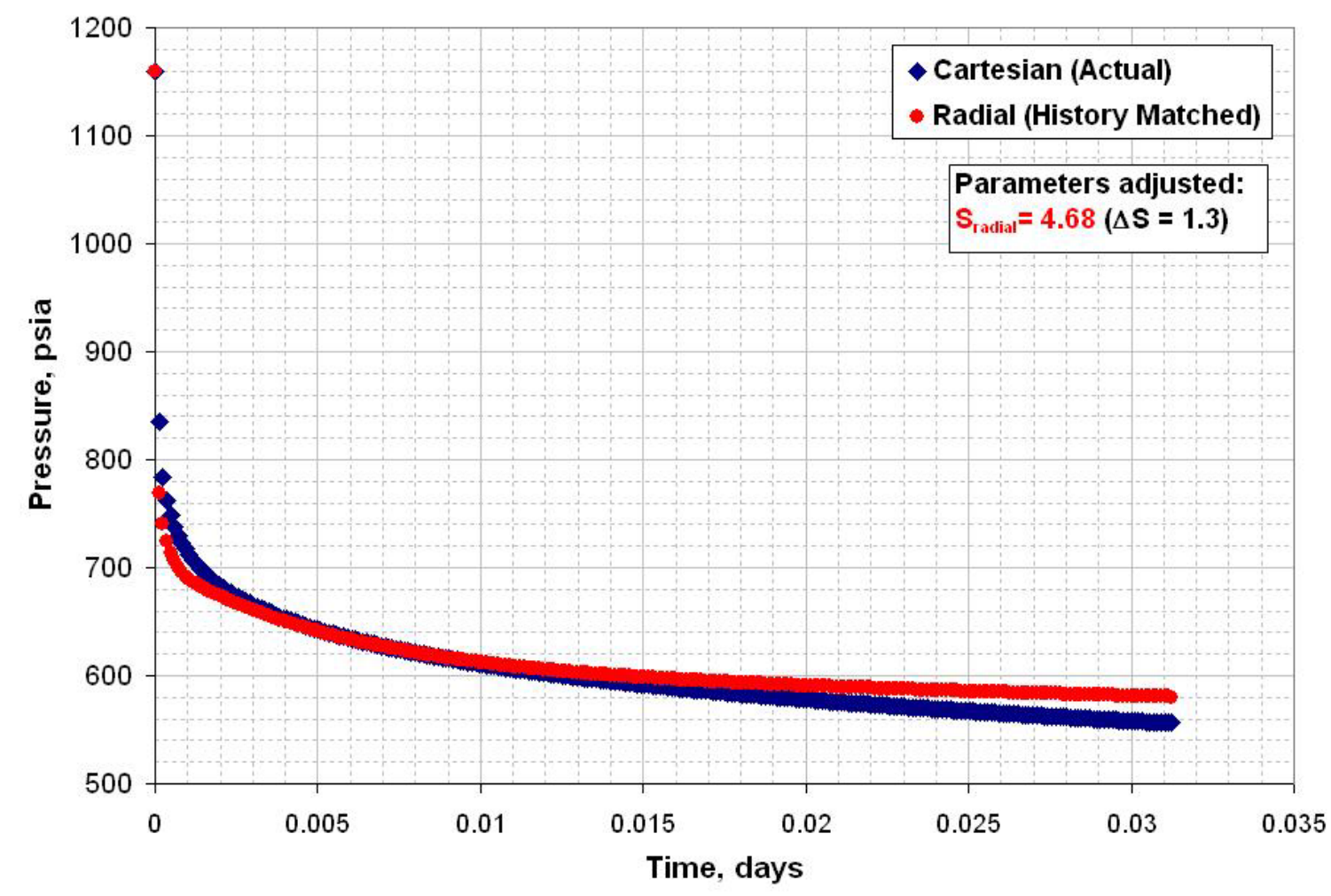

Figure 4-8: History match of SRT data of the radial model by changing S from 3.38 to 4.68.

The summary of the change in the skin from multi rate test to the single rate test is shown on the $4^{\text {th }}$ column of Table $4-4$.

In order to test the change in the skin factor another case $\left(2^{\text {nd }}\right.$ Case $)$ was also studied. The Cartesian model kept same with the previous cases while the three parameters of the radial model were modified during the history match of multi rate test data. This time, by adjusting the permeability as $87 \mathrm{md}$, skin factor as 2.2 while keeping the Darcy factor as $9 E-05$, shown on the $6^{\text {th }}$ column of Table $4-3$, in the radial model, a match was obtained. The results are illustrated in Figure 4-9.

The SRT match was obtained by changing the skin factor from 2.2 to 3.5 in the radial model during the test while keeping the other parameters constant (Figure 4-10). Again for both models the change in the skin factor is equal to 1.3.

The summary of the adjusted parameters, $\mathrm{k}, \mathrm{S}$ and $\mathrm{D}$, before and during performing the multi rate test for all the cases of homogeneous system are shown on Table 4-3. The first column of this table shows those parameters, the second column shows the values of those parameters as inputs during building the high resolution Cartesian model. The third 
column is the result of the well test analysis, which was performed on the multi rate test data of Cartesian simulation model. Those values were calculated by using conventional methods (and they were calculated almost equal to the input values). The fourth column is the initial values of the radial model. Those values were obtained from the analysis of Cartesian model's MRT. They were used as initial values of history matching. However since match could not get obtained with those values, they were modified until getting the MRT match. First set of parameters are shown on the fifth column of the table and second set of parameters on the sixth column of the table.

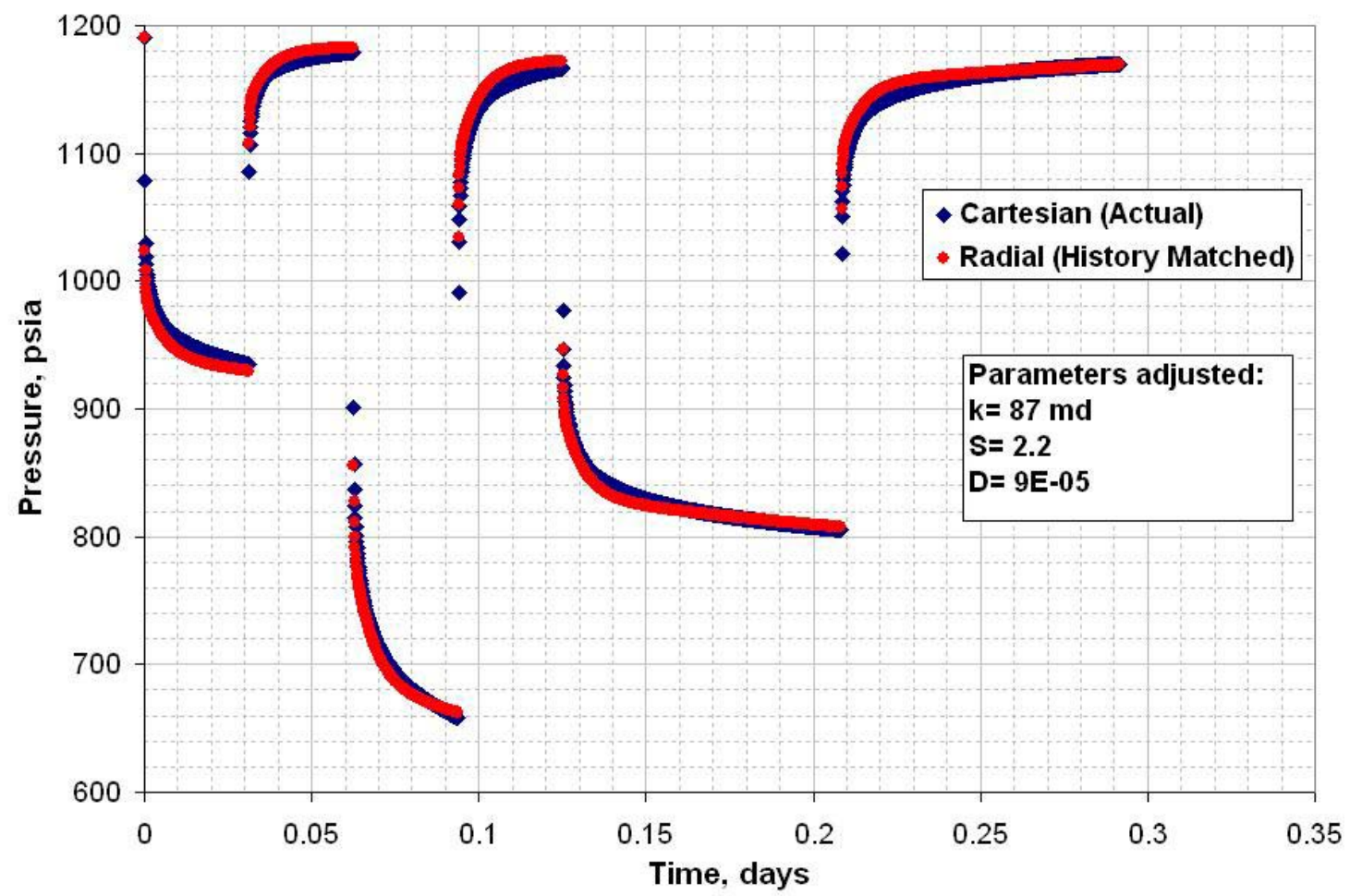

Figure 4-9: History match of MRT data of radial model with different modified parameters in homogeneous case for verification (Case 2). 


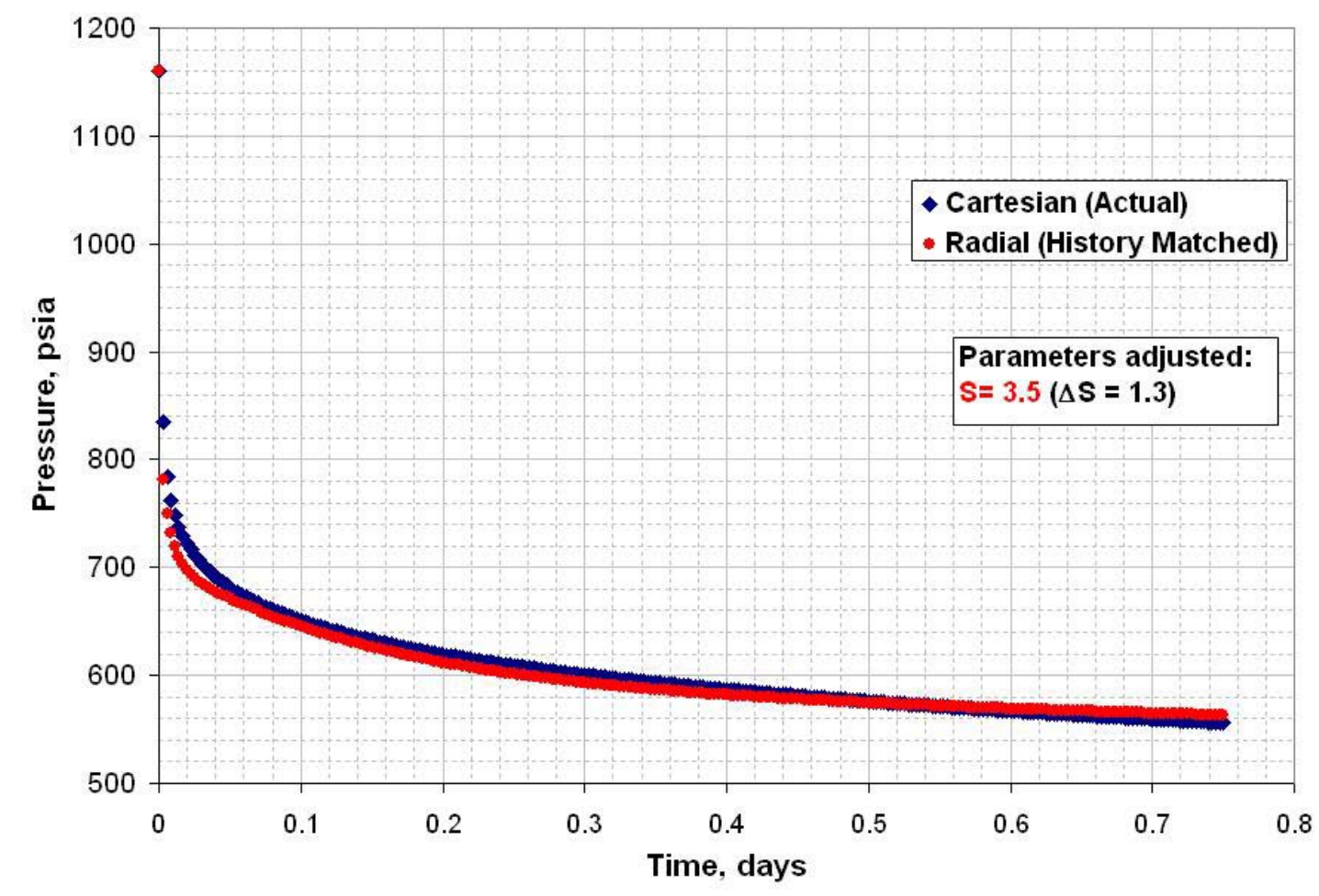

Figure 4-10: History match of the SRT data of the radial model by changing S from 2.2 to 3.5 .

Getting a match with two different set of parameters in the same system shows that the history matched model is one probable version of reality in which there can be several possibilities. Thus, our history matched model is non-unique but the key in this method is consistency and attributing the change in the well production behavior to skin.

Table 4-4 shows the summary of the change in the skin factor from history match of multi rate test to single rate test for each simulation model.

Table 4-3: Summary of parameters adjusted in the history match of multi rate test data, homogeneous case.

\begin{tabular}{|l|c|c|c|c|c|}
\hline Homogeneous Case: & Cartesian Input & Well Test Analysis & Radial Input & $1^{\text {st }}$ Case & $2^{\text {nd }}$ Case \\
\hline Permeability, md & 80 & 80 & 80 & 100 & 87 \\
\hline Skin factor & 1.2 & 1.2 & 1.2 & 3.38 & 2.2 \\
\hline Darcy factor & $9.00 \mathrm{E}-05$ & $9.00 \mathrm{E}-05$ & $9.00 \mathrm{E}-05$ & $9.00 \mathrm{E}-05$ & $9.00 \mathrm{E}-05$ \\
\hline
\end{tabular}

Table 4-4: Summary of change in skin factor for homogeneous case verification.

\begin{tabular}{|l|c|c|c|c|}
\hline Homogeneous Case & Cartesian Input & Radial Input & Radial $1^{\text {st }}$ Case Match & Radial $2^{\text {nd }}$ Case Match \\
\hline Skin, match of MRT & 1.2 & 1.2 & 3.38 & 2.2 \\
\hline Skin, match of SRT & 2.5 & 2.5 & 4.68 & 3.5 \\
\hline Delta skin & 1.3 & 1.3 & 1.3 & 1.3 \\
\hline Match with MRT data & & Obtained & Obtained & Obtained \\
\hline Match with SRT data & & Not obtained & Obtained & Obtained \\
\hline
\end{tabular}




\subsubsection{Heterogeneous Systems}

In this section of the verification process, heterogeneity was introduced to the Cartesian model by changing only the permeability values in the grids of the model. Three different types of heterogeneities were brought into the model. In the first case, permeability values were selected and distributed randomly. Second case showed radial permeability distribution on the model and the last case has a different shape of heterogeneity. For all three cases, the average permeability kept between 80-90 md.

\section{Case 1}

In the first case of the heterogeneous systems, permeability values were selected and distributed randomly on the Cartesian numerical simulation model. This high resolution Cartesian model consists of 289 grid blocks. Spot permeability distribution was aimed instead of changing the value of permeability in each grid block. 4 different spots were introduced to the permeability distribution as $150 \mathrm{md}, 120 \mathrm{md}, 100 \mathrm{md}$ and $60 \mathrm{md}$. Between these values kriging was performed by using statistical software called Gslib. Figure 4-11 shows the heterogeneity type of the model in terms of permeability. The spots could not get clearly obtained since there is fine grid refinement on the model. 


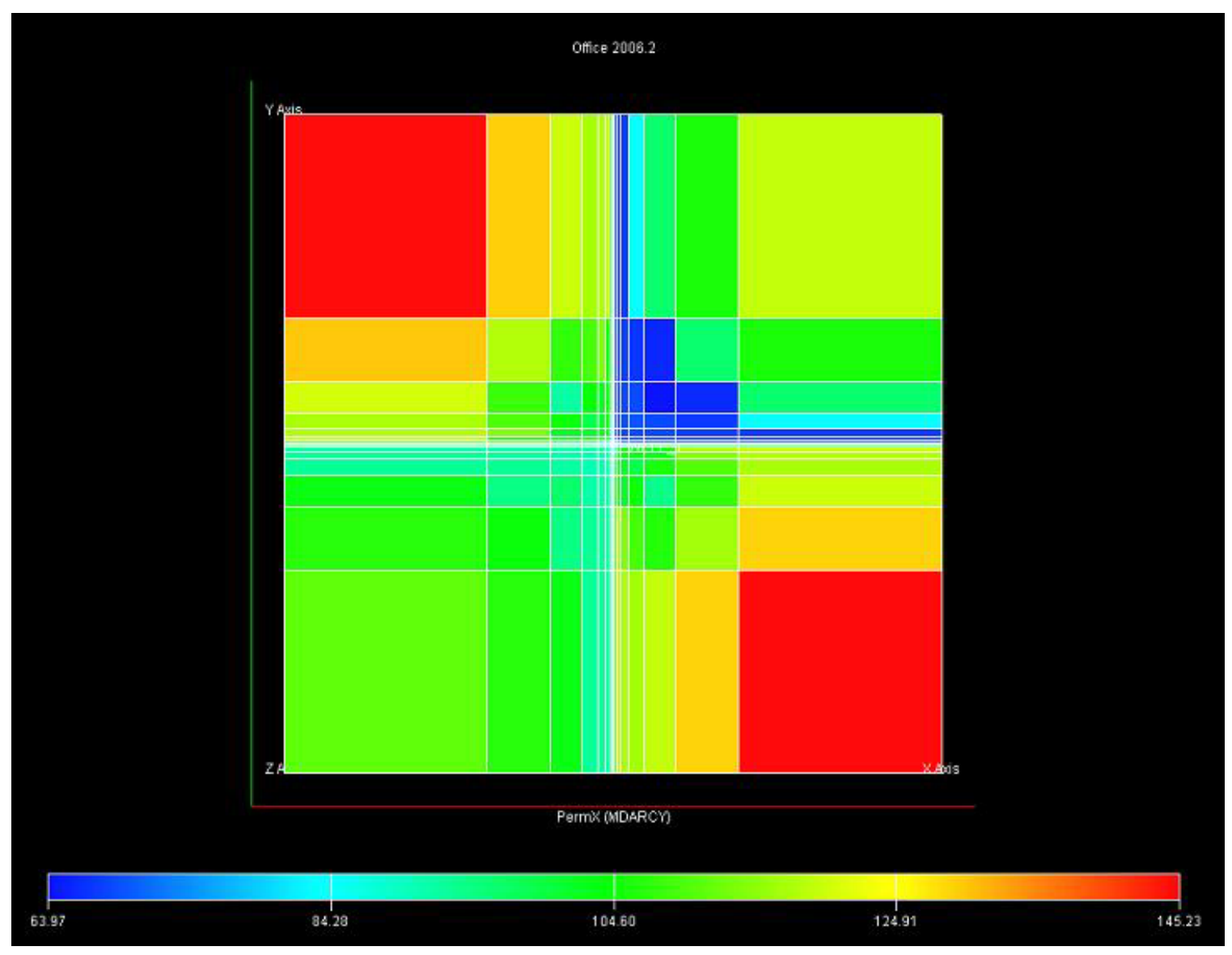

Figure 4-11: Permeability distribution on the Cartesian model of Case 1, heterogeneous case.

The model has one well located at the center. A multi rate test was performed on this well. From three drawdown periods of this test, three different permeability values and three different apparent skin factors were calculated (Table 4-5). Non-Darcy skin factor (S) and Darcy factor (D) were estimated by performing linear regression between the apparent skin factor data and flow rates (Figure 4-12).

Table 4-5: Conventional well test analysis results from the three drawdown periods of the MRT performed on the heterogeneous Cartesian model of case 1.

\begin{tabular}{|c|c|c|c|}
\hline Heterogeneous Case-1 & Permeability (k) & Apparent Skin (s') & Flow Rate (q) \\
\hline Drawdown-1 (DD-1) & $82 \mathrm{md}$ & 2.30 & $6800 \mathrm{Mscf} / \mathrm{D}$ \\
\hline Drawdown-2 (DD-2) & $95 \mathrm{md}$ & 3.61 & $12000 \mathrm{Mscf} / \mathrm{D}$ \\
\hline Drawdown-3 (DD-3) & $93 \mathrm{md}$ & 3.24 & $8750 \mathrm{Mscf} / \mathrm{D}$ \\
\hline
\end{tabular}




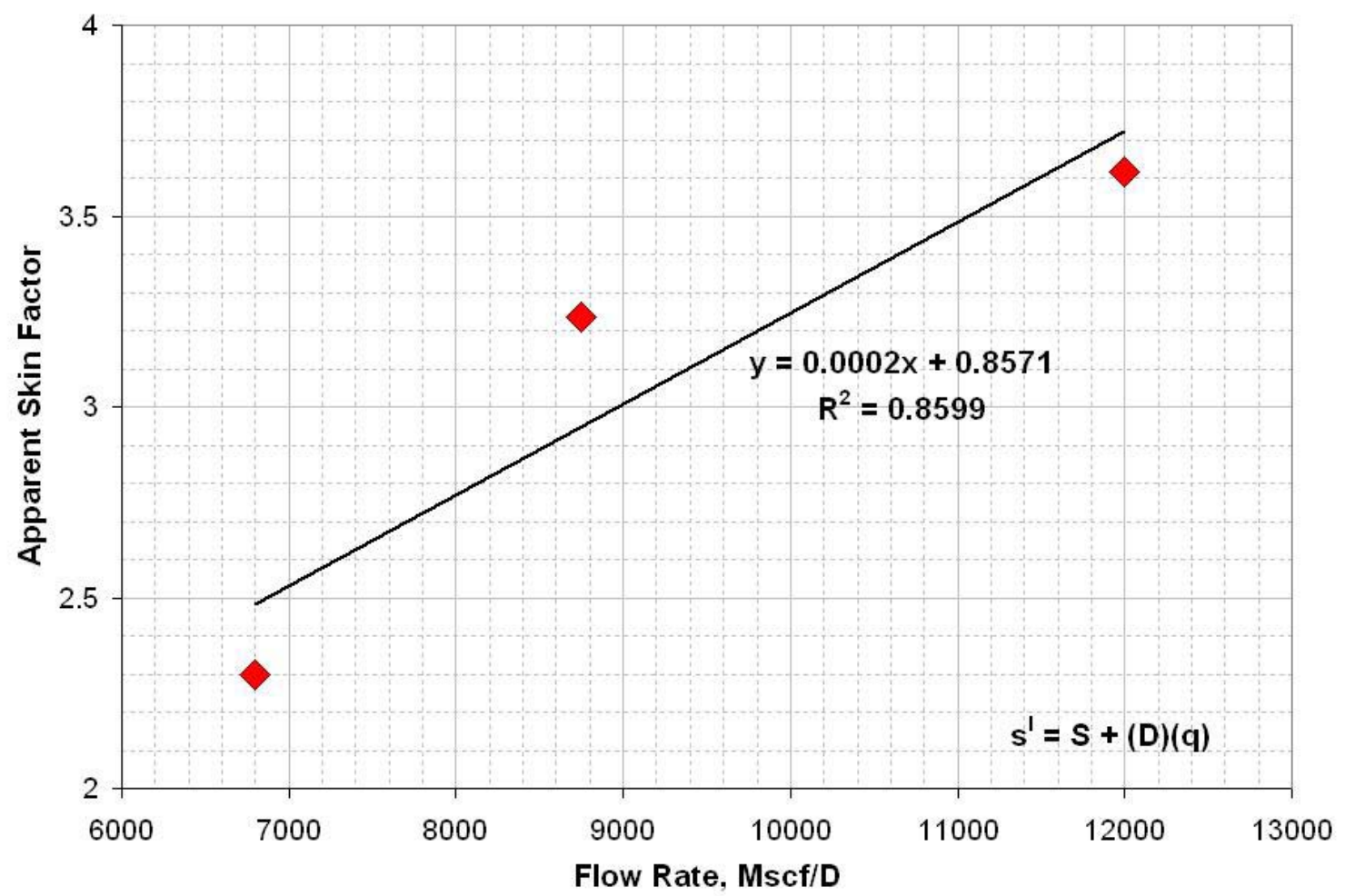

Figure 4-12: Estimation of true skin factor and D-factor by regression of the data calculated by conventional analysis method, heterogeneity, Case 1.

True skin factor was estimated around 0.86 and the D factor as 2E-04. The values are not same with their initial input values $(\mathrm{S}=1.28$ and $\mathrm{D}=9 \mathrm{E}-05)$. It shows that conventional analysis calculations do not always give the accurate results because their formulas are based on some basic assumptions like the reservoir is homogeneous. There can be two reasons for this. First, the analytical analysis followed in this study is based on the assumption that each drawdown period should start with a stabilized pressure value. However, in a multi rate test (modified isochronal test) there is no wait for the stabilization in each build-up period. Thus, the drawdown periods do not start with a stabilized pressure, which affects the estimation of the permeability from the analytical analysis. Second, in the Cartesian model the permeability values on the grids located near to the well bore are high and gradually decreasing to the boundaries of drainage area. This high value of the permeability may cause less pressure drop near the well bore, hence less skin factor, since in the simulator input skin parameter directly affects the well bore, not the first grid located next to the well bore. 
Three different permeability values, calculated by conventional analysis, were averaged equal to $90 \mathrm{md}$. This average permeability and the estimated true skin factor and the Darcy factor were used as some of the initial input prameters to build a homogeneous radial model. The other characteristics of both models are same. Radial model has a well located at the center of the model as well. A multi rate test (MRT) was performed on the well of radial model with same duration and flow rates values of the MRT performed on the heterogeneous Cartesian model's well. Pressure vs. time data of this test was tried to match with the Cartesian model's MRT data. The match could not get obtained (Figure 4-13). Although all the parameters of both models are almost same (accept the heterogeneity of permeability values in Cartesian Model), the match could not get obtained with the calculated values of $\mathrm{k}, \mathrm{S}$ and $\mathrm{D}$.

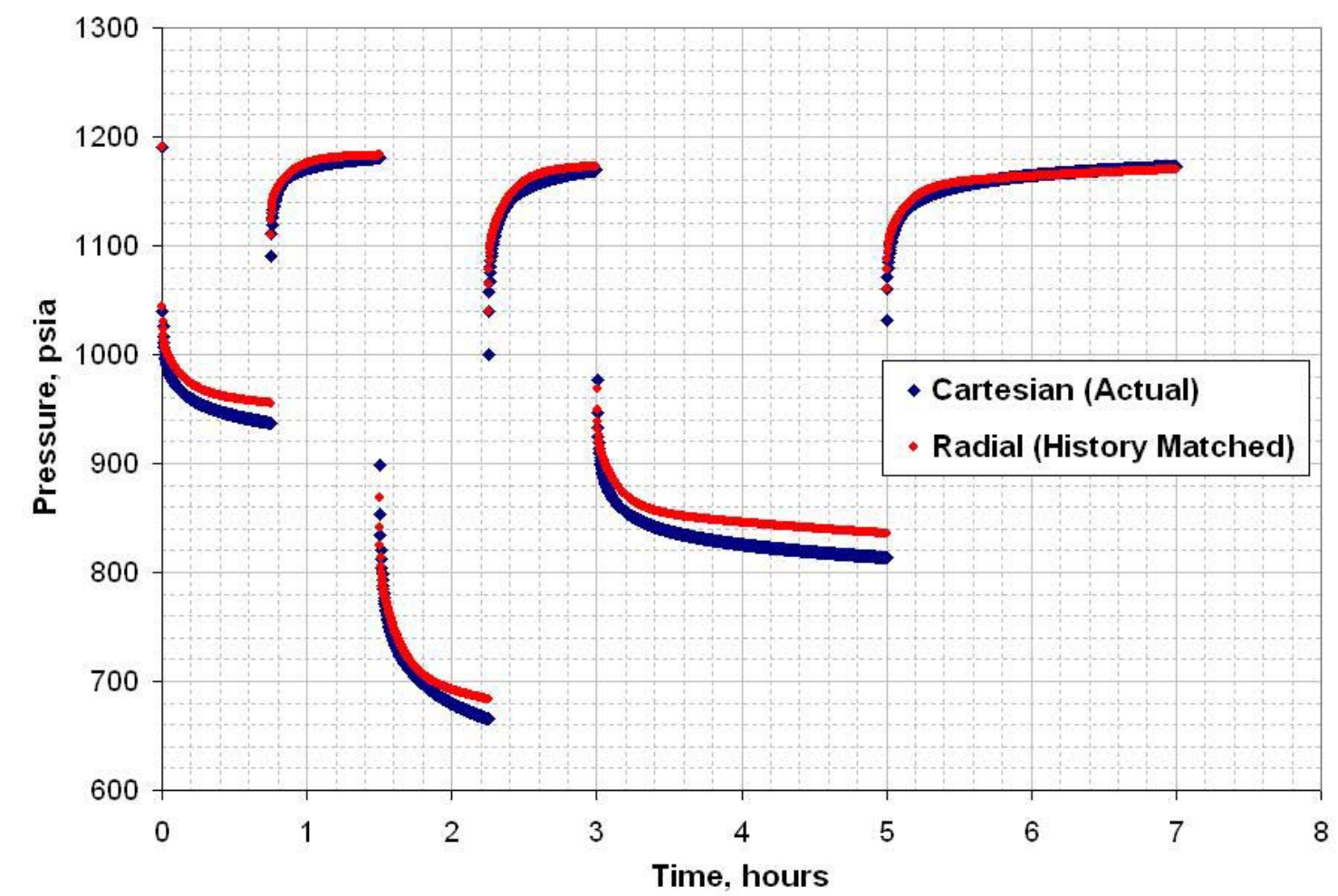

Figure 4-13: MRT match of the radial model with Cartesian model data of Heterogeneous system, case 1.

It was started to change the values of the $\mathrm{k}, \mathrm{S}$ and $\mathrm{D}$ parameters of the radial model in order to get a match with the MRT data of Cartesian model. Figure 4-14 shows a match of both multi rate tests. The blue line represents the Cartesian model's data, and the red line shows the match of radial model's MRT data with adjusted parameters. 


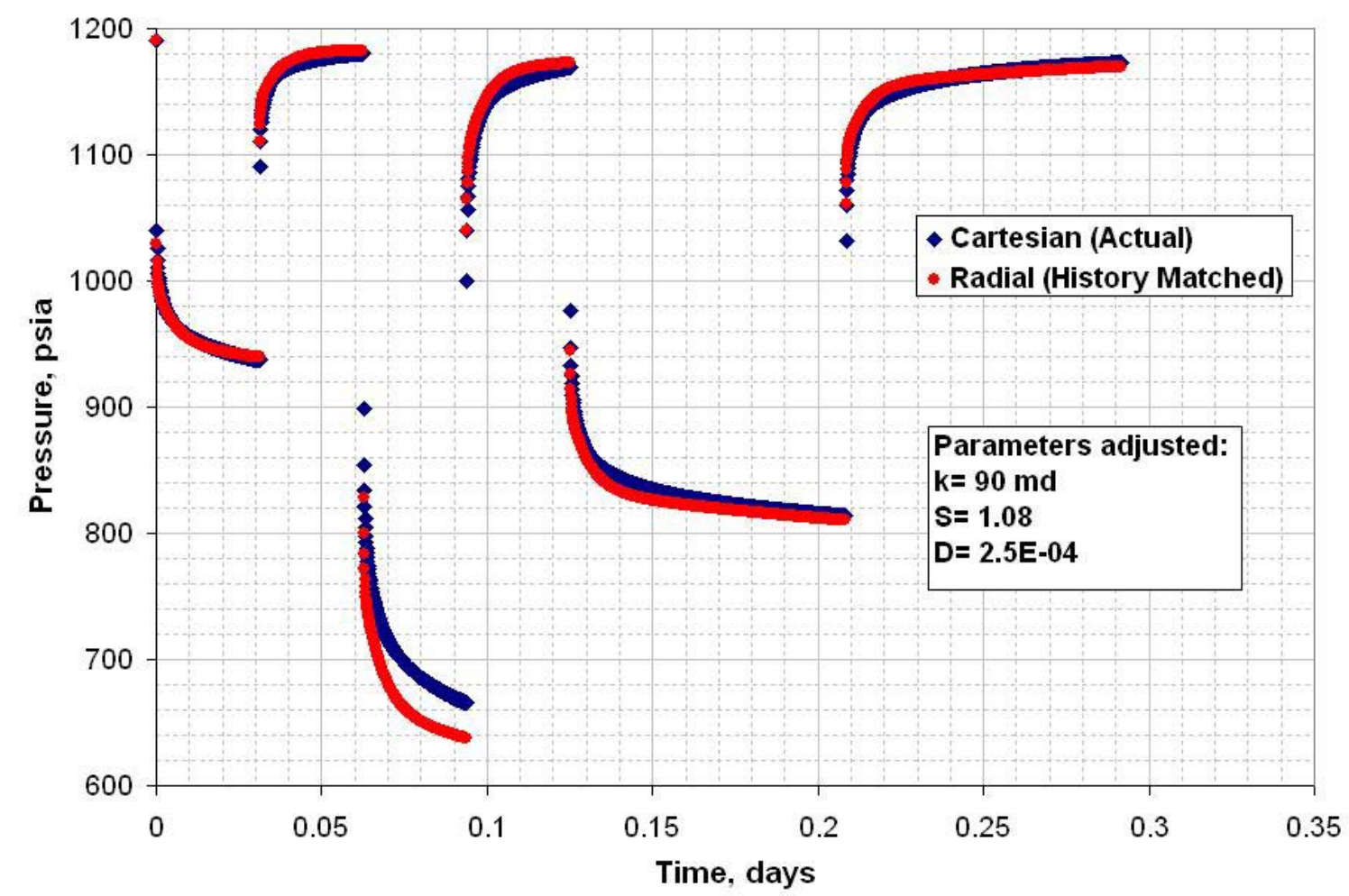

Figure 4-14: History match of MRT data of radial model with modified parameters in heterogeneous case 1 for verification.

After getting the match of MRT data with the adjusted parameters $\mathrm{k}$ as $90 \mathrm{md}$, $\mathrm{S}$ as 1.08 and D as 2.5E-04, a SRT was performed on the Cartesian model with a changing skin factor equal to 1.94 while keeping the other parameters constant. The change in the skin of Cartesian model became,

$$
\begin{aligned}
\Delta S & =S_{2}-S_{1} \\
\Delta S & =1.94-1.28 \\
\Delta S & =0.66
\end{aligned}
$$

The same SRT (with equal duration and flow rate) was performed on the history matched radial model. From the pressure vs. time data of this test history match could not get obtained with the heterogeneous Cartesian model's SRT data until skin factor of the radial model was modified to 1.74 from 1.08 while keeping the other parameters constant (Figure 4-15). 


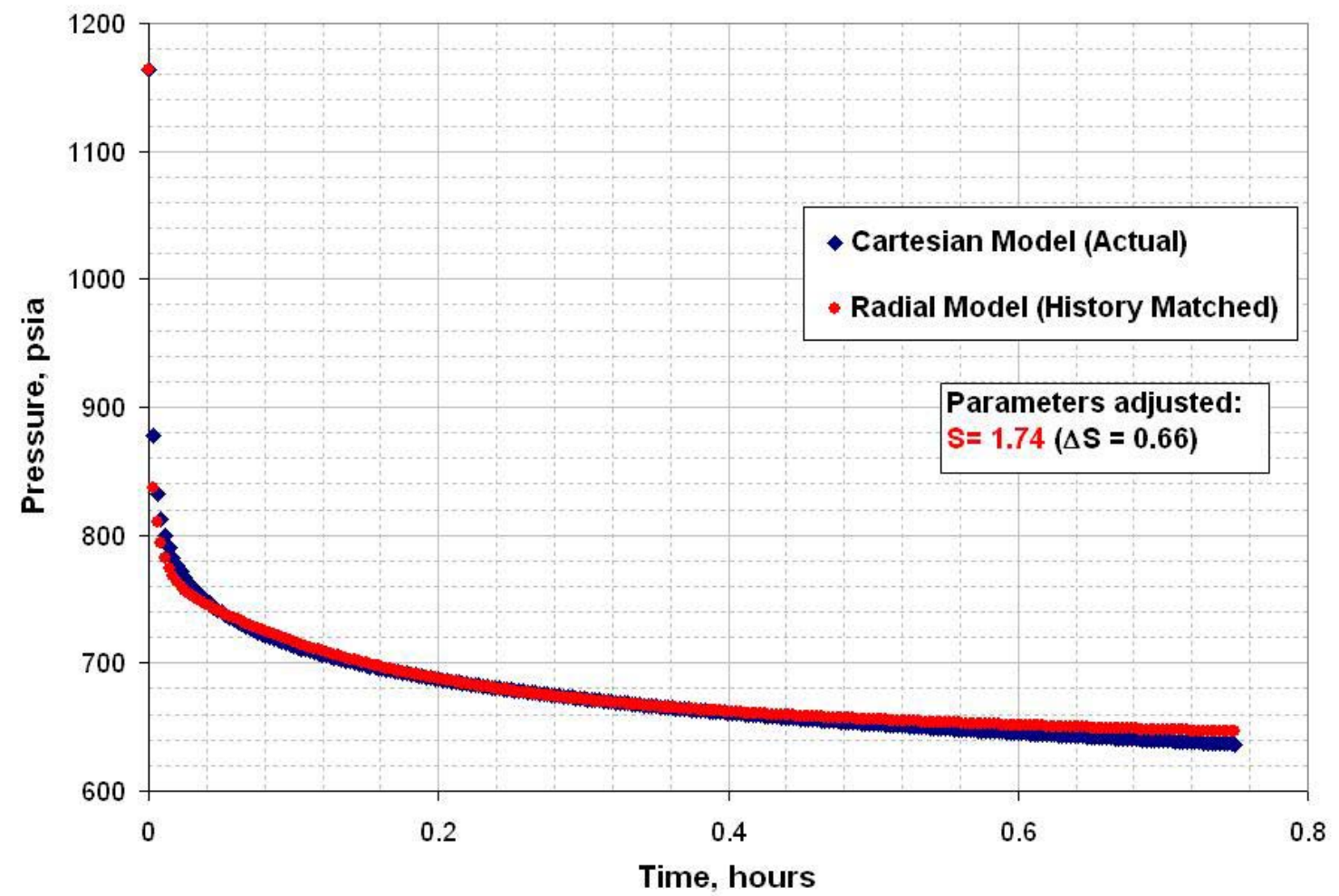

Figure 4-15: History match of SRT data of the radial model by changing $S$ from 1.08 to 1.74 .

The summary of the adjusted parameters, permeability, skin factor and Darcy factor, before and during performing the multi rate test are shown in Table 4-6.

The summary of change in skin factor from history match of multi rate test to single rate test for each simulation model is shown in Table 4-7. As a result the change in the skin, delta skin, is equal to 0.66 .

Table 4-6: Summary of the parameters to be adjusted during the history match, Case 1 of heterogeneous system.

\begin{tabular}{|l|c|c|c|c|}
\hline Heterogeneous - Case 1 & Cartesian Input & Well Test Analysis & Radial Input & Radial Matched \\
\hline Permeability, md & 90 (AVG) & 90 & 90 & 90 \\
\hline Skin factor & 1.28 & 0.86 & 0.86 & 1.08 \\
\hline Darcy factor & $9.00 \mathrm{E}-05$ & $2.00 \mathrm{E}-04$ & $2.00 \mathrm{E}-04$ & $2.50 \mathrm{E}-04$ \\
\hline
\end{tabular}

Table 4-7: Summary of change in skin factor for Case-1 of heteregeneous system.

\begin{tabular}{|l|c|c|c|}
\hline Heteregeneous - Case 1 & Cartesian Input & Radial Input & Radial finalized matching \\
\hline Skin before MRT & 1.28 & 0.86 & 1.08 \\
\hline Skin before SRT & 1.94 & & 1.74 \\
\hline Delta skin & 0.66 & $2.00 \mathrm{E}-04$ & 0.66 \\
\hline Match with SRT data & & Not obtained & Obtained \\
\hline
\end{tabular}




\section{Case 2}

In this case of the heterogeneous system, distributing the heterogeneity radial on the Cartesian model was aimed. Since the grids were refined on the model, this type of heterogeneity is not clear (Figure 4-16).

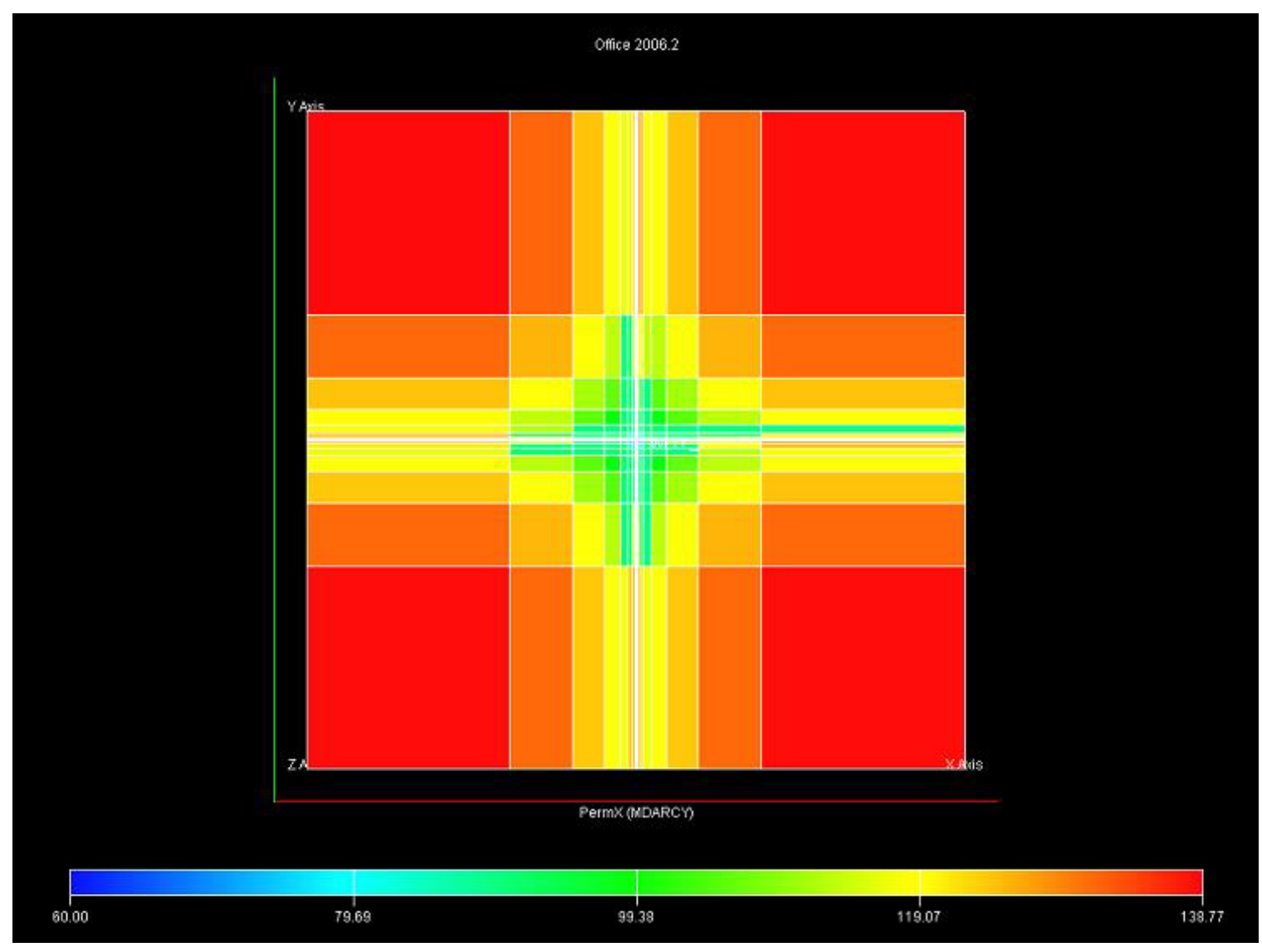

Figure 4-16: Permeability distribution on the Cartesian model of Case 2 of heterogeneous system.

In this case, all the properties of the Cartesian model were same with the previous case, case 1's Cartesian model except the shape and values of permeability distribution. The same MRT was performed on this model as well and conventional well test analysis was performed by using the pressure vs. time data of the test. The calculated values of $k$, $\mathrm{S}$ and $\mathrm{D}$ were not same with their input values to the model, which are shown in the first and second column of Table 4-8.

In order to get a match with the MRT data of the Cartesian model, a radial model was built with one well. On that well a multi rate test followed by a single rate test was performed. Before performing a single rate test on the Cartesian model, its skin factor was changed from 1.28 to 0.28 . 


$$
\begin{aligned}
& \Delta S_{\text {cartesian }}=S_{2}-S_{1} \\
& \Delta S_{\text {cartesian }}=0.28-1.28 \\
& \Delta S_{\text {cartesian }}=-1
\end{aligned}
$$

The input permeability, skin factor and D-factor of the radial model were the calculated parameters by well test analysis of the MRT of the Cartesian model. Although there was a match of MRT data of the radial model with Cartesian model data, the single rate well test history match could not get obtained with those values. Figure 4-17 and Figure 4-18 shows these results.

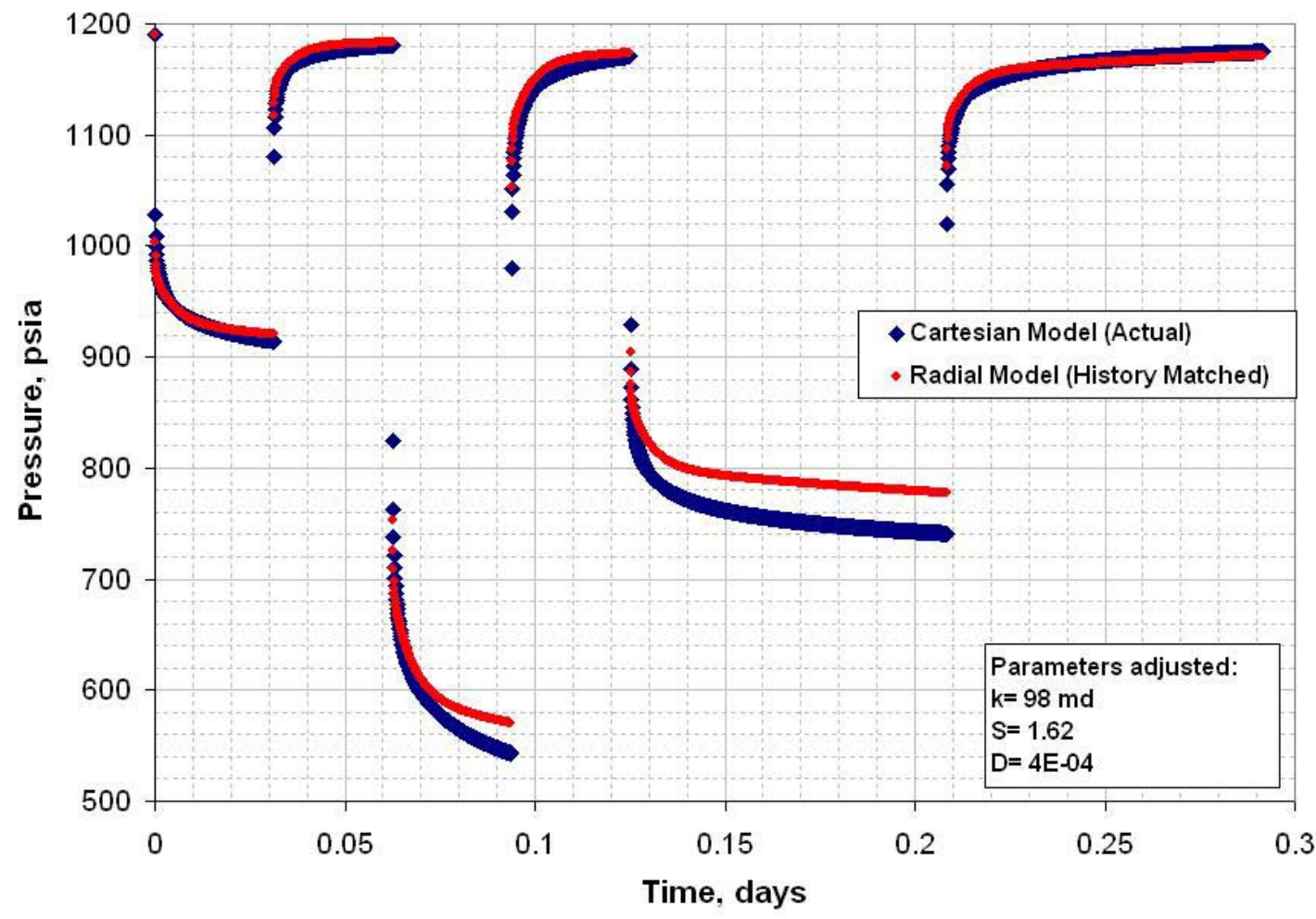

Figure 4-17: MRT match of the radial model with initially calculated values, Case 2 of heteregeneous system.

There were two different set of parameters to get a match with the MRT followed by a match of SRT data of the Cartesian model of this case. In the first set of parameters permeability was modified as $100 \mathrm{md}$, skin factor S as 2.5 and D-factor as $4 \mathrm{E}-04\left(5^{\text {th }}\right.$ column of Table 4-8) to get a match with the Cartesian model's multi rate test data (Figure 4-19). The SRT match was also obtained by adjusting the skin factor of radial model from 2.5 to 1.5 (Figure 4-20). So, delta skin of the radial model is same with delta skin of Cartesian model and equal to -1 ( $4^{\text {th }}$ column of Table $\left.4-9\right)$. 


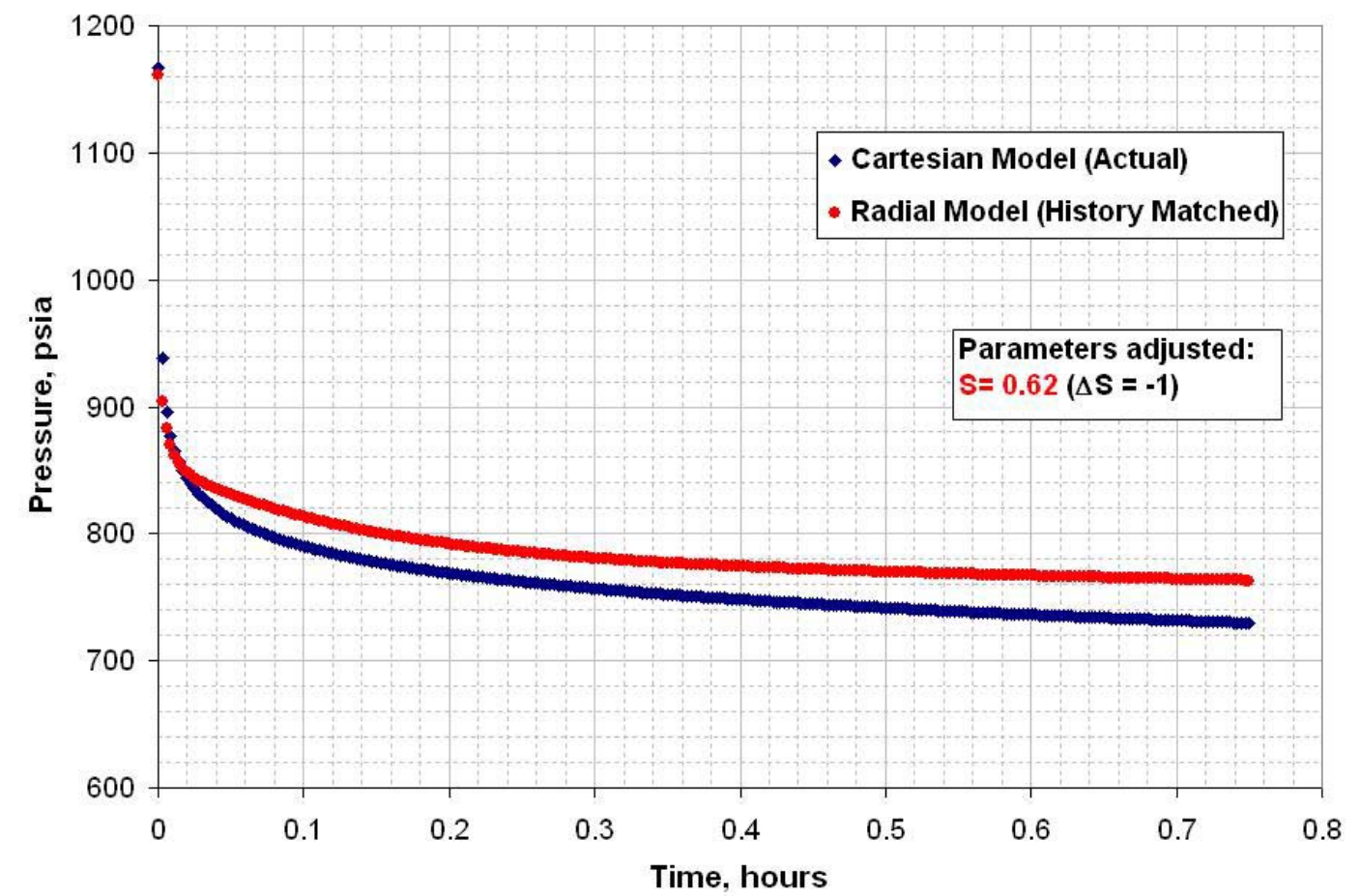

Figure 4-18: SRT match could not get obtained with the initial $k, S$ and $D$ parameters of radial model, Case 2 of heterogeneous model.

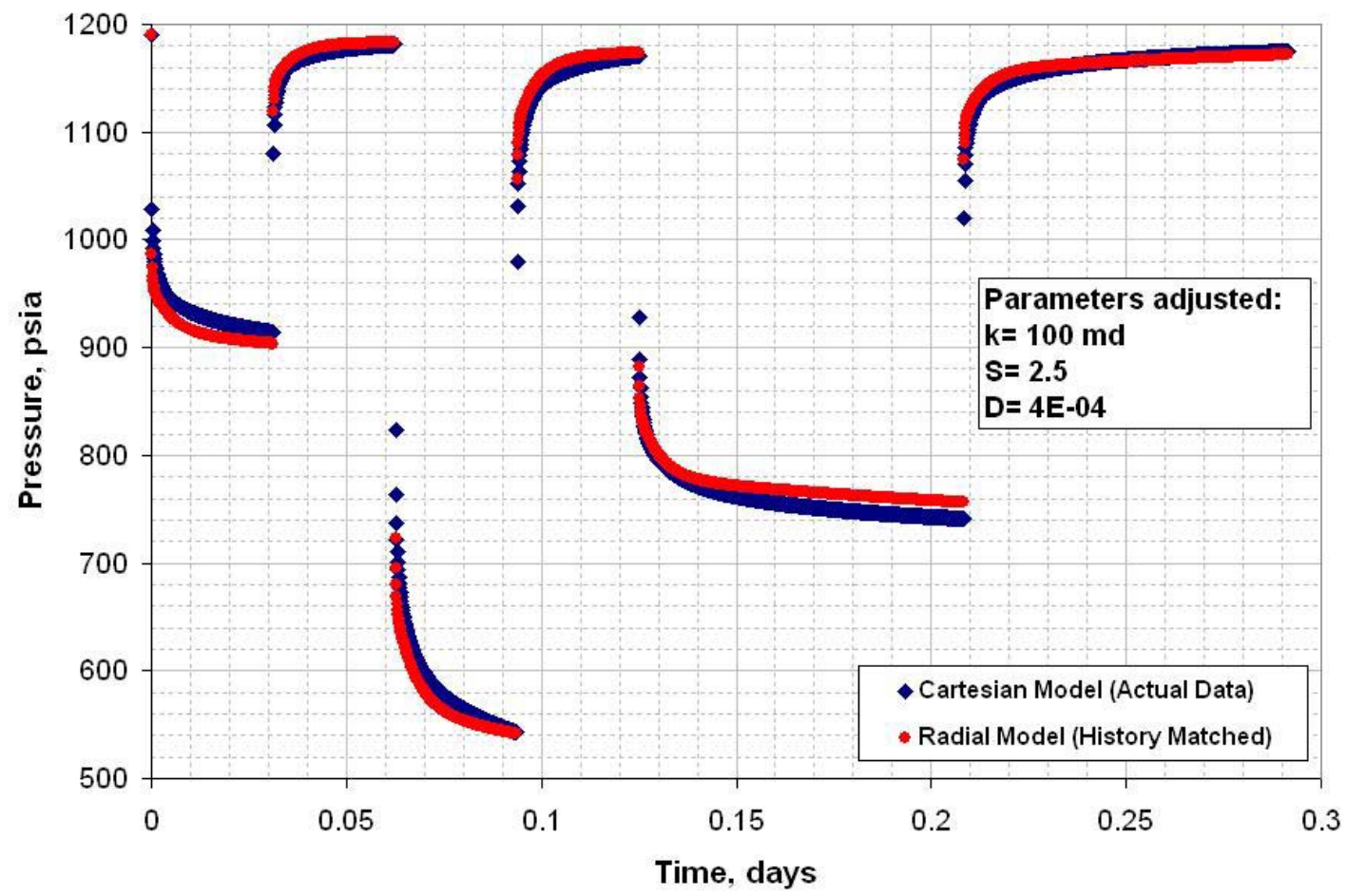

Figure 4-19: The MRT match of radial model with the Cartesian model of Case 2 with first set of adjusted parameters. 


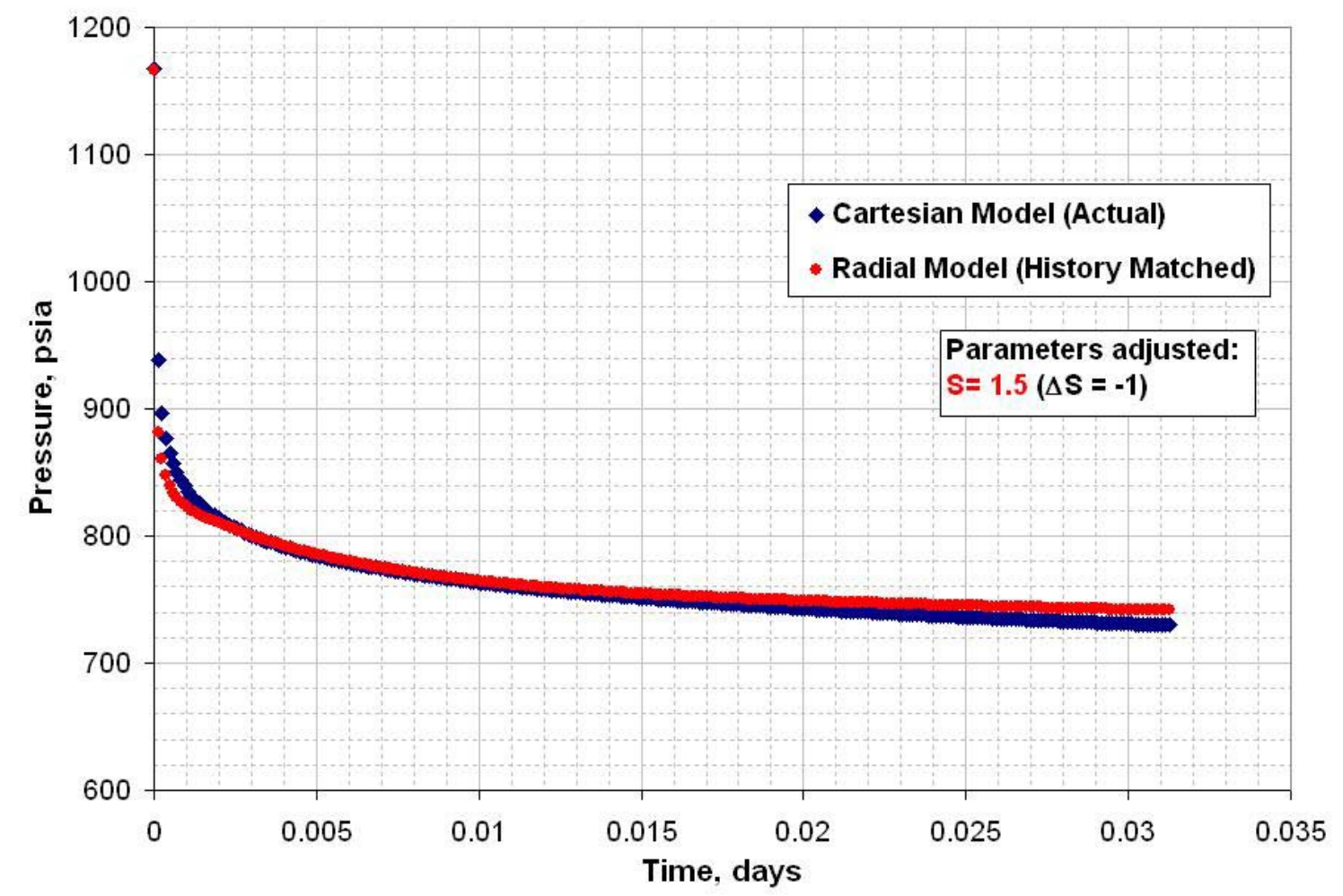

Figure 4-20: History match of SRT data of the radial model by changing the skin of realization 1 from 2.5 to 1.5 .

As a second set of parameters, permeability was modified as $94 \mathrm{md}$, skin factor $\mathrm{S}$ as 1.56 and D-factor as $4.5 \mathrm{E}-04$ ( $6^{\text {th }}$ column of Table $\left.4-8\right)$ to get a match with the Cartesian model's multi rate test data while keeping the other parameters constant (Figure 4-21). The SRT match was also obtained by adjusting the skin factor of radial model from 1.56 to 0.56 (Figure 4-22). So, delta skin of the radial model is same with delta skin of Cartesian model and equal to -1 ( $5^{\text {th }}$ column of Table 4-9).

The summary of change in skin factor from history match of multi rate test to single rate test for each simulation model is shown in Table 4-9. As a result the change in the skin, delta skin, is equal to -1 of both models. 


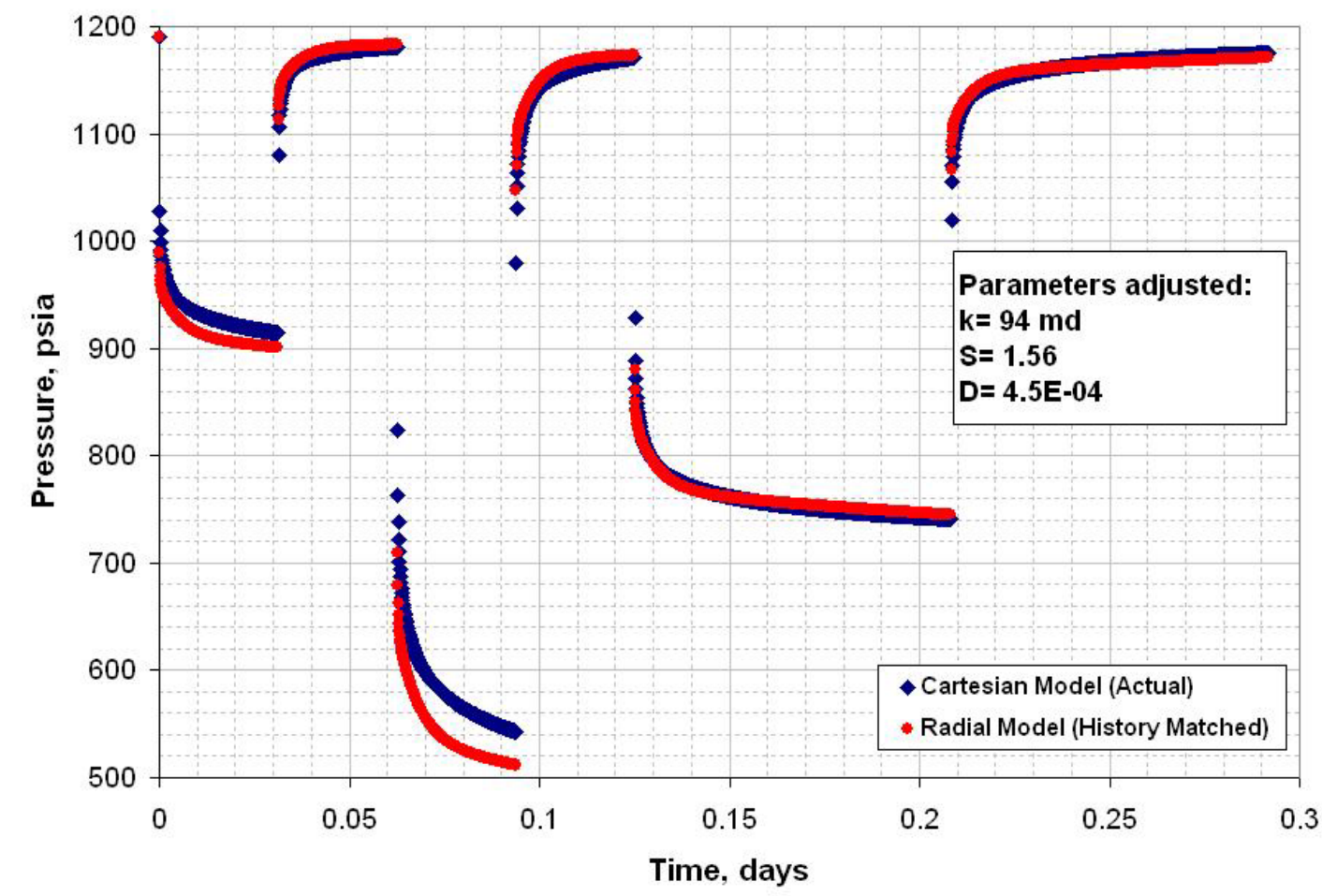

Figure 4-21: MRT match of radial model with the Cartesian model of Case 2 with second set of adjusted parameters.

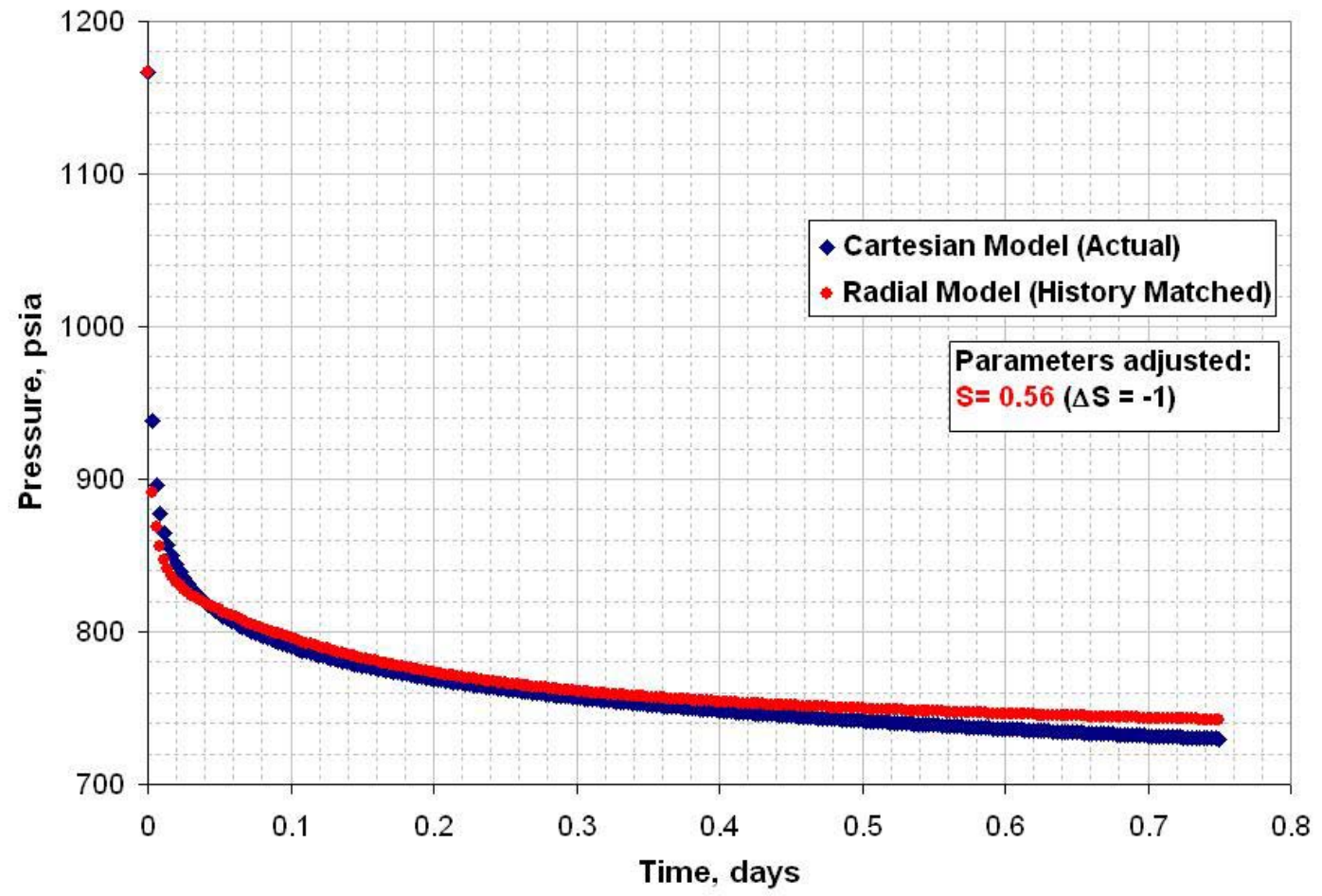

Figure 4-22: History match of SRT data of the radial model by changing the skin of realization 2 from 1.56 to 0.56 . 
Table 4-8: Summary of the parameters to be adjusted during the history matc, Case 2 of heteregeneous system.

\begin{tabular}{|l|c|c|c|c|c|}
\hline Heteregeneous - Case 2 & Cartesian Input & Well Test Anlaysis & Radial Input & Radial Match 1 & Radial Match 2 \\
\hline Permeability, md & $90(\mathrm{AVG})$ & 98 & 98 & 100 & 94 \\
\hline Skin factor & 1.28 & 1.62 & 1.62 & 2.5 & 1.56 \\
\hline Darcy factor & $9.00 \mathrm{E}-05$ & $4.00 \mathrm{E}-05$ & $4.00 \mathrm{E}-05$ & $4.00 \mathrm{E}-05$ & $4.50 \mathrm{E}-04$ \\
\hline
\end{tabular}

Table 4-9: Summary of change in skin factor for Case 2 of heteregeneous system.

\begin{tabular}{|l|c|c|c|c|}
\hline Heteregeneous - Case 2 & Cartesian Input & Radial Input & Radial Match -1 & Radial Match -2 \\
\hline Skin before MRT & 1.28 & 1.62 & 2.5 & 1.56 \\
\hline Skin before SRT & 0.28 & 0.62 & 1.5 & 0.56 \\
\hline Delta skin & -1 & -1 & -1 & -1 \\
\hline Match with SRT data & & Not obtained & Obtained & Obtained \\
\hline
\end{tabular}

\section{Case 3}

The type of the heterogeneity is in Figure 4-23. For the heterogeneity kriging was done while keeping the average permeability in the drainage area around $90 \mathrm{md}$.

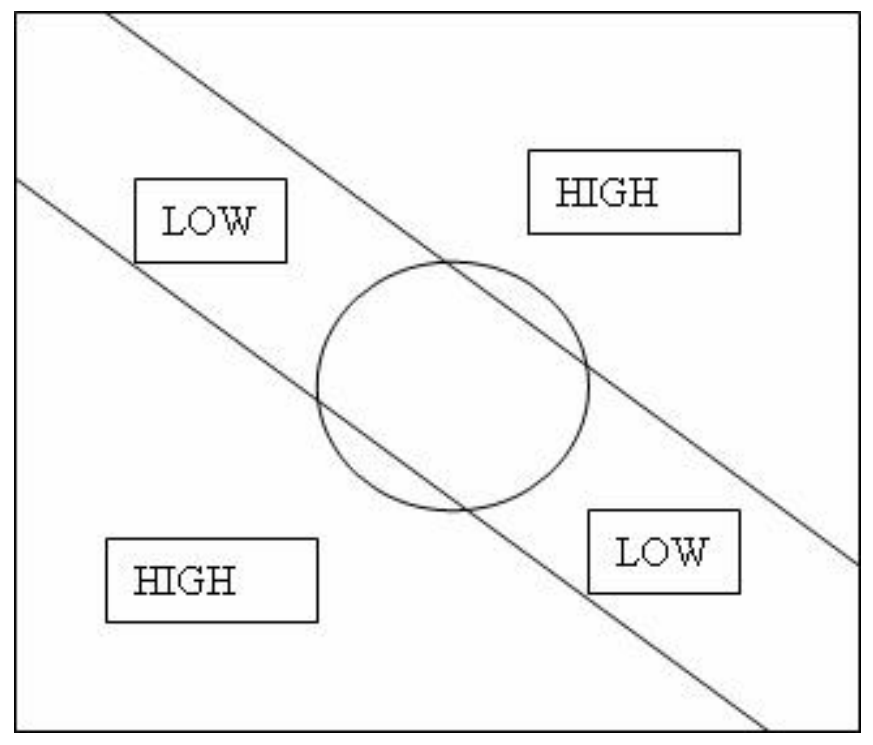

Figure 4-23: Type of the heterogeneity of Case 3.

The permeability values were tried to be arranged consistent with the locally refined grids in order to keep the configuration like in Figure 4-23. The drainage area was thought around $171 \mathrm{ft}$ because of the drainage area calculated from the MRT data of the homogeneous Cartesian model. (The only difference of this model with the homogeneous one is permeability distribution). The permeability can be averaged around 90 md inside of the drainage area (Figure 4-26). Skin factor was put as 1.28 and D factor as 9E-05 
inside the model. A multi rate test was performed on this heterogeneous, high resolution Cartesian model. By analyzing three flow periods of this test three different apparent skin factors and permeability values were calculated (Table 4-10). True skin factor and Darcy factor were estimated by linear regression of flow rates and calculated apparent skin factors (Figure 4-24). Again; the permeability values could not be calculated equal from each drawdown period and the estimated true skin factor and Darcy factor are different from their input values.

Table 4-10: Results of the conventional analysis performed on the Cartesian model of Case 3.

\begin{tabular}{|c|c|c|c|}
\hline & Permeability (k) & Apparent Skin $\left(\mathrm{s}^{\prime}\right)$ & Flow Rate $(\mathrm{q})$ \\
\hline Drawdown-1 (DD-1) & $89 \mathrm{md}$ & 4.09 & $6800 \mathrm{Mscf} / \mathrm{D}$ \\
\hline Drawdown-2 (DD-2) & $103 \mathrm{md}$ & 5.26 & $12000 \mathrm{Mscf} / \mathrm{D}$ \\
\hline Drawdown-3 (DD-3) & $108 \mathrm{md}$ & 5.01 & $8750 \mathrm{Mscf} / \mathrm{D}$ \\
\hline
\end{tabular}

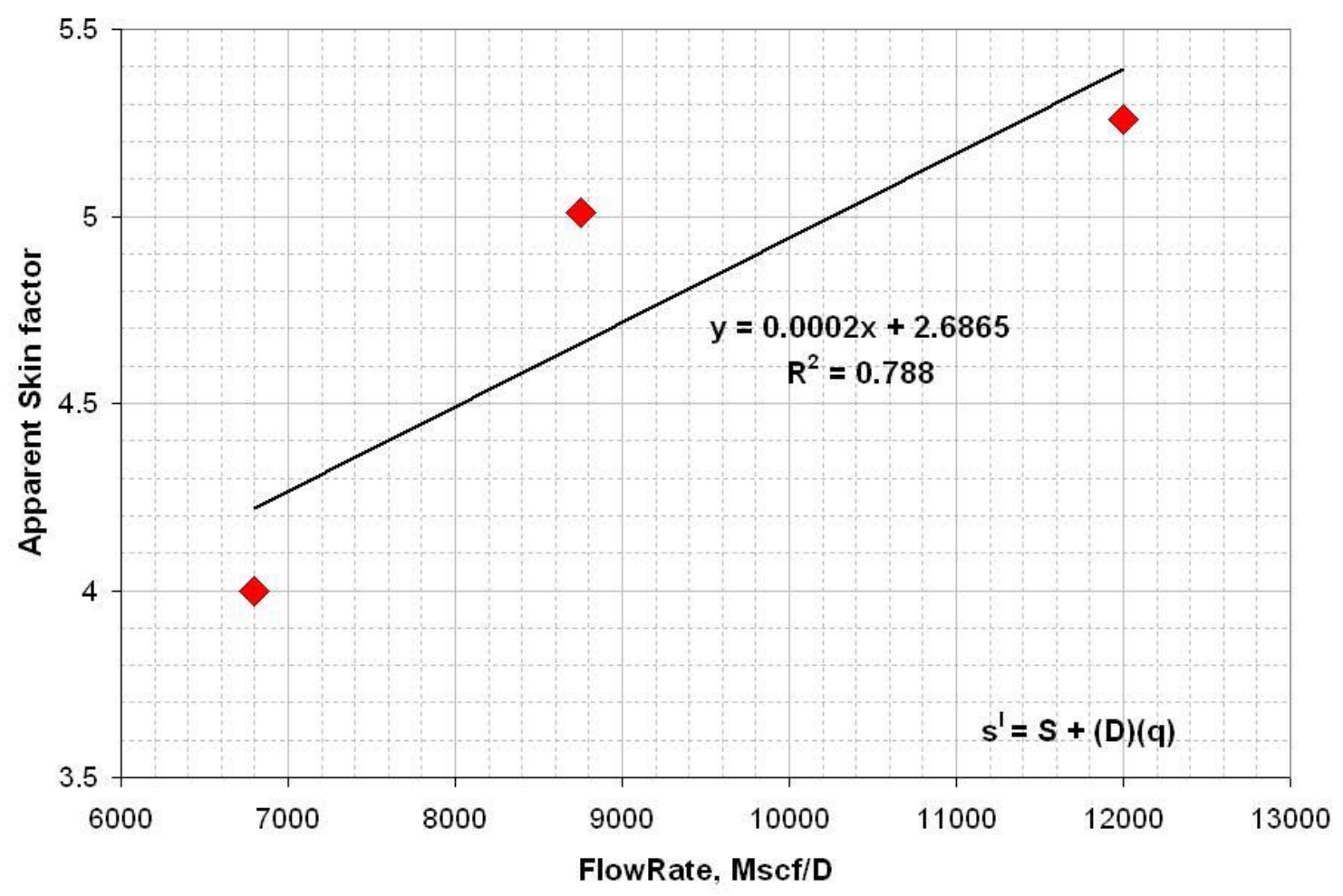

Figure 4-24: Estimation of true skin factor and Darcy factor by regression of the apparent skin factor values calculated from well test analysis.

Like the previous case, a radial homogeneous model was built to history match with the heterogeneous Cartesian model. The calculated parameters by analytical analysis were set to be initial values of the homogeneous radial model. 
The parameters adjusted during the history match are the same with the previous cases. The match was obtained with a permeability of $95 \mathrm{md}$, true skin factor of 2.95 and D-factor of 1.9E-04 (Figure 4-25).

After getting the match with the multi rate test (MRT) data, a single rate test (SRT) was performed on the Cartesian model with a changing skin factor equal to 1.5. The change in the skin factor from the MRT to the SRT in the Cartesian model is $\Delta S=0.22$.

On the radial model a SRT was also performed to match with the Cartesian model's SRT data. The match was obtained when the skin factor of the radial model was modified to $S=3.17$ while keeping other parameters constant ( $\mathrm{k}=95 \mathrm{md}$ and $\mathrm{D}=1.9 \mathrm{E}-04)$. Figure 4-27 shows the results of the history match of SRT data. For both models the change in the skin was estimated as 0.22 .

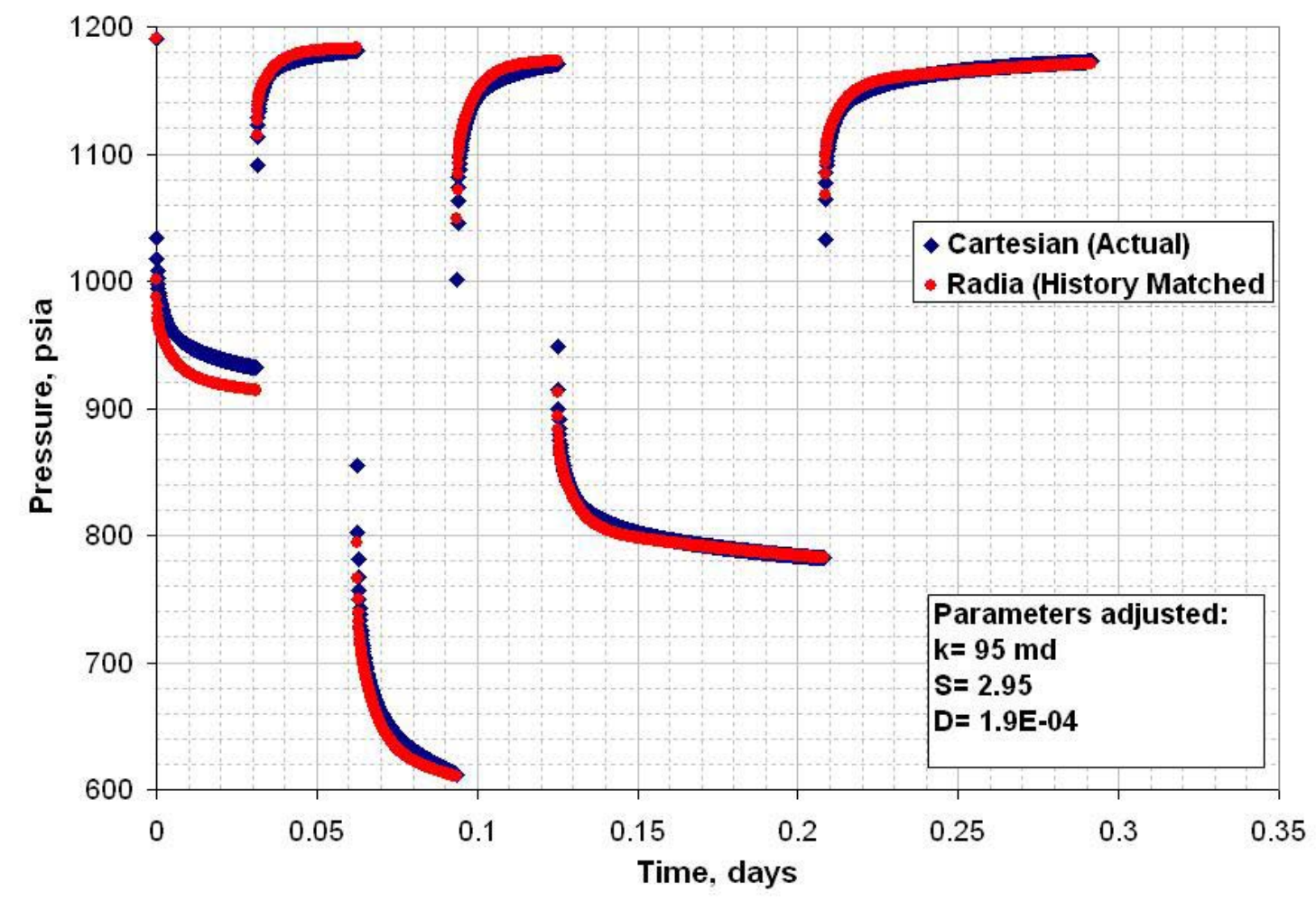

Figure 4-25: Match of the multi rate test data with heterogeneous Cartesian model's data, Case 3. 


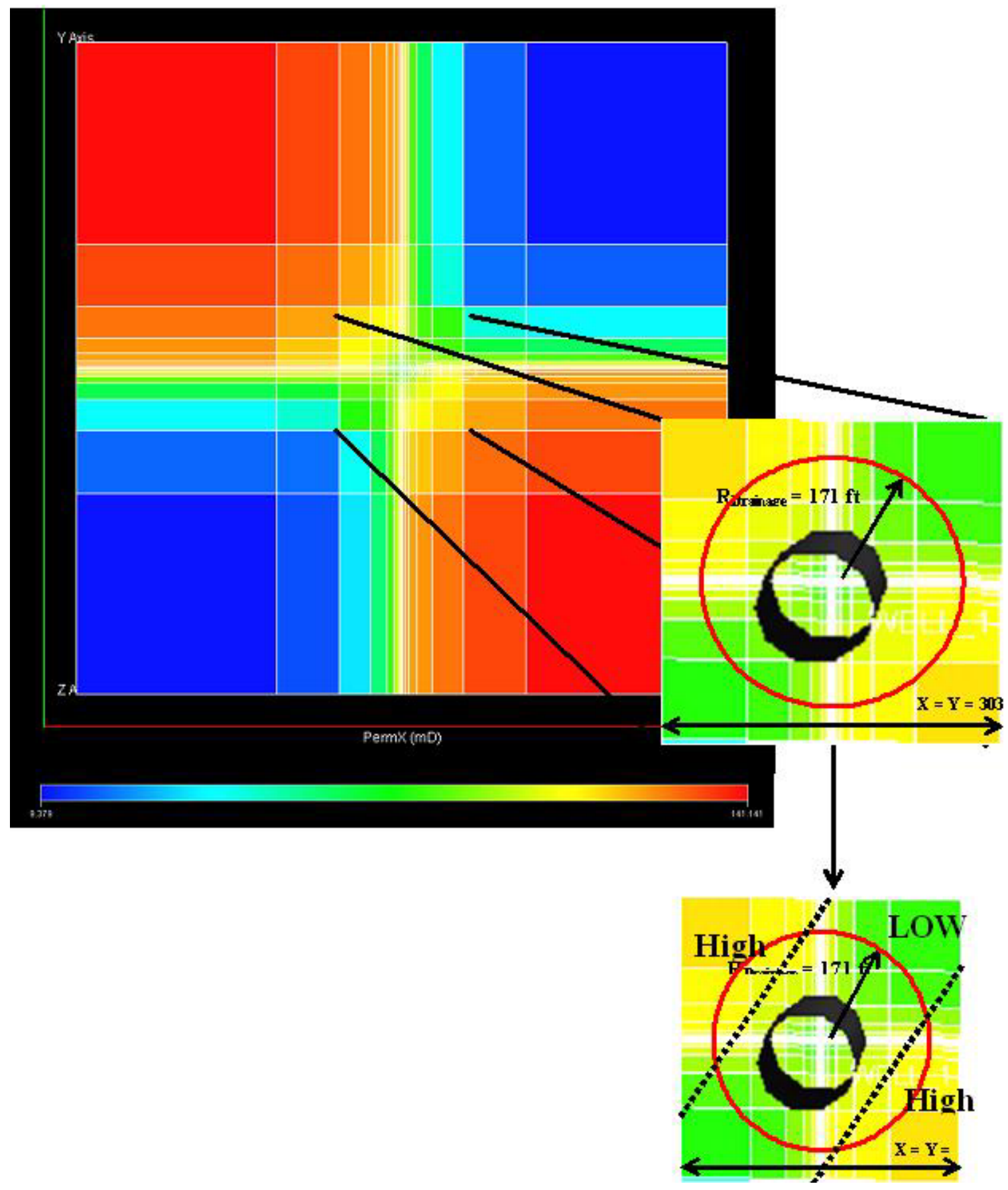

Figure 4-26: Permeability distribution of the heterogeneous Cartesian model of Case 3. The minimum permeability is $3 \mathrm{md}$ and the maximum is $150 \mathrm{md}$. 


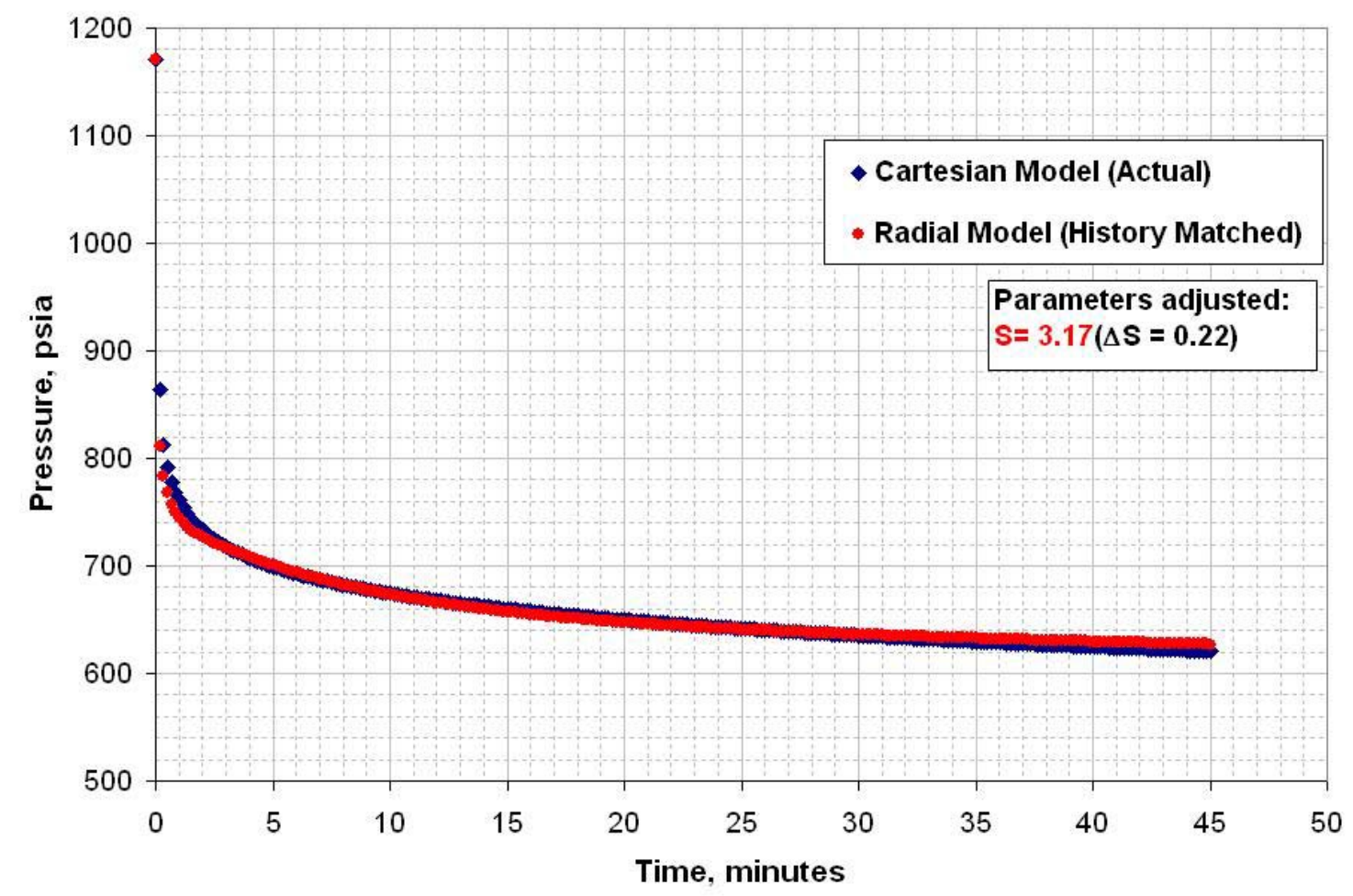

Figure 4-27: Match of the SRT data of the radial model with heterogeneous Cartesian model's SRT data, Case 3.

The summary of the adjusted parameters, $\mathrm{k}, \mathrm{S}$ and $\mathrm{D}$, before and during performing the multi rate test for all the Case 3 of the heterogeneous system shown in Table 4-11, summary of the change in the skin factor from history match of multi rate test to single rate test for each simulation model of Case 3 is shown in Table 4-12.

Table 4-11: Summary of parameters adjusted in the history match of multi rate test data, heterogeneous Case 3.

\begin{tabular}{|l|c|c|c|}
\hline Heterogeneous - Case 3 & Cartesian Input & Well Test Analysis & Radial finalized matching \\
\hline Permeability, md & $90(\mathrm{AVG})$ & 100 & 95 \\
\hline Skin factor & 1.28 & 2.69 & 2.95 \\
\hline Darcy factor & $9.00 \mathrm{E}-05$ & $2.00 \mathrm{E}-04$ & $1.90 \mathrm{E}-04$ \\
\hline
\end{tabular}

Table 4-12: Summary of change in skin factor for the Case 3 of the heterogeneous system, verification.

\begin{tabular}{|l|c|c|}
\hline Heterogeneous - Case 3 & Cartesian Input & Radial finalized matching \\
\hline Skin before MRT & 1.28 & 2.95 \\
\hline Skin before SRT & 1.5 & 3.17 \\
\hline Delta skin & 0.22 & 0.22 \\
\hline Match with SRT data & & Obtained \\
\hline
\end{tabular}




\subsection{Field Examples}

To evaluate the accuracy of the methodology introduced in this paper, two wells from a gas storage field called Lucas field were selected. Figure 4-28 shows the Lucas field and the two wells selected to be worked with. The gas formation is Clinton sand stone and the field properties are shown in Table 3-1. The field has 429 producer/injector wells on which at least one of the three well tests was performed. These tests are Absolute Open Flow Test (AOF), single rate test (SRT) and multi rate test (MRT). Two wells, Well A and Well B were selected since for each of them data of a multi rate test followed by a single rate test was found.

\subsubsection{Well A}

The multi rate test was performed in October of 1997 and the single rate test in September of 1998 on this well. The well was stimulated in 1969. The known properties of the well are well bore radius as $0.26 \mathrm{ft}$., thickness as $10 \mathrm{ft}$, and permeability of the reservoir near to the well bore ranges between $296 \mathrm{md}$ and $428 \mathrm{md}$ (Table 4-13).

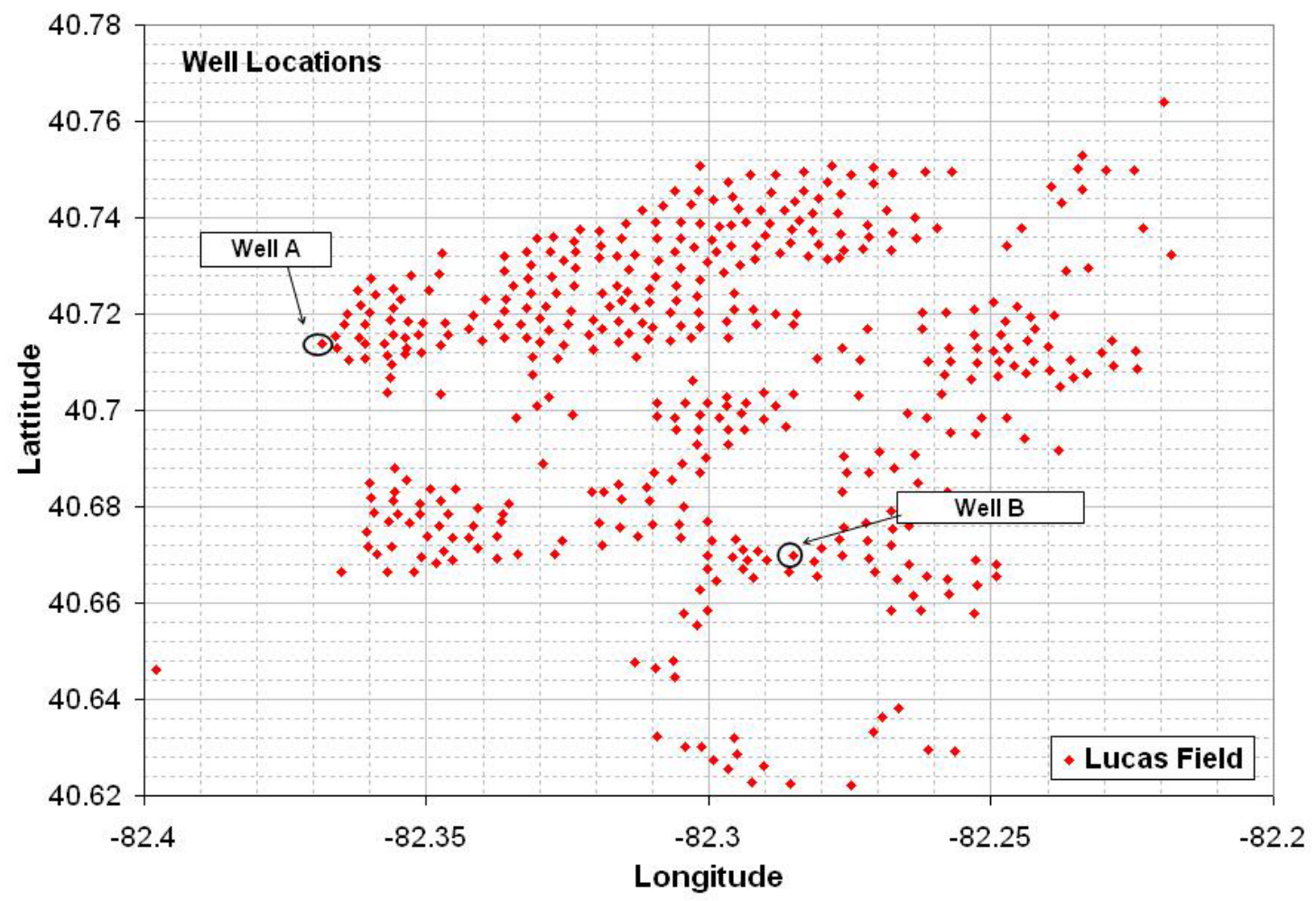

Figure 4-28: Well locations of the Lucas Field. 
The duration of the multi rate test is 7 hours with three drawdown periods and three buildup periods. The last flow period is 2 hour long shut-in period. Flow rate changes slightly during the flow periods. Single rate test, on the other hand, consists of only one flow period with slightly changing rates for 45 minutes. From the multi rate test's pressure data permeability was calculated as 230 md by performing conventional well test analysis. The estimated true skin factor is -2.03 and the non-Darcy factor is 0.0003 .

Table 4-13: Reservoir parameters of Well A.

\begin{tabular}{|c|c|}
\hline $\mathrm{T}_{\text {reservoir }}$ & $535^{\circ} \mathrm{R}$ \\
\hline Thickness & $10 \mathrm{ft}$ \\
\hline Porosity & $14 \%$ \\
\hline Gas gravity & 0.585 \\
\hline Well radius & $0.26 \mathrm{ft}$ \\
\hline
\end{tabular}

Radius of investigation is another parameter estimated with analytical analysis as 312 $\mathrm{ft}$. Considering this parameter as well as the skin factor and well bore storage effects, the numerical model was refined to fine grid sizes from the coarse grid sizes not only in the drainage area (investigation radius) of the well test but also in the whole reservoir. The local grid refinement (LGR) of the numerical model is in Figure 4-29.

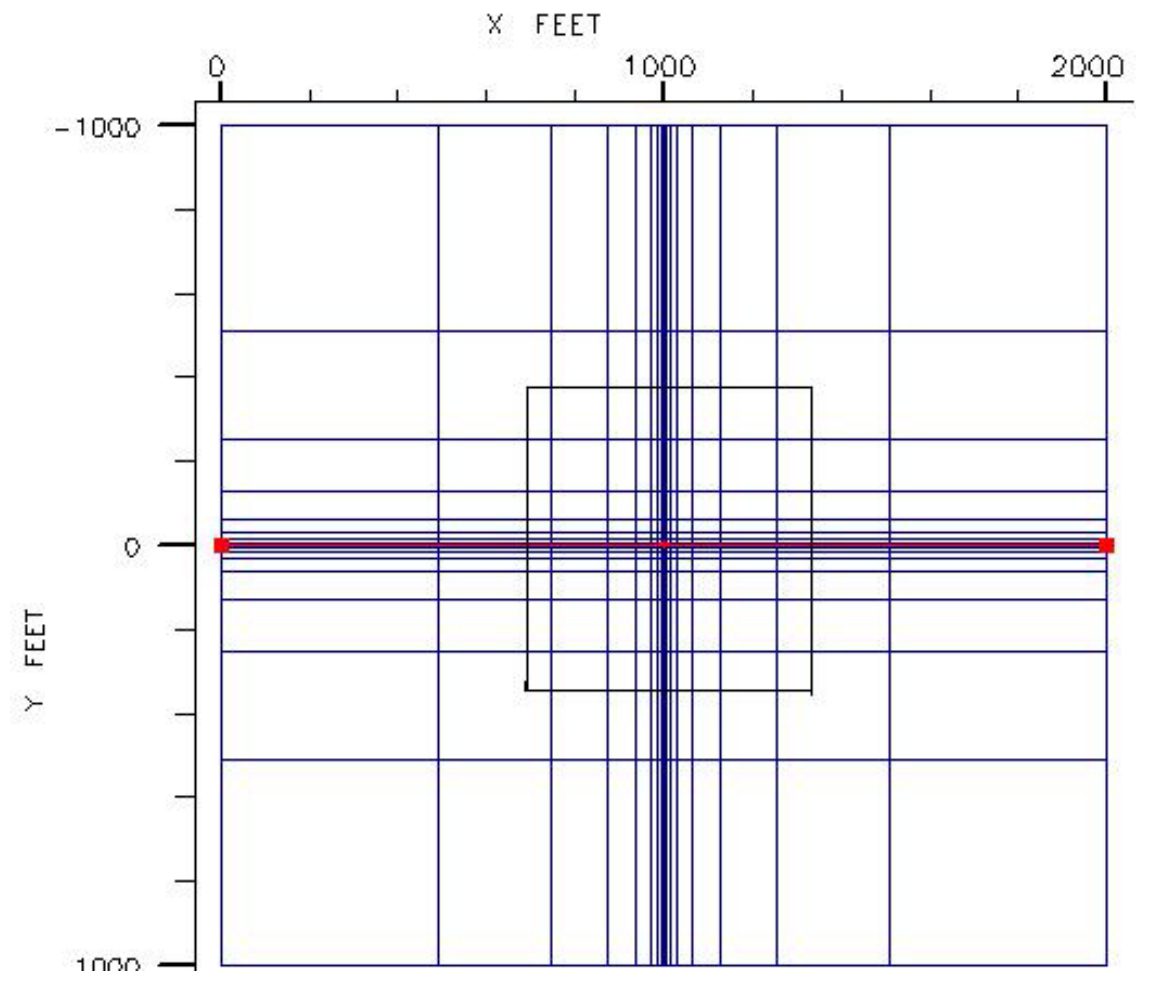

Figure 4-29: Cartesian model with its refined grids to be matched with Well A. 


\section{Case 1:}

The history matching started with the initial values of $\mathrm{k}, \mathrm{S}$ and $\mathrm{D}$ calculated with analytical equations. After modifications of these parameters a match was obtained with the actual multi rate test data. The result of the pressure vs. time data match is in Figure 4-30, in Cartesian coordinates. At the end of the multi rate test the match was obtained with parameters; permeability as $387.5 \mathrm{md}$, true skin factor as 0 and non-Darcy factor as 0.000145 .

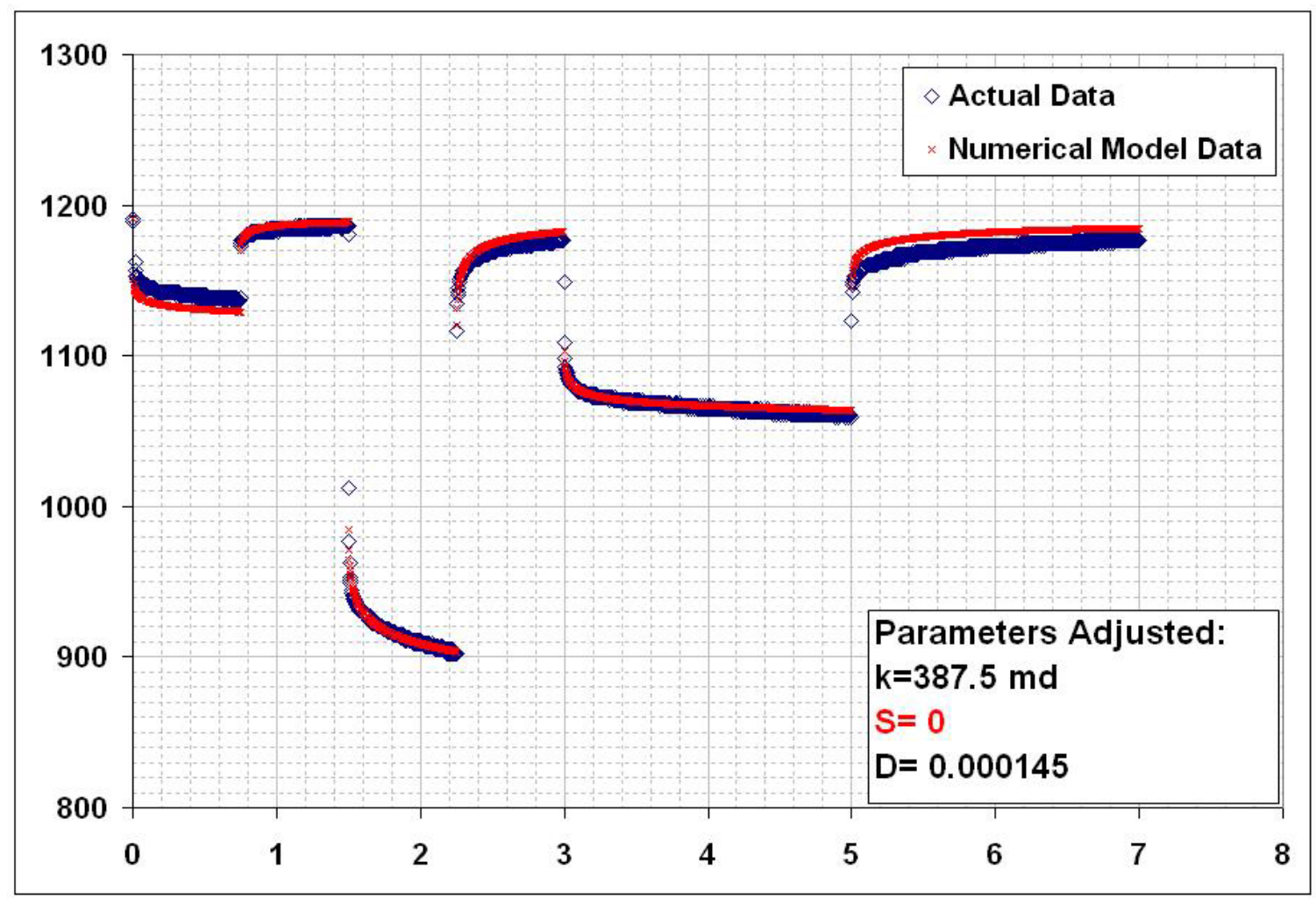

Figure 4-30: History match of the MRT of the numerical model with the test data of Well A, Case 1.

After getting a pressure match with multi rate test data, a single rate test was performed on the numerical model without changing any parameters adjusted in the previous step. Figure 4-31 shows the result of the pressure match of the single rate test. Without changing the parameters $\mathrm{k}, \mathrm{S}$ and $\mathrm{D}$ the match could not get obtained. On the figure, the blue line shows the actual data. The orange line shows the numerical simulation model's data with the parameters adjusted in the previous step. The value 15210 is the flow rate of the test in Mscf/d. Value of the numerical model's flow rate is same with the actual fields. By adjusting the skin factor parameter, from 0 to 2 while 
keeping the other parameters constant (values of $\mathrm{k}$ and D from the previous MRT match), the match got obtained. The green data-line of Figure 4-31 shows the pressure match of numerical model's pressure data with the actual test data. As a result, there is a 2 unit difference in the skin factor from the multi rate test to the single rate test.

Pressure vs. Time

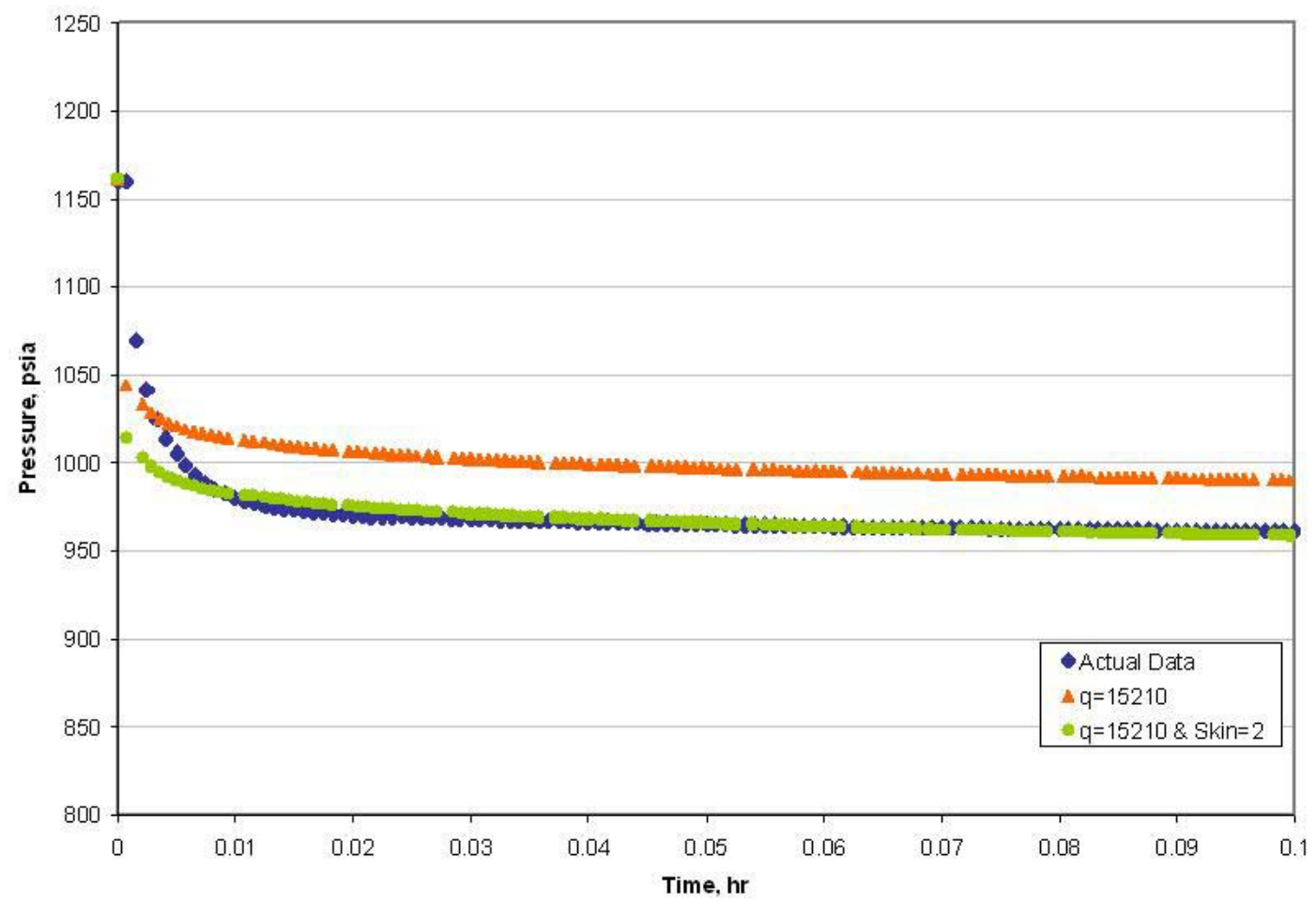

Figure 4-31: History match of the SRT data of the simulation model with the data of Well A, Case 1.

\section{Case 2:}

In order to test the change in skin factor, another numerical simulation model was created to history match with the well test data of Well A. This model is similar with the model used in Case 1. However, the area of the model has been changed as well as non-Darcy factor. The pressure match of the multi rate test was obtained with the parameters shown in the Figure 4-32. The match was achieved by adjusting the non-Darcy factor as 0.00016 and skin factor as 1 . The permeability values are same for both numerical model cases as $387.5 \mathrm{md}$. 
The pressure match of single rate test was obtained after modifying the skin factor to 3 while keeping the values of the other two parameters constant as estimated in the MRT match. Figure 4-33 shows pressure vs. time data of numerical model and of actual well in Cartesian coordinates. The $\mathrm{y}$ axis is the pressure data with psia unit whereas the $\mathrm{x}$-axis is the time in hours.

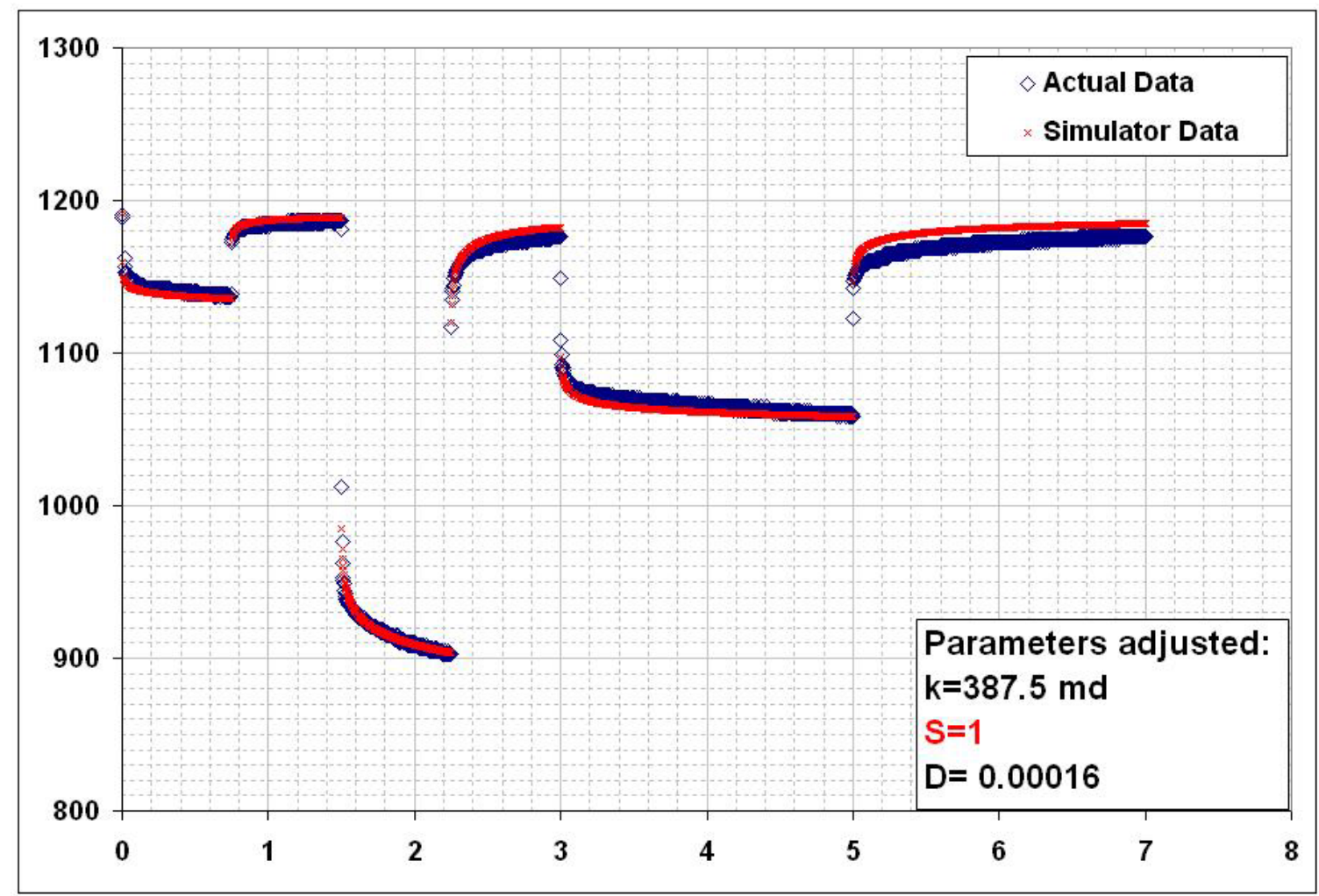

Figure 4-32: History match of the MRT of numerical model with the test data of Well A, Case 2. 


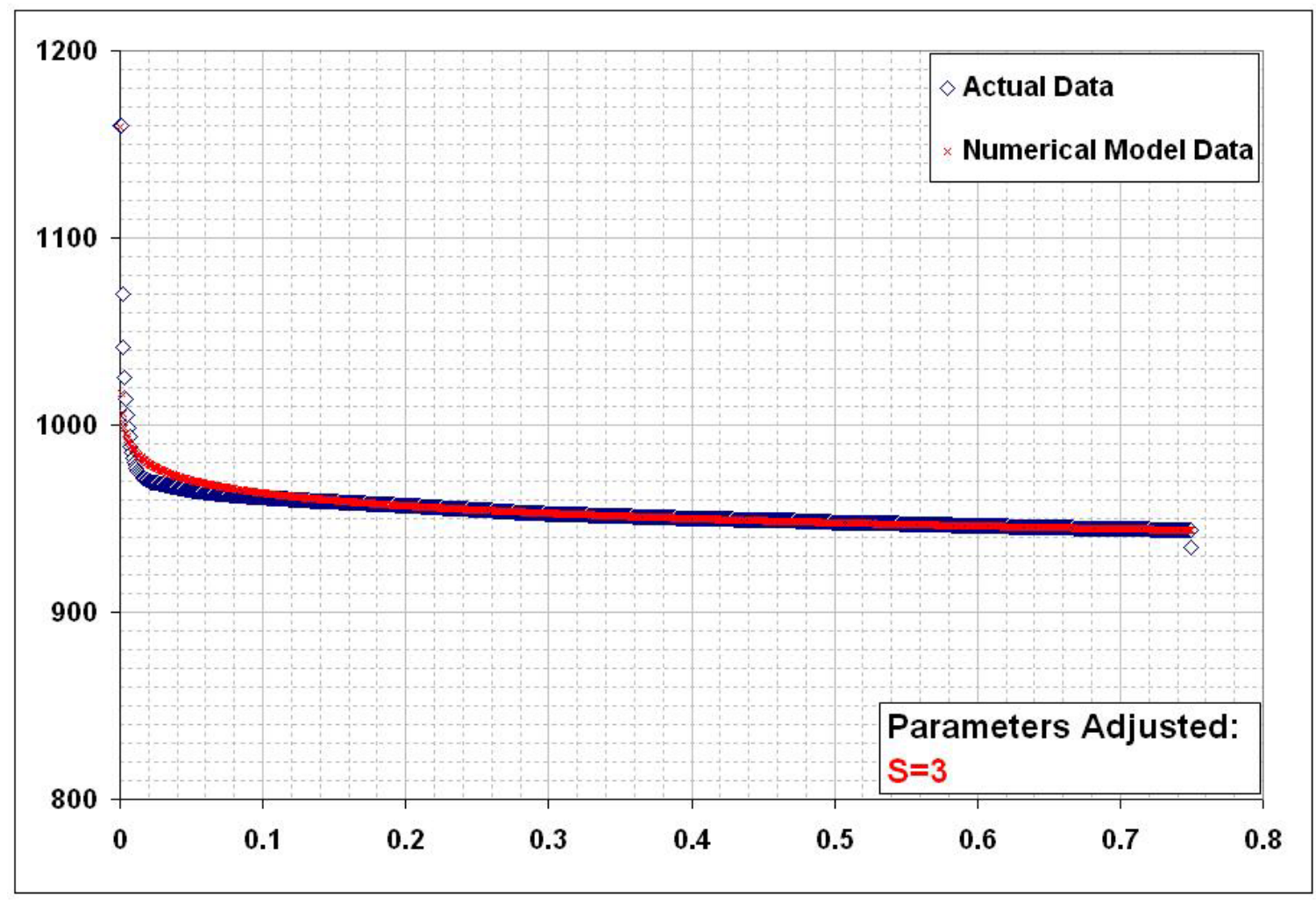

Figure 4-33: History match of the SRT data of the simulation model with the data of Well A, Case 2.

For Well A, both models responded similar performance with different values of the skin factor. In the first case, the match was obtained with $S=0$, which was adjusted as 2 in the single point test-match. Delta skin is equal to 2 . In the second case the skin factor was estimated as 1 to get a match with the multi rate test data and it was as 3 at the end of the single rate test-match. For both cases Delta skin is 2 .

This result should not be interesting when considering the fact that having obtained a set of reservoir parameters that match the actual reservoir response does not mean that those parameters are $100 \%$ accurate and same with the unknown actual reservoir parameters. The combinations of these estimated parameters play an important role in history matching to have a reliable numerical model that will represent the actual reservoir. 


\subsubsection{Well B}

On this well, the multi rate test was performed in October of 1997 and the single rate test in September, 1998. There was a stimulation treatment in 1996. The well-bore radius is $0.3 \mathrm{ft}$ and the thickness is $15 \mathrm{ft}$. Permeability of the reservoir near to the well-bore ranges from 60 to $75 \mathrm{md}$.

The duration of both tests is same with the tests of Well A and the flow rates change slightly during the flow periods. From the multi rate test's data permeability was calculated as 70 md by performing conventional well testing analytical analysis. The estimated true skin factor is -1.16 and the non-Darcy factor is 0.00005 . LGR is applied to the grid system of the numerical model as well in order to get more analogous pressure response in/near to the well bore.

After modifications of the parameters, calculated to be used as the initial values of the numerical model, a match was obtained with the actual multi rate test data. Figure 4-34 shows the pressure match and the adjusted parameters; permeability as $71 \mathrm{md}$, true skin factor as -0.6 and non-Darcy factor as 2.439E-5. 


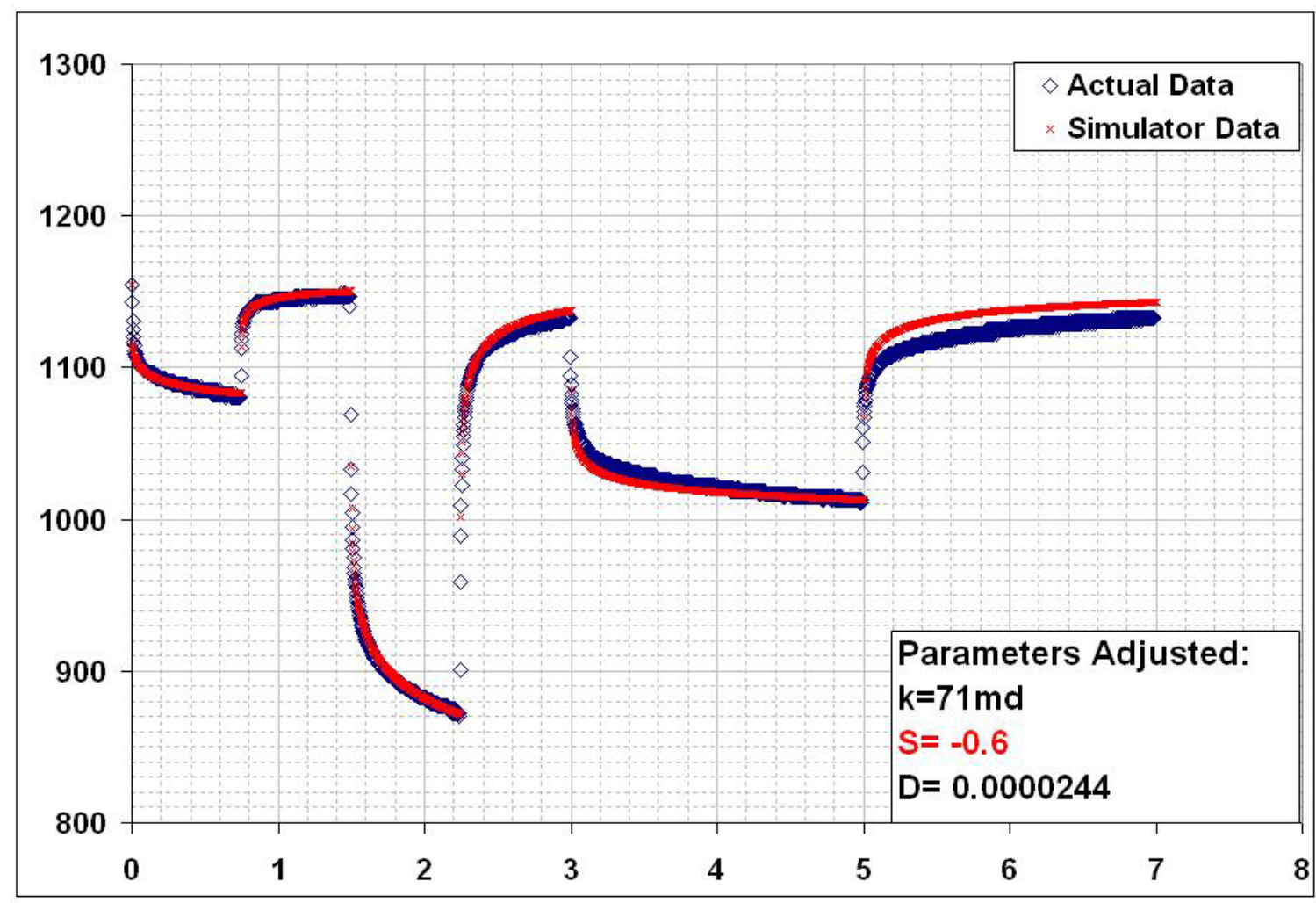

Figure 4-34: History match of multi rate test data with the actual data of Well B.

In the next step, a single rate test was performed on the numerical model to be matched with the actual SRT data of Well B. Figure 4-35 shows this match in Cartesian plot with pressure (psia) vs. time (hr) data. The blue line represents the actual well test data. The green line shows the numerical data with the parameters adjusted at the end of the multi point test match. As it is seen on the figure, match could not get obtained by keeping the skin factor parameter as -0.6 during the single rate test. The red line of the figure was obtained by adjusting the skin factor parameter from -0.6 to 1.3 while keeping the other parameters constant. As a result, change in the skin of the Well-W was estimated as,

$\Delta S=S_{2}-S_{1}$

$\Delta S=1.3-(-0.6)$

$\Delta S=1.9$ 


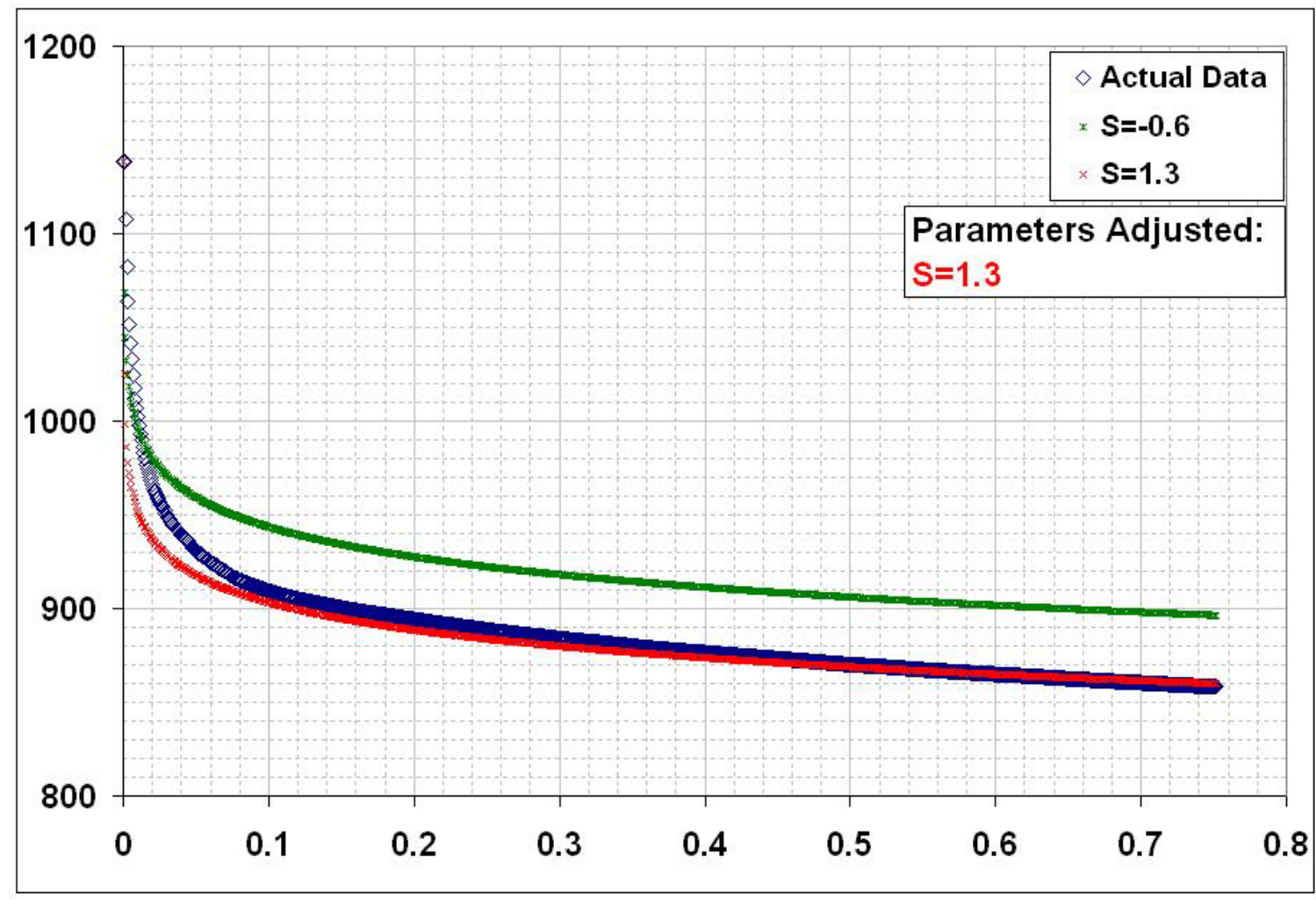

Figure 4-35: History match of single rate test data with the actual data of Well B. 


\section{CONCLUSION}

In this project estimation of change in skin with time in gas storage wells is studied. The objective is achieved by introducing the new procedure to enhance the current practices of estimating the true skin factor from a single rate test data. The new skin factor was compared with the previous value estimated from a multi rate test. The methodology included history matching of the actual multi rate test using the history matched model.

The following conclusions may be drawn from this study:

1. This method gives the opportunity to improve the accuracy of the reservoir and well parameters obtained from the analytical well test analysis since it uses those results as the initial parameters of the numerical simulation model, built for history matching.

2. The method was used in two actual well examples. The results showed that estimation of true skin factor from a single rate test is possible. In one well, two cases studied with different reservoir parameters. Each case gave the $\Delta \mathrm{S}$.

3. The method is verified with two numerical simulation models. Cartesian model was a substitute of a real field and the radial model was built to history match the data with the Cartesian data. Skin factor of the Cartesian model was changed from multi rate test value to single rate test. This change is $\Delta S_{1}$. The radial model's skin factor was modified from its adjusted value obtained in multi rate test match to a new value to get a match with the single rate test data of Cartesian model. This change in the skin is $\Delta S_{2}$. In this study it has been verified that, $\Delta S_{1}=\Delta S_{2}$

4. The estimation of the reservoir parameters by analytical analysis in the presence of heterogeneity was studied. It is shown that the accuracy of the estimation depends on the existence of stabilized pressure at the beginning of the each drawdown period of the multi rate test and on the assumption that the reservoir should be homogeneous in order to get the correct results. The change in the permeability near the wellbore may cause extra pressure drop in the numerical simulation mode, and can be resulted in extra skin effect. 
5. Keeping the Darcy factor constant may be a limitation on this study. Nevertheless, some previous works showed that $\mathrm{D}$ factor can be constant under low-drawdown wells. 


\section{REFERENCES}

(1) American Gas Association, Survey of Underground Gas Storage Facilities in the United States and Canada 1993, (1993).

(2) GSTC Spring Proposal Meeting, Enhancing OpEx Economics by Improving the Analysis \& Periodicity of Gas Storage Well Testing, Presenter: West Virginia University, Buffalo Marriott Niagara, (2007).

(3) http://www.naturalgas.org

(4) Energy Resources Conservation Board, Theory and Practice of Gas Wells, Calgary, Canada, $3^{\text {rd }}$ Edition, (1975).

(5) Rawlins E.L. and Schelhardt M.A. "Backpressure Data on Natural Gas Wells and Their Application to Production Practices” USBM Monograph 7, (1936)

(6) Brannon A.W., Aminian K., Ameri S., and Bilgesu H.I.: “A New Approach for Testing Gas Storage Wells" paper SPE 39223 presented at the 1997 SPE Eastern Regional Meeting, Lexington, KY, Oct. 22-24.

(7) Cullender, M.H. "The Isochronal Performance method to Determining the Flow Characteristics of Gas Wells', Trans., AIME, 204, 137-142, (1955).

(8) Katz, D.L., Cornell, D., Kobayashi, R., Poettman, F. H., Vary, J.A., Elenbaas, J.R., and Weinaug, C.F., Handbook of Natural Gas Engineering, McGraw-Hill Book Co., Inc., New York.

(9) Chaudry, A.U., Gas Well Testing Handbook, Elsevier Science, (2003).

(10) Swift, G.W. and Kiel, O.G. "The Prediction of Gas-Well Performance Including the Effect of Non-Darcy Flow" JPT, (July, 1962), 791.

(11) Ertekin,T., Abou-Kassem, J.H., King, G.R: Basic Applied Reservoir Simulation, Society of Petroleum Engineers Inc., Texas, 2001.

(12) Kamal, M.M. "Use of Pressure Transients to Describe Reservoir Heterogeneity", JPT, (Aug. 1979), 1061, Trans., AIME, Vol. 257, SPE Reprint Series No. 14.

(13) Landa, J.L., Kamal, M.M., Jenkins, C.D, and Horne, R.L. "Reservoir Characterization Constrained to Well Test Data: A Field Example", SPEREE, August 2000, 325-334. 
(14) Kamal, M.M., Pan, Y., Landa J.L., and Thomas O.O. " Numerical Well Testing-A Method To Use Transient Testing Results in Reservoir Simulation" paper SPE 95905 presented at the 2005 SPE Annual Technical Conference and Exhibition, Dallas, TX, Oct. 9-12 